MATRIX-FIBER STRESS TRANSFER IN COMPOSITE MATERIALS

ELASTO-PLASTIC MODEL WITH AN INTERPIIASE LAYER

by

Frederic C. Lhotellier

Thesis submitted to the Faculty of the

Virginia Polytechnic Institute and State University

in partial fulfillment of the requirements for the degree of

Masters of Science

in

Engineering Science and Mechanics

APPROVED:

II. F. Brinson, Chairman

D. A. Dillard

J.P. Wighthan

November, 1987

Blacksburg, Virginia 


\title{
MATRIX-FIBER STRESS TRANSFER IN COMPOSITE MATERIALS \\ ELASTO-PLASTIC MODEL WITH AN INTERPHASE LAYER
}

\author{
by \\ Frederic C. Lhotellier \\ H. F. Brinson, Chairman \\ Engineering Science and Mechanics
}

(ABSTRACT)

The matrix-fiber stress transfer in glass/epoxy composite materials was studied using analytical and experimental methods. The mathematical model that was developed calculates the stress fields in the fiber, interphase, and neighboring matrix near a fiber break. This scheme takes into account the elastic-plastic behavior of both the matrix and the interphase, and it includes the treatment of stress concentration near the discontinuities of the fibers. The radius of the fibers and the mechanical properties of the matrix were varied in order to validate the mathematical model. The computed values for the lengths of debonding, plastic deformation, and elastic deformation in the matrix near the fiber tip were confirmed by measurements taken under polarized light on loaded and unloaded single fiber samples. The fiber-fiber interaction was studied experimentally using dog-bone samples that contained seven fibers forming an hexagonal pattern. 


\section{Acknowledgements}

The author wishes to express his appreciation to:

- P.J. Sabat whose work oriented this research.

- The committee members for their suggestions and comments on the manuscript.

- D. Reed and B. Simonds for their help during the experimental part of this research.

- The students of the Center for Optic fibers for their advice and the use of their equipment.

- Mrs. P. Epperly for typing this report

- The Office of Naval Research for the financial support through the contract N00014-82-K-0185 supervised by Dr. Larry Peebles, Jr.. 


\section{Table of Contents}

I. INTRODUCTION $\ldots \ldots \ldots \ldots \ldots \ldots \ldots \ldots \ldots \ldots \ldots \ldots \ldots \ldots \ldots$,

II. LITERATURE REVIEW $\ldots \ldots \ldots \ldots \ldots \ldots \ldots \ldots \ldots \ldots \ldots \ldots \ldots \ldots \ldots$

A. Chemistry of Fiber-Matrix Bonds $\ldots \ldots \ldots \ldots \ldots \ldots \ldots \ldots \ldots \ldots$

B. Mechanics of the Fiber-Matrix Adhesion $\ldots \ldots \ldots \ldots \ldots \ldots \ldots \ldots \ldots$

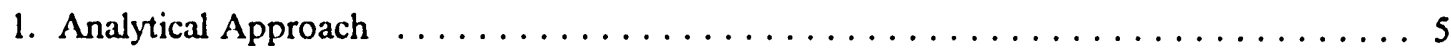

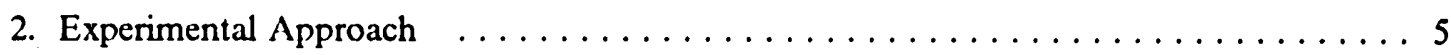

III. ANALYTICAL ANALYSIS $\ldots \ldots \ldots \ldots \ldots \ldots \ldots \ldots \ldots \ldots \ldots \ldots \ldots \ldots$

A. INTRODUCTION $\ldots \ldots \ldots \ldots \ldots \ldots \ldots \ldots \ldots \ldots \ldots \ldots \ldots \ldots \ldots \ldots \ldots$

B. SHEAR LAG MODEL WITH AN INTERFACIAL LAYER (SINGLE FIBER) $\ldots 12$

C. STRESS CONCENTRATION NEAR DISCONTINUITIES OF FIBERS $\ldots \ldots \ldots 15$

D. PERFECT BOND (MULTIPLE FIBERS) $\ldots \ldots \ldots \ldots \ldots \ldots \ldots \ldots \ldots$

1. Effects of the Stress Concentration on the Shear Lag Model $\ldots \ldots \ldots \ldots \ldots$

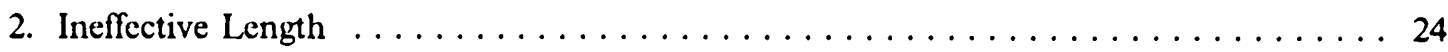

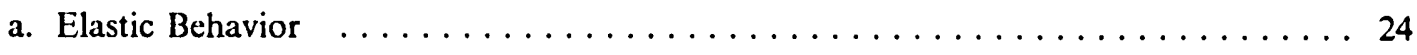

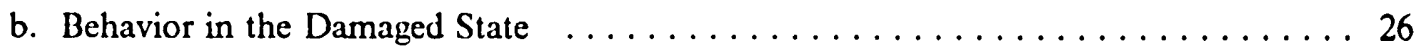

Table of Contents $\quad$ iv 
3. Results and Discusssion $\ldots \ldots \ldots \ldots \ldots \ldots \ldots \ldots \ldots \ldots \ldots \ldots \ldots$

E. LIMITED FRICTION $\ldots \ldots \ldots \ldots \ldots \ldots \ldots \ldots \ldots \ldots \ldots \ldots \ldots \ldots \ldots \ldots$

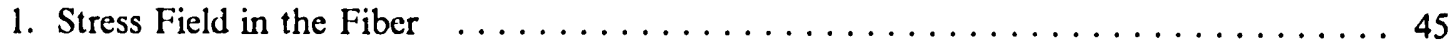

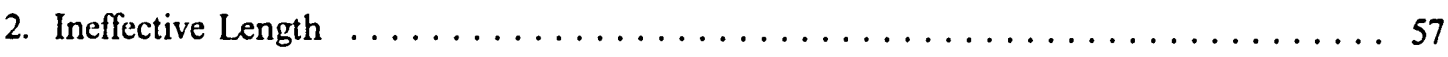

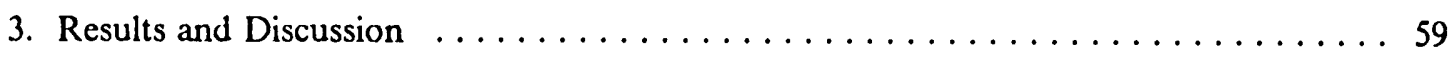

IV. EXPERIMENTAL PROCEDURES AND OBSERVATIONS $\ldots \ldots \ldots \ldots$

A. DESCRIPTION OF THE MATERIALS $\ldots \ldots \ldots \ldots \ldots \ldots \ldots \ldots \ldots \ldots \ldots \ldots \ldots$

B. PROPOSAL FOR A FIBER-MATRIX ADHESION ADVANCED TEST METHOD 63

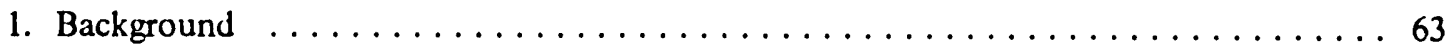

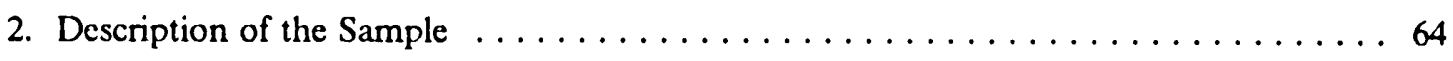

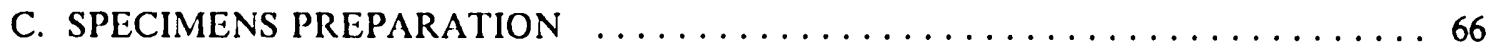

D. MECHANICAL TESTING $\ldots \ldots \ldots \ldots \ldots \ldots \ldots \ldots \ldots \ldots \ldots \ldots \ldots$

1. Tensile Testing of the Fibers $\ldots \ldots \ldots \ldots \ldots \ldots \ldots \ldots \ldots \ldots \ldots \ldots \ldots \ldots$

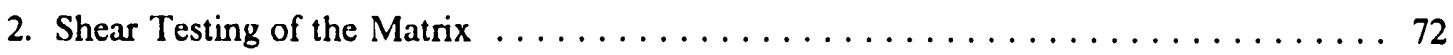

3. Observation with Polarized Light of the Single Fiber Sample $\ldots \ldots \ldots \ldots \ldots$

4. Critical Fiber Length Test $\ldots \ldots \ldots \ldots \ldots \ldots \ldots \ldots \ldots \ldots \ldots \ldots \ldots \ldots$

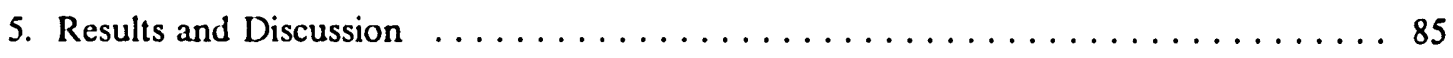

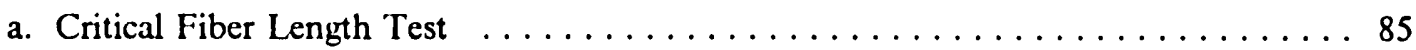

b. Measurement of the Deformed Zone in the Matrix Under Polarized Light $\ldots . \ldots 87$

V. COMPARISON BETWEEN THE PREDICTIONS OF TIE "ELASTO-DAMAGED" MODEL AND TIE OBSERVATIONS UNDER POLARIZED LIGHT $\ldots \ldots \ldots \ldots$

VI. SUMMARY AND CONCLUSION $\ldots \ldots \ldots \ldots \ldots \ldots \ldots \ldots \ldots \ldots \ldots \ldots$

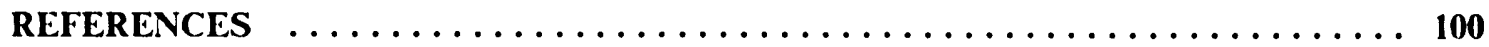




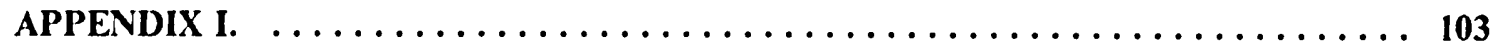

CHANGE OF COORDINATE SYSTEM FOR THE MODELS OF THE STRESS FIELD

IN THE MATRIX, THE INTERFACE, AND TIE FIBER, DEVELOPED BY P. J. S 103 


\section{List of Illustrations}

IFigure 1. a) l'ull out test specimen; b) Pull out test droplet type specimen $\ldots \ldots \ldots \ldots \ldots$

Figure 2 . Schematic of the microdebond test $\ldots \ldots \ldots \ldots \ldots \ldots \ldots \ldots \ldots$

Figure 3 . Schematic of the single fiber critical length test $\ldots \ldots \ldots \ldots \ldots \ldots \ldots$

Iigute 4 . Diagrain of the model with interphase $\ldots \ldots \ldots \ldots \ldots \ldots \ldots \ldots$

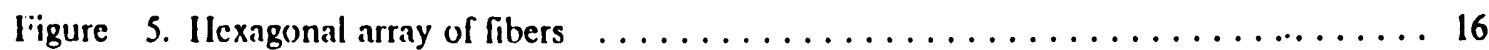

ligure 6. Variation of shear stress concentration near an infinitely small discontinuity $\ldots \ldots 19$

Figure 7. Plasticity model: slicar stress in the matrix (for one to six broken neighboring fibers) 22

Iigure 8. Flasticity model: tensile stress in the fiber (for one to six broken neighboring fibers) 23

ligure 9. Ilastic model: ineffective length as a function of the stress concentration $\ldots \ldots 25$

Figure 10. Behavior of the matrix and of the interphase $\ldots \ldots \ldots \ldots \ldots \ldots \ldots \ldots$

Higure 11. Schematic of the elasto-damaged model $\ldots \ldots \ldots \ldots \ldots \ldots \ldots \ldots$

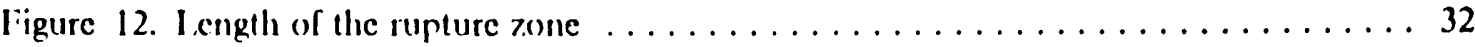

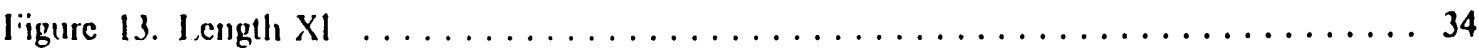

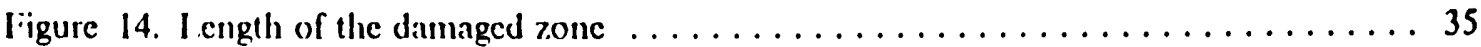

Figure 15. Iilow chart of the computer program to compute the ineffective length $\ldots \ldots \ldots 39$

Iigure 16. Iilasto-damaged model: shear stress in the matrix (for one to six broken neighboring

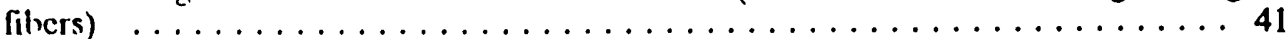

ligure 17. Flasto-damaged model: tensile stress in the fiber (for one to six broken neighboring

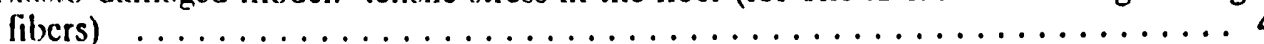

Iigure 18. Elasto-damaged model: Incffective length as a function of the stress concentration 44

ligure 19. Influence of the radius of the fiber on $\delta$ (clasto-damaged model) $\ldots \ldots \ldots 46$

Figure 20. Influcnce of $\mathrm{G}$ in on the incffective length (elasto-dannaged model) $\ldots \ldots \ldots 47$ 
Figure 21 . Unit cell for the limited friction model $\ldots \ldots \ldots \ldots \ldots$

Figure 22. Free body diagrams for the element $(x, x+d x)$ of the unit cell $\ldots \ldots \ldots \ldots$

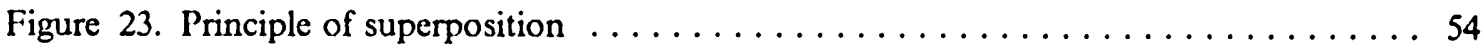

Figure 24 . Limited friction model: tensile stress in the fiber $\ldots \ldots \ldots \ldots \ldots \ldots \ldots$

Figure 25. Limited friction model: ineffective length as a function of the friction coefficient . 60

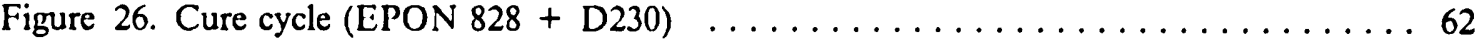

Figure 27. a) Seven fiber critical length test (scale 1); b) Cross section of the central part of the

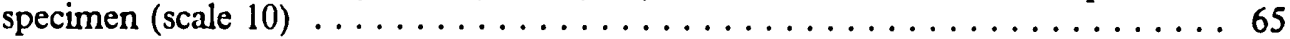

Figure 28. Neat resin dogbone specimen (geometry) $\ldots \ldots \ldots \ldots \ldots \ldots \ldots \ldots$

Figure 29. Neat resin Iosipescu specimen (geometry) $\ldots \ldots \ldots \ldots \ldots \ldots \ldots \ldots \ldots$

Figure 30. Silicone rubber mold for both single and 7 fiber specimens $\ldots \ldots \ldots \ldots \ldots$

Figure 31 . Steps 3 and 4 of the 7 fiber specimen preparation $\ldots \ldots \ldots \ldots \ldots \ldots \ldots$

Figure 32. Iosipescu test fixture (specimen mounted) $\ldots \ldots \ldots \ldots \ldots \ldots \ldots \ldots$

Figure 33. Iosipescu specimen (rosette mounted). Failure in shear. $\ldots \ldots \ldots \ldots \ldots \ldots 77$

Figure 34. Neat resin shear stress-shear strain curve (Iosipescu test) $\ldots \ldots \ldots \ldots \ldots \ldots 79$

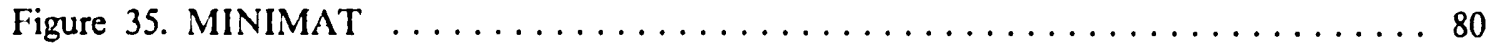

Figure 36. Spectra-tech microscope (minimat mounted) $\ldots \ldots \ldots \ldots \ldots \ldots \ldots$

Figure 37. Single fiber break a)specimen unloaded b)specimen loaded $\ldots \ldots \ldots \ldots 2$

Figure 38. Critical fiber length test setup $\ldots \ldots \ldots \ldots \ldots \ldots \ldots \ldots \ldots \ldots \ldots$

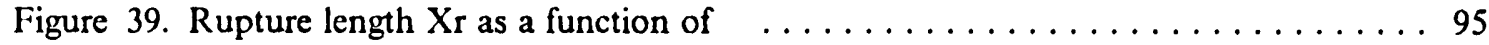

Figure 40 . Damage length $\mathrm{Xd}$ as a function of $\ldots \ldots \ldots \ldots \ldots \ldots \ldots \ldots \ldots \ldots \ldots \ldots \ldots$

Figure 41 . Ineffective length $\delta$ as a function of $\ldots \ldots \ldots \ldots \ldots \ldots$

Figure 42. a) Sabat's coordinate system; b) Our coordinate system $\ldots \ldots \ldots \ldots \ldots$

$\begin{array}{ll}\text { List of Illustrations } & \text { viii }\end{array}$ 


\section{List of Tables}

Table 1. Coefficients of stress concentration near fiber discontinuities $\ldots \ldots \ldots \ldots$

Table 2. Input data for the elasto-damaged model $\ldots \ldots \ldots \ldots \ldots \ldots$

Table 3. Mechanical response of the matrices used to generate Figure $20 \ldots \ldots$. . . 48

Table 4. Tensile properties of the fibers $\ldots \ldots \ldots \ldots \ldots \ldots \ldots \ldots \ldots \ldots \ldots \ldots$

Table 5. Iosipescu shear test results $\ldots \ldots \ldots \ldots \ldots \ldots \ldots \ldots \ldots \ldots \ldots \ldots$

Table 6. Critical fiber length (single fiber sample) $\ldots \ldots \ldots \ldots \ldots \ldots \ldots$

Table 7 . Critical fiber length $(7$ fiber sample $) \ldots \ldots \ldots \ldots \ldots \ldots$

Table 8. Observation under polarized light. $\ldots \ldots \ldots \ldots \ldots \ldots \ldots \ldots \ldots$

Table 9. Observation under polarized light. Ineffective length. $\ldots \ldots \ldots \ldots \ldots \ldots 1$

Table 10. Observation under polarized light. Damage length. . . . . . . . . 92 


\section{INTRODUCTION}

The volume of fibrous composites used as high performance structural materials is increasing very rapidly because of the possibilities to adapt the mechanical properties of the composites in the elastic domain to a particular loading situation. This tailoring of the extensional and bending stiffnesses as well as of the coupling between bending and extension is not possible for the fatigue life or the static strength. The failure modes of composite matcrials are many and interdependent. Consequently, the understanding of the phenomenon has to be related to the manner in which fibers and matrix which have different mechanical properties, are put together to form a unidirectional composite.

Many attempts have been made in the past to describe the properties of a composite lamina

based on the properties of its constituents. In all of these studies hypotheses have been made about the stress transfer between the fibers and the matrix. This load transfer is the key to the micromechanical approach of composite materials. The properties of both the matrix and the fibers can be determined experimentally without difficulty, but if the load transfer is not understood, the state of stress in the different constituents cannot be evaluated, and consequently, the properties of the composite cannot be calculated. Until now, the mathematical representations of the stress transfer between the fibers and the matrix have given results that do not compare well with experimental measurements. 
Much work has been done, especially by chemists, to define and analyze the zone, known as the fiber matrix interface, where the stress transfer occurs. It has been proved with chemical analysis and photomicrographs [1] that a layer of finite thickness, exists between the fiber and the matrix, and that it is chemically different from both of them. This layer, described in references 2 and 3 , is referred to as the interphase, and poses a new problem because its thickness is only on the order of a micron. As a result, the mechanical properties of this region cannot yet be measured experimentally.

It is now commonly accepted that progress in micromechanics is not possible without both an understanding of the physics of the interphase and its mathematical representation. Consequently, interdisciplinary studies $[4,5]$ have determined that the mechanical simulation of the stress transfer between the matrix and the fibers must include parameters that result from a better understanding of the chemistry of adhesion. According to this idea, a mechanical model of stress transfer that includes an interphase layer has been developed [6], and this study improves the previous analysis by considering the possibilities of damage in the interphase.

The fiber matrix stress transfer is not the only problem in the determination of the properties of unidirectional composites. The interaction between fibers has been observed to be of significant influence when discontinuities exist in the filaments [7]. Fiber discontinuities can be attributed to the use of whiskers, or, in continuous fiber composites, to flaws in the filaments and stresses induced by the fabrication and curing processes. During the service life other fiber breaks appear due to the loading of the structure. Using the results for the stress concentrations in a three dimensional array of fibers reported in reference 7 , this present study examines the influence of the fiber-fiber interaction on the stress transfer between the matrix and the fibers. 


\section{LITERATURE REVIEW}

Our study is oriented towards developing a mathematical model of the stress transfer between the matrix and the fibers. However, as mentioned in a later section, different models correspond to the different types of bonding between the fibers and the matrix that have been observed in composite materials. Consequently, for the micromechanical study of fibrous composites to be significant, the physics of the bonding process needs to be understood.

\section{A. Chemistry of Fiber-Matrix Bonds}

Along with the understanding of the fiber-matrix bonds, another, by no means insignificant, purpose of studying the chemistry of adhesion is the improvement of the bonds.

Many studies have already provided results about glass/epoxy systems [4-6], the composites used in the experimental part of this research. These systems, because of the very high strength of the fiber matrix bond in dry environment, are often used for data comparison in the literature. However, this report is not limited to glass/epoxy composites. In other cases where no chemical link is established between the fibers and the matrix, the interphase is only a thin layer of the matrix 
that has reacted differently from the bulk material because of the presence of the fiber. This layer is not mechanically attached to the fiber and therefore constitutes a weak boundary layer. The attachment of the interphase to the fiber can be realized in most of the cases by applying different surface treatments to the fibers, or by adding coupling agents to the matrix. Hence, chemical analysis techniques have replaced the empirical series of tests that have been used in the past to investigate fiber-matrix bonds. In reference 8 , Baun reviews no less than fifty four microscopic, spectroscopic, thermodynamic, and kinetic techniques of investigation of the interphase.

The chemistry of the matrix is usually available, but the surface of the fibers has to be analyzed. Glass surfaces have been studied using different techniques listed by Sabat in reference [6]. Furthermore, in order to obtain a better understanding of the functionality of the surface, a derivation process adapted from Everhart's and Reilly's technique [9] can be used. This procedure consists of using reagents that contain elemental tags. These reagents are chosen to react with specific functional groups, and by scanning for an elemental tag using XPS, the presence of the corresponding functional group can be identified on the surface.

It must be said that all the techniques of analysis of surface chemistry cannot be used once the fibers and the matrix are put together. Consequently, the nature of the interface inside actual composites remains a guess based on the analysis of the elements before assembly.

\section{B. Mechanics of the Fiber-Matrix Adhesion}

The mechanics of matrix-fiber load transfer has been studied since the early 1950's [10], but it was not until 1963 that the stress concentration due to discontinuities in the fibers was considered [11]. Along with the analytical research, many experimental studies have been conducted on the subject adapting photoelasticity and other test measurements. 


\section{Analytical Approach}

Originally the problem of the matrix-fiber stress transfer was approached by applying fiber theories [10-14]. Later, four different types of analysis arose;

- Elasticity theory

- Finite element analysis

- Fracture mechanics

- Shear-lag analysis

These are referenced in detail by Sabat [6] who also classifies the papers on the subject according to the assumptions made about the bond and the nature of the interface between the fibers and the matrix.

The treatment of the stress concentration due to discontinuities in the fibers has been studied separately [7], and has rarely been included in mathematical models of the matrix fiber stress transfer. The only cases when the influence of the neighboring fibers has been taken into account are statistical treatments of the unidirectional composite strength $[15,16]$.

\section{Experimental Approach}

The measurement of the maximum stress transfer between the matrix and the fibers can be approached in two ways. Mechanical tests such as short beam shear, four point shear, or flexural strength can be run on composite specimens to determine indirectly the "interfacial" shear strength. But the results of these tests are very controversial because of the complex states of stress they induce at the interface between the matrix and the fibers.

A more direct approach is to measure the maximum stress transfer by observing the behavior of a single fiber. Four different single fiber tests have been developed thus far: 

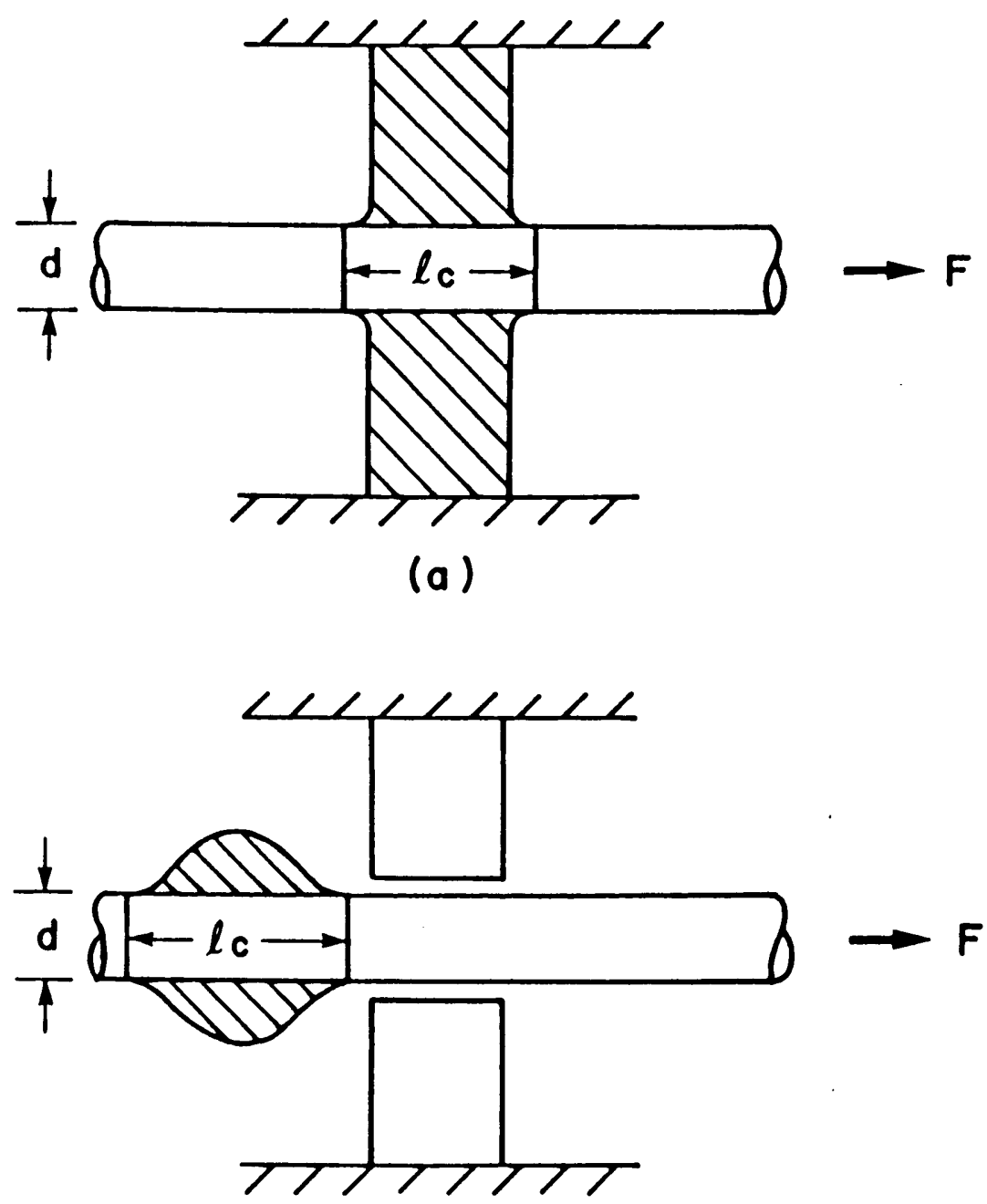

(b)

Figure 1. a) Pull out test specimen; b) Pull out test droplet type specimen 
- The pull out test. The experiment is represented in figure 1a), and the following test procedure is used: a single fiber is embedded in a thin disc of the polymer matrix in such a manner that it represents the axis of the sample. Then the fiber is pulled out of the polymer, and the necessary force is recorded. The thickness of the polymer disc is increased until the fiber cannot be pulled out and breaks. The pull out force is plotted versus the thickness of the disc, which is also the length of the bond. The slope of this curve is supposed to be the "interfacial shear strength" [17].

The high scatter in the data led the researchers to question the assumption of pure uniform shear stress at the interface $[18,19]$. It appears that the polymer meniscus at the reentrant corner generates stress concentration, and that a tensile stress exists that pulls the matrix away from the fiber. Consequently, variations in the shape of the polymer block have been investigated [20]. The pull out droplet type specimen is represented in Figure lb). Because the analysis of this test is still not precise about what is measured, the results of this experimental procedure must be considered as being qualitative information.

- The microdebond test (Figure 2). This is the most recent test method, and probably the most representative of the problem we are concerned with because it studies a fiber embedded in an actual composite material. A cross section of a fibrous composite is polished, and placed under a microscope. A spherical indenter is then placed over the end of a fiber and loaded until the detachment between the fiber and the matrix occurs. The load recorded at the time of the detachment serves as input in a micromechanical model that gives the "interfacial strength." Regretably, the understanding of the mechanism of detachment is not complete, and there is no evidence that the recorded load is a function of the debonding process only $[21,22]$.

- Transverse tensile test [23]. A single fiber is embedded in a compression specimen of the polymeric matrix. Under load, the Poisson's effect creates a tensile force normal to the fiber in the center of the specimen. The debonding of the fiber from the matrix is detected using reflected light, and the corresponding value of the load is used to calculate an "interfacial tensile strength." 


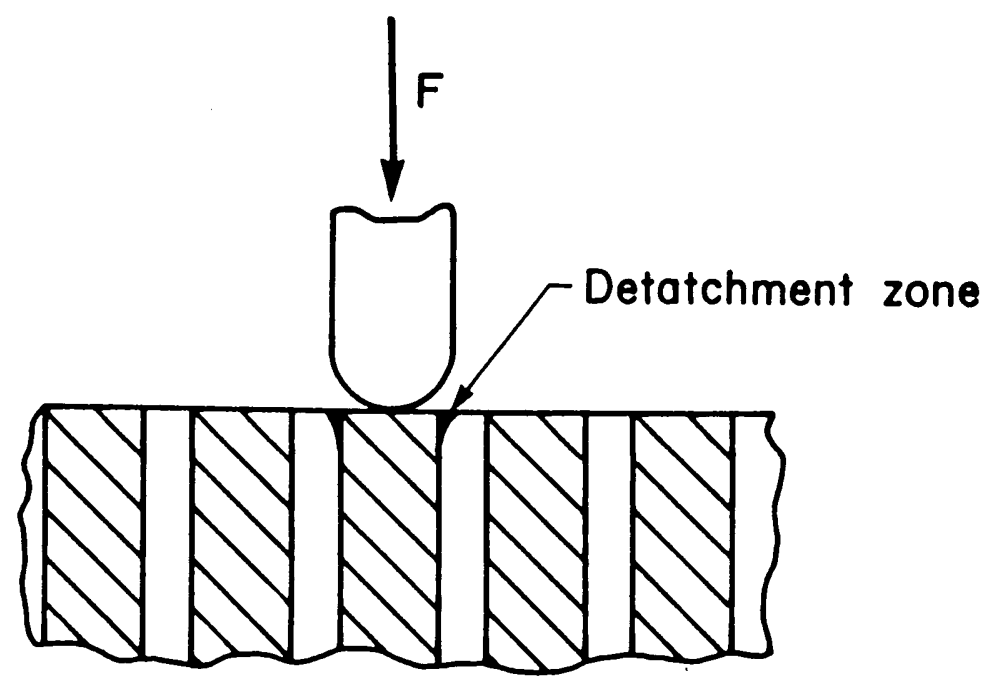

Figure 2. Schematic of the microdebond test 
- Critical fiber length test. Because it is easy to run, this test method has been largely used and studied. The initial fiber length test was originally described by Kelley [24]. A latter section of this report contains a detailed description of the test, and proposes some modifications in order to tailor it to the study of fibrous composite materials. 


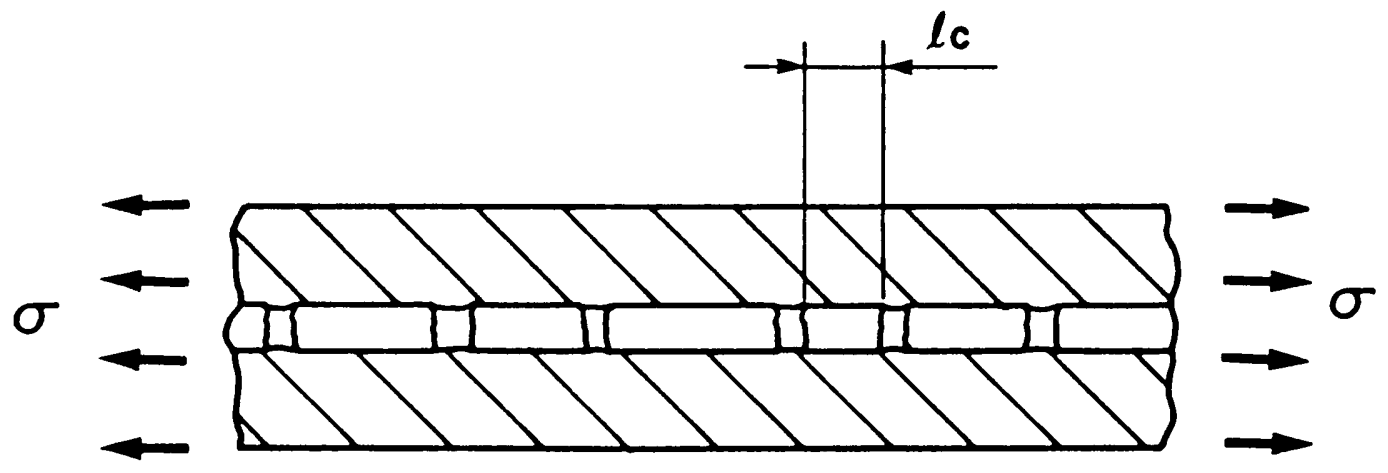

Figure 3. Schematic of the single fiber critical length test 


\section{ANALYTICAL ANALYSIS}

\section{A. INTRODUCTION}

The mechanical properties of fiber reinforced composites are significantly influenced by the stress transfer between the matrix and the fibers. Several approaches are used to quantitatively approximate this load transfer. Rosen, followed by many others, considers the fiber-matrix bond as being perfect [13]. This means that the fiber and the matrix constitute a single unit with two zones having different mechanical properties. Furthermore, the "dual" material behaves elastically, even in highly stressed regions like the fiber tips. This model has been greatly improved by P. J. Sabat who adds an interfacial layer between the fiber and the matrix. But still, all the materials are considered as elastic, and the possibilities of breakage or yielding of the matrix, or of slippage of the fiber with respect to the matrix are not considered.

The purpose of the first model developed in this chapter is to quantify the possibilities of damage in an "elasto-damageable" matrix surrounding a fiber in the case of a strong chemical bond, i.e., in the case of continuity at the atomic level between the fiber and the interphase, and between the interphase and the matrix. This study is conducted for a fiber embedded in a fibrous composite material, and considers all the problems of stress concentration due to broken fibers. In the second 
model, the fiber matrix adhesion is assumed to be only mechanical with no atomic link between the fiber and the matrix. Both models are then used to define the ineffective length. The influence of the ineffective length on the mechanical properties of short fiber composites has been addressed in the past by Reifsnider et al. [47], and consequently is not reiterated in this report.

\section{B. SHEAR LAG MODEL WITH AN INTERFACIAL LAYER (SINGLE FIBER)}

In the last decade much progress has been made in the field of adhesion science. One of the most important advancements is obviously the observation in certain cases of an interfacial layer that exists between the adhesive and the adherend. As a result, P. J. Sabat developed a shear-lag model [6], derived from Rosen's theory [13], to calculate teh stresses in the fiber, the neighboring matrix and the interfacial layer, for a single fiber embedded in a composite material. His hypotheses are:

- the fibers carry only tensile load

- the matrix carries only shear stress

- the average material carries only tensile load

- the interphase carries part of the tensile load of the fiber and part of the shear stress of the matrix

$$
\begin{aligned}
& \sigma_{l}(x)=\alpha \cdot \sigma_{f}(x) \\
& \tau_{l}(x)=\beta \cdot \tau_{m}(x)
\end{aligned}
$$

- shear transfer is limited to matrix interphase 
- the bonds between fiber-interphase, interphase-matrix and matrix-average material are perfect.

The hypotheses of the shear-lag analysis have already been used by many researchers as reported by Holister and Thomas [28], and are reasonable enough in the case of high modulus fibers embedded in a ductile matrix. However, the last assumption concerning the perfect bond, even near the fiber end, has been criticized by Amirbayat and Hearle [29] who consider the possibility of fiber-matrix debonding and slippage at the fiber end because of the high stress concentration in this region.

Sabat also neglected the overstress in the matrix due to discontinuities in the neighboring fibers. Because he was more interested in comparing resin properties, filament surface characteristics and surface treatments, this approximation was not significant for his results. This simplification, however, certainly cannot be used to characterize the stress field in a fiber embedded in a composite material.

Using Sabat's equation for the equilibrium of the unit cell represented with our coordinate system in Fig. 4, we obtain the following formula for the stresses in the fiber and in the neighboring matrix: (the resolution for the change of axis is given in Appendix 1)

$$
\sigma_{f}(x)=\frac{\bar{\sigma} E_{f}}{E_{a}}(1-\exp [-\eta x])
$$

and

$$
\tau_{m}(x)=\frac{-R_{f} \eta \bar{\sigma} E_{f}}{2 E_{a}} \exp [-\eta x]
$$

where:

$$
\eta^{2}=\frac{2 R_{l} / E_{a}\left(R_{a}^{2}-R_{m}^{2}\right)+2 \beta / E_{f} R_{f}}{\left(R_{m}-R_{i}\right) / G_{m}+\beta\left(R_{l}-R_{f}\right) / G_{l}}
$$



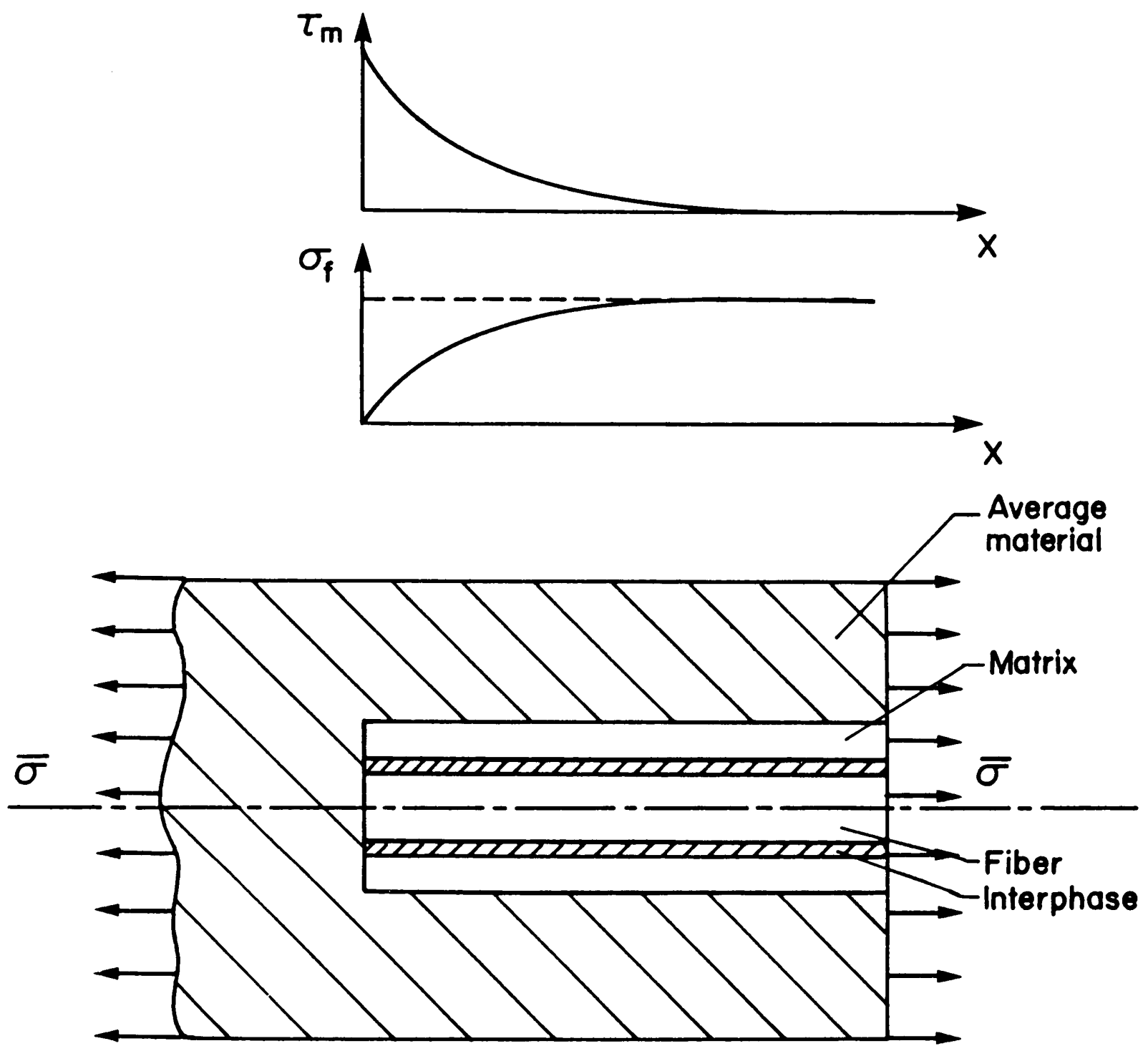

Figure 4. Diagram of the model with interphase 
This approach of the fiber-matrix adhesion could be the starting point for a new generation of models which take into account the existence of an interfacial layer whose chemical and mechanical properties are different from those of both adhesive and adherend. The influence of the interphase upon the strength of the material itself will be given in a later part of this report. However, for equations 3 and 4 to be representative of the conditions in a fiber reinforced plastic, the overstresses due to discontinuities in the neighboring fibers have to be taken into account. Furthermore, this model has shown that perfect fiber-matrix bonding is probably an illusion near the fiber end. Consequently, modifications have to be made in order to consider this phenomenon.

\section{STRESS CONCENTRATION NEAR}

\section{DISCONTINUITIES OF FIBERS}

The problem of stress transfer between a broken fiber and the neighboring ones has already been extensively studied, and different types of 2-D models have been developed: linear elastic analysis [30,31], elastic plastic analysis [32] and bilinear stress strain curves [33] have been included in finite element programs; analytical solutions have also been found using the shear lag theory [7,34,35]. The most advanced model, to our knowledge, is that of Hedgepeth and Van Dicke [7] and presents the solution of the 3-D problem for fibers arranged in an hexagonal array, Figure 5 , using a shear lag analysis.

The figures in Table 1 have been calculated using this last reference, and the following hypotheses:

- Zero to six of the outer fibers can break.

- The fiber breaks are infinitely small, i.e., there is contact between the two broken ends of a fiber. 


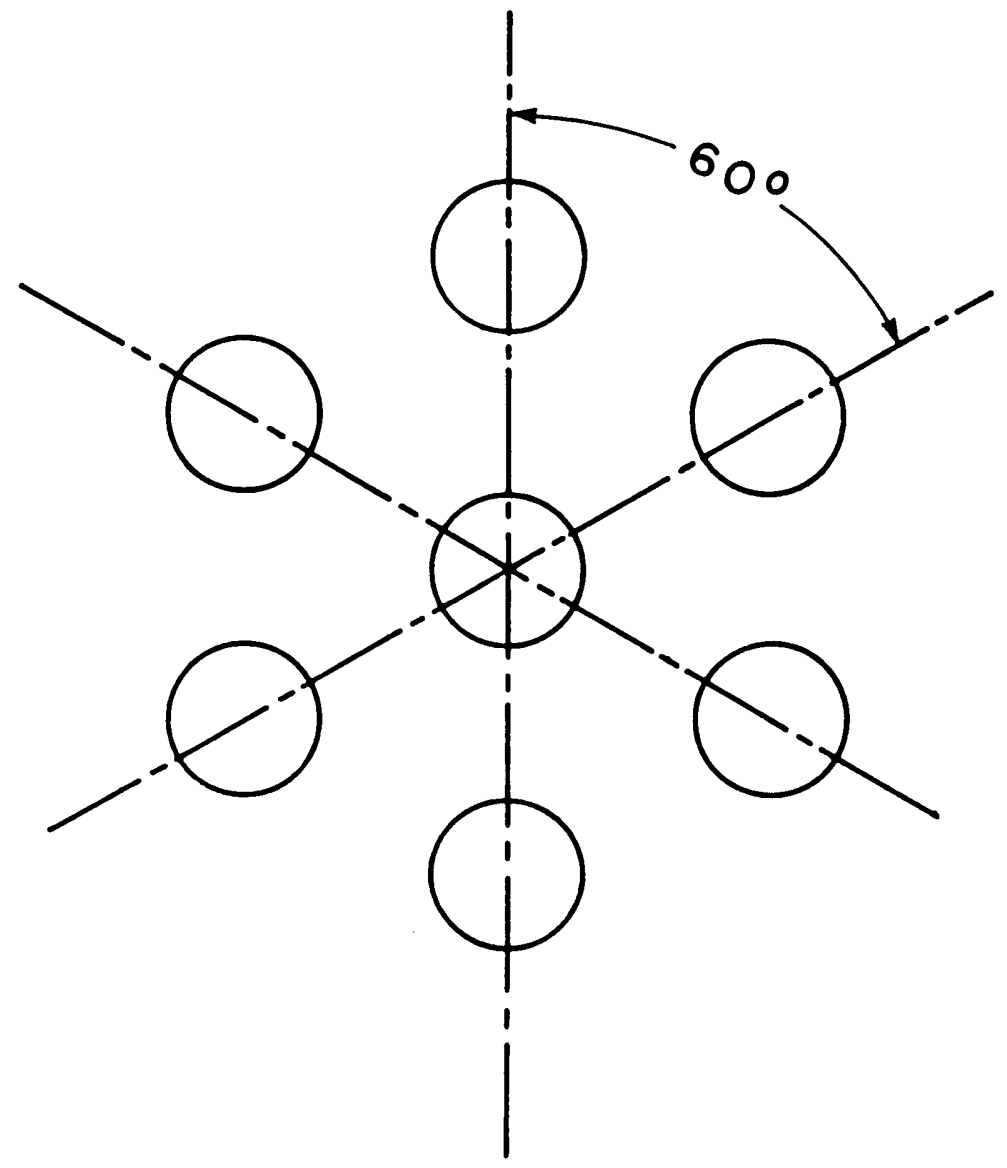

Figure 5. Hexagonal array of fibers 
- The breaks of the outer fiber induce stress concentration at the interface between the central fiber and the matrix.

- In the plane perpendicular to the fibers and passing through the break, the stress concentration decreases when the distance from the break increases.

- The fiber volume fraction is equal to .44 .

- The value of the stress concentration induced in the matrix by a number of coplanar breaks of the outer fibers is constant around the central fiber, and it is equal to an average value calculated at the center of the fiber.

We notice that the first value corresponds with the result of the finite element analysis conducted by Barker [30].

A point neglected in almost all the previous treatments is that the overstress is not only applied to a plane but to a volume and this in a non-equal fashion. The distribution of overstress has been studied in both two dimensions $[27,36,37,38]$ and three dimensions [7]. We consider in this study that the stress concentration is maximum in the plane of the break, and that it decreases along the axis of the central fiber proportionally to the distance from this plane. We assume that the effects of coplanar breaks of the outer fibers is not sensitive at the interface between the central fiber and the matrix if the distance from the plane of the breaks is larger than eight times the radius of the fibers. This value of the length of the overstressed zone has been chosen according to previous finite element studies of the problem $[30,33]$. Consequently, the mathematical function representing the overstress in the matrix along the interface between the central fiber and the matrix is defined by:

$$
f_{i}(x)=c_{l}+\frac{x}{8 R_{f}}\left(1-c_{l}\right)
$$

and is shown in figure 6. 
Table 1. Coefficients of stress concentration near fiber discontinuities

\begin{tabular}{ccccccc}
\hline $\begin{array}{l}\text { Number of } \\
\text { broken fiber }\end{array}$ & 1 & 2 & 3 & 4 & 5 & 6 \\
\hline $\mathrm{Ci}$ & 1.104 & 1.41 & 1.63 & 1.87 & 2.21 & 2.5 \\
\hline
\end{tabular}



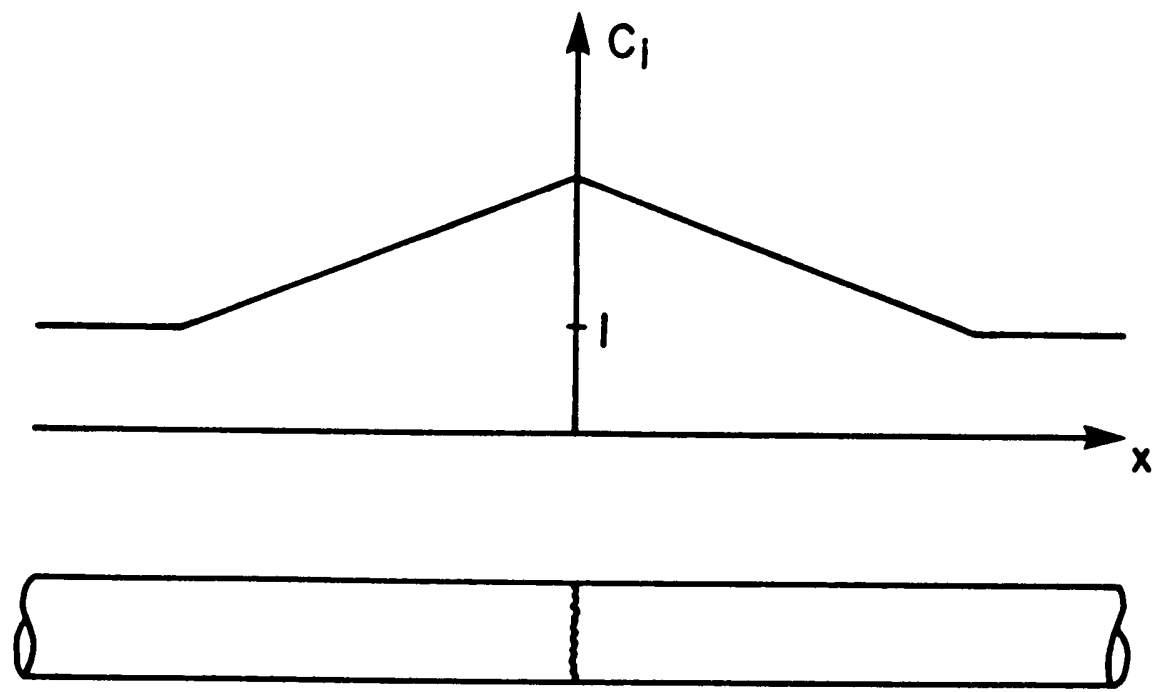

Figure 6. Variation of shear stress concentration near an infinitely small discontinuity 


\section{PERFECT BOND (MULTIPLE FIBERS)}

\section{Effects of the Stress Concentration on the Shear Lag Model}

The stress concentration has so far been defined in the matrix only; hence, the shear stress in the matrix $\tau_{m}$ is formulated as follows:

For $0<\mathrm{x}<8 R_{f}$

$$
\tau_{m}(x)=\frac{-\bar{\sigma} R_{f} E_{f} \eta}{2 \beta E_{a}} \exp [-\eta x]\left(c_{l}+\frac{x}{8 R_{f}}\left[1-c_{l}\right]\right)
$$

and for $\mathrm{x}>8 R_{f}$

$$
\tau_{m}(x)=\frac{-\bar{\sigma} R_{f} E_{f} \eta}{2 \beta E_{a}} \exp [-\eta x]
$$

Because the equilibrium of the fiber still has to be satisfied, the equation 7A of Appendix 1 is still valid and is recalled here

$$
\frac{d \sigma_{f}}{d x}=\frac{-2 \beta}{R_{f}} \tau_{m}
$$

By integrating equation 9 we obtain for $0<\mathrm{x}<8 R_{f}$

$$
\sigma_{f}=\frac{\bar{\sigma} E_{f} \eta}{E_{a}}\left[\int\left[\exp (-\eta x) \times\left(c_{l}+\frac{x}{8 R_{f}}\left[1-c_{l}\right]\right)\right] d x+K\right]
$$

where $\mathrm{K}$ is a constant of integration. 
Performing the integration:

$$
\sigma_{f}=\frac{-\bar{\sigma} E_{f}}{E_{a}}\left[\left(c_{i}+\frac{1-c_{l}}{8 R_{f}} \frac{\eta x+1}{\eta}\right) \exp [-\eta x]+K_{1}\right]
$$

The boundary condition $\sigma(o)=0$ inserted in Eq. 10 leads to

$$
K_{1}=-\left(c_{l}+\frac{1-c_{l}}{8 R_{f}}\right)
$$

Eq. 11 into Eq. 10

$$
\sigma_{f}(x)=\frac{-\bar{\sigma} E_{f}}{E_{a}}\left[c_{l}(\exp [-\eta x]-1)+\frac{1-c_{l}}{8 R_{f} \eta}([\eta x+1] \exp [-\eta x]-1)\right]
$$

Figures 7 and 8 show respectively the distribution of the shear stress in the matrix and the tensile stress in the fiber.

It is useful to remember that all the calculations in this section have been made for infinitively strong linear-elastic materials. As we shall see later, this is far from reality and the breakage of the fibers occurs at a stress level lower than the one for which the discontinuities in the stress-strain curves appear. Consequently, Figures 8 and 9 are displayed here uniquely to demonstrate the influence of the stress concentration due to discontinuities in the neighboring fibers and are of no value concerning the actual stress field in and around a fiber embedded in a fibrous composite material subjected to tensile load. 


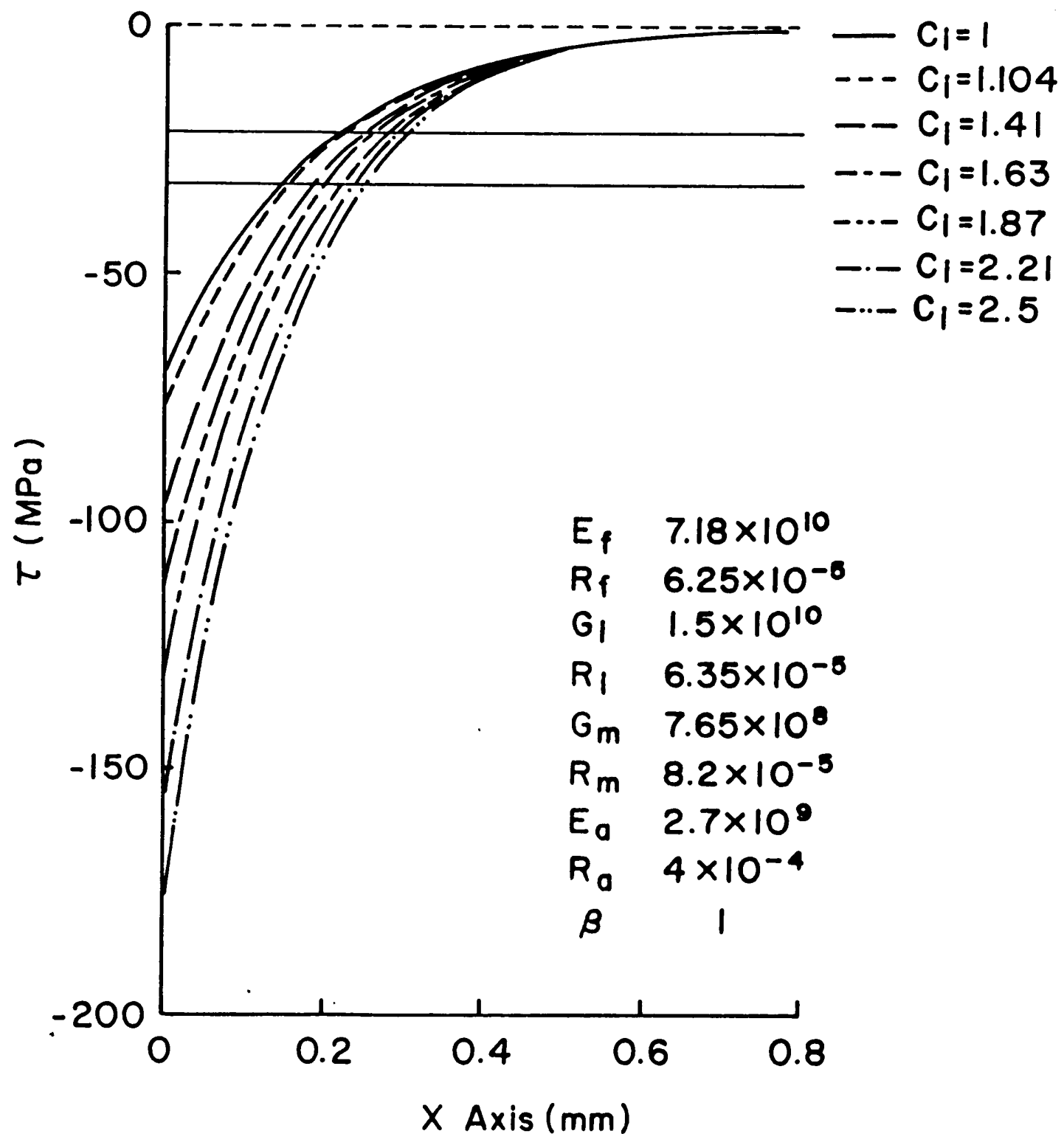

Figure 7. Elasticity model: shear stress in the matrix (for one to six broken neighboring fibers) 


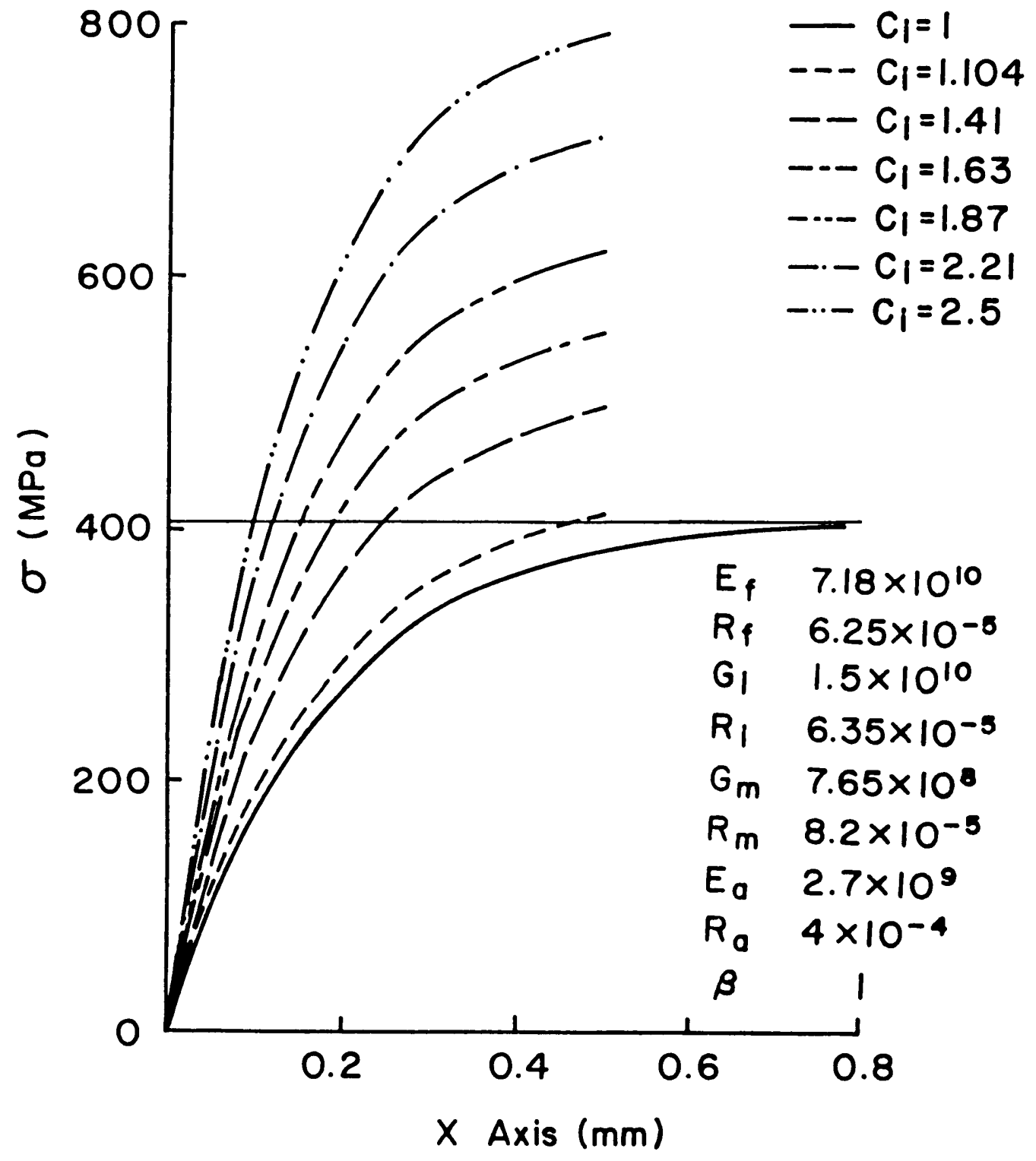

Figure 8. Elasticity model: tensile stress in the fiber (for one to six broken neighboring fibers) 


\section{Ineffective Length}

\section{a. Elastic Behavior}

Rosen in reference 2 defines the ineffective length as follows:

At some distance from an internal break, the fiber stress will be a given fraction of the undisturbed fiber stress $\sigma(\infty)$. One may define this fraction $\phi$ of the average stress such that the fiber length $\delta$ over which the stress is less than $\sigma(\infty)$ may be considered ineffective. Thus, this ineffective length $\delta$ is defined as:

$$
\phi=\sigma_{f}(\delta) / \sigma_{f}(\infty)
$$

The model with an interfacial layer developed in Appendix 1 results in:

$$
\phi=1-\exp [-\eta x]
$$

this leads to:

$$
\delta=1 / \eta \times \ln [1 /(1-\phi)]
$$

Inserting Eq. 5 into Eq. 15 we obtain:

$$
\delta=\left[\frac{\left(R_{m}-R_{l}\right) / G_{m}+\beta\left(R_{l}-R_{f}\right) / G_{l}}{2 R_{l} / E_{a}\left(R_{a}^{2}-R_{m}^{2}\right)+2 \beta \mid E_{f} R_{f}}\right]^{1 / 2} \ln [1 /(1-\phi)]
$$

Assuming a perfect bond, i.e., a good stress transfer between the matrix and the fiber, and assuming the elastic behavior of the materials, a filament is more likely to break in a region of high stress. Consequently, the possibility of breakage in the ineffective length is very low.

The effects of the overstress due to discontinuities in the adjacent fibers on the ineffective length has never been reported despite its importance. To demonstrate this influence, we recall the formula of the stress in the fiber in an overstressed region, Eq. 12, and use it in Rosen's formula of the fiber efficiency, Eq. 13. We obtain: 


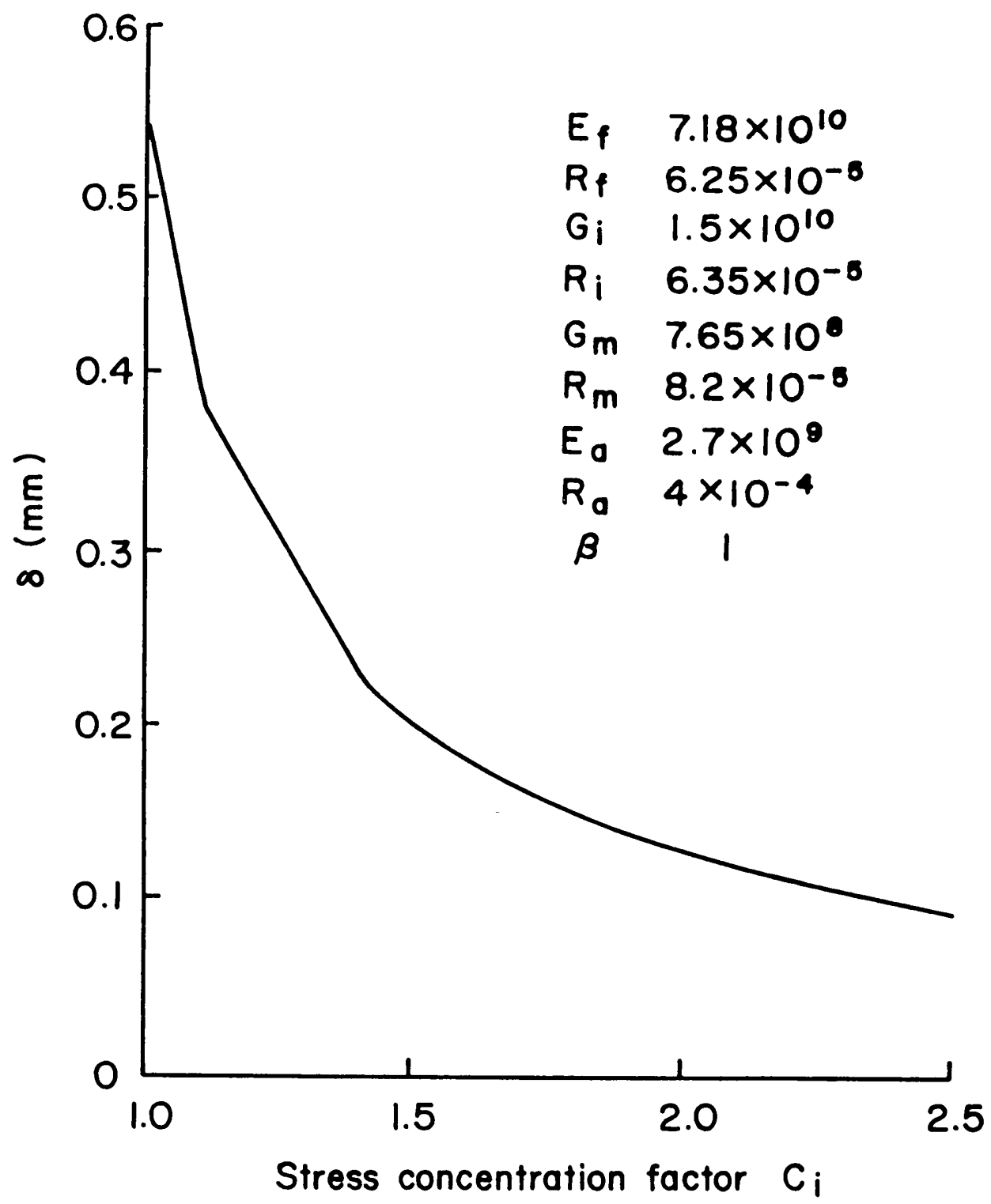

Figure 9. Elastic model: ineffective length as a function of the stress concentration 


$$
\phi=c_{l}(1-\exp [-\eta x])+\left(c_{l}-1\right) / 8 R_{j} \eta \times[(\eta \delta+1) \exp [-\eta \delta]-1]
$$

This equation is solved numerically to find $\delta$, and Figure 9 shows the influence of the stress concentration characterized by $c_{i}$ on the ineffective length.

\section{b. Behavior in the Damaged State}

In the previous section, the behavior of the fiber, matrix, and interphase were assumed to be elastic, even though the polymer matrix is known to yield under either tensile or shear loading. In this section the fiber is still considered elastic, but both the matrix and the interphase are assumed perfectly elastic-plastic. A schematic of the behavior of these materials is represented in figure 10 . Consequently, the ratio of the shear strength of the matrix to the shear strength of the interphase in part determines the locus of failure. Similarly, the ratio of the shear yielding point of the matrix to the shear yielding point of the interphase determines whether the matrix or the interphase undergoes plastic deformation.

The following mathematical model can describe any fiber-matrix system with chemical links between the constituents. But in order to use this model in an appropriate manner, the composite system must be characterized according to whether the debonding occurs because of the failure of the interphase or of the failure of the matrix. The locus of the failure can be determined by using surface analysis techniques on the surface of the fiber as described in reference 6 . Then, if the failure occurs in the interphase, our model can be used to calculate either the ineffective length or the bond strength, according to which of these is used as input data. On the other hand, if the failure occurs in the matrix, the model can be used to calculate the ineffective length or the plasticity in situ of the matrix. In both cases, the value calculated corresponds to the maximum matrix-fiber stress transfer.

The case treated in the following section corresponds to a study of the ineffective length for a composite in which failure occurs in the matrix itself. This choice has been made to match with 


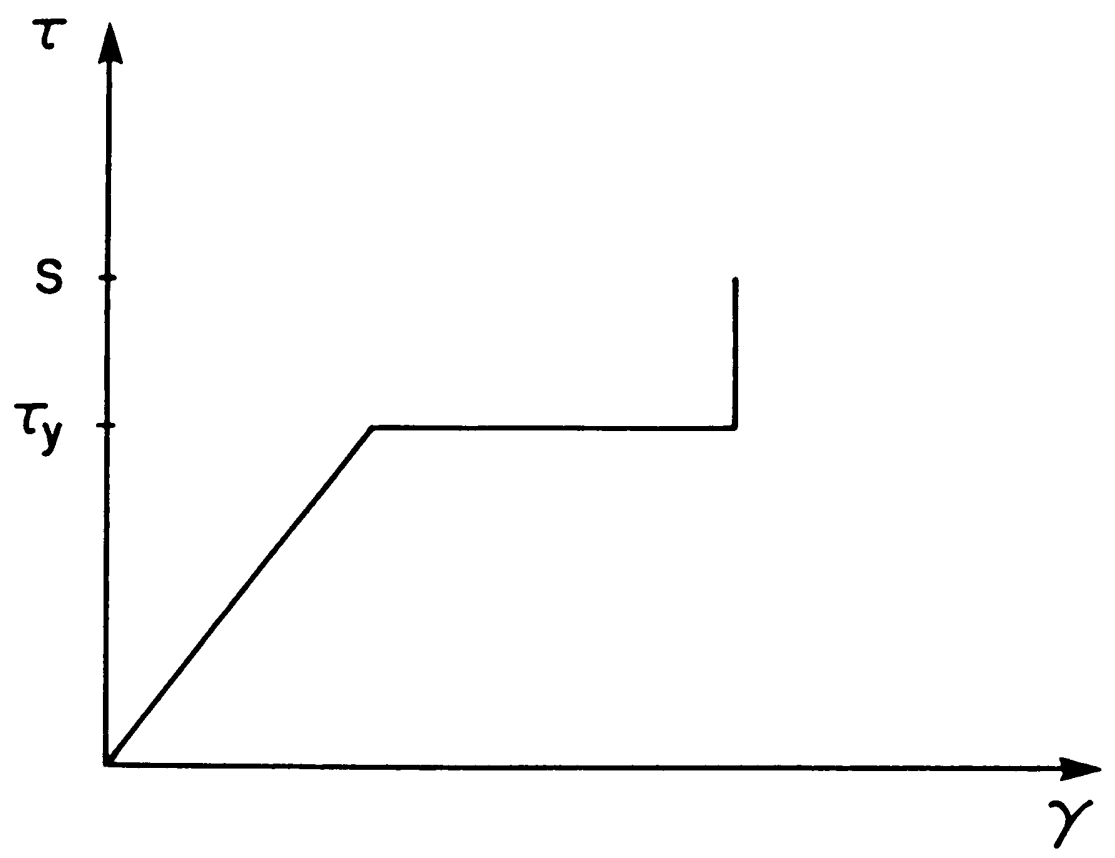

Figure 10. Behavior of the matrix and of the interphase 
the case of the glass/epoxy composite used in the experimental part of this research. The mechanical properties of the constituents are listed in Table 2.

As shown in Figure 7, the matrix evidences a large damaged zone, and even a region where rupture occurs near the fiber tip. However, whether the behavior of the matrix is elastic or not, the same load has to be transferred. Consequently, the area under the two curves in Figure 11 have to be equal.

To define the function representing the shear stress in the matrix in its damaged state, the length $\mathrm{Xr}, \mathrm{X} 1$, and $\mathrm{Xd}$ must be defined. First of all, the length $\mathrm{Xr}$ of the zone where rupture occurs, can be defined by:

$$
\tau_{m}(X r)=S_{m}
$$

where $S_{m}$ is the shear strength of the matrix.

The mathematical function represented in Figure 7, and used in this section to characterize the overstress in the matrix near the fiber end shows a singular point at a distance from the fiber tip equal to eight times the radius of the fiber. As a result, we now have to solve the equations where the overstress function appears in two steps in order to consider the two different domains of definition of the function.

Thus two formula can be used for $\tau_{m}^{d}(x)$ whether the value of the shear stress at the end of the overstressed zone $\tau_{m}\left(8 R_{f}\right)$ is smaller or larger than $S_{m}$, the shear strength of the matrix.

Consequently, for $\tau_{m}\left(8 R_{f}\right) \geq S_{m}$ (the case represented in Figure 8), Eq. 7 is inserted in Eq. 18

$$
\frac{-\bar{\sigma} R_{f} E_{f} \eta}{2 \beta E_{a}} \exp [-\eta X r] \times\left(c_{l}+\frac{X r}{8 R_{f}}\left[1-c_{l}\right]\right)=S_{m}
$$

The easiest way to solve this equation is numerically. Figure 12 represents the influence of the stress concentration on the length $\mathrm{Xr}$.

On the other hand, for $S_{m}>\tau_{m}\left(8 R_{f}\right)$, Eq. 8 is inserted in Eq. 18 
Table 2. Input data for the elasto-damaged model

$$
\begin{aligned}
& a:=\text { average material } \\
& m=\text { matrix material } \\
& i=\text { interphase } \\
& f=\text { fiber }
\end{aligned}
$$

$$
\begin{aligned}
& \mathrm{Ef}=71800 \mathrm{MPa} \\
& \mathrm{Rf}=62.5 \mathrm{E}-06 \mathrm{~m} \\
& \mathrm{Xf}=410.0 \mathrm{MPa} \\
& \mathrm{Gi}=15000 \mathrm{MPa} \\
& \mathrm{Ri}=63.5 \mathrm{E}-06 \mathrm{~m} \\
& \mathrm{Gm}=765 \mathrm{MPa} \\
& \mathrm{Rm}=80.7 \mathrm{E}-06 \mathrm{~m} \\
& \mathrm{Tym}=21.37 \mathrm{MPa} \\
& \mathrm{Sm}=32.0 \mathrm{MPa} \\
& \mathrm{Ea}=2700 \mathrm{MPa} \\
& \mathrm{Ra}=1 \mathrm{E}-03 \mathrm{~m} \\
& \beta=1 . \\
& \bar{\sigma}=15.44 \mathrm{MPa}
\end{aligned}
$$




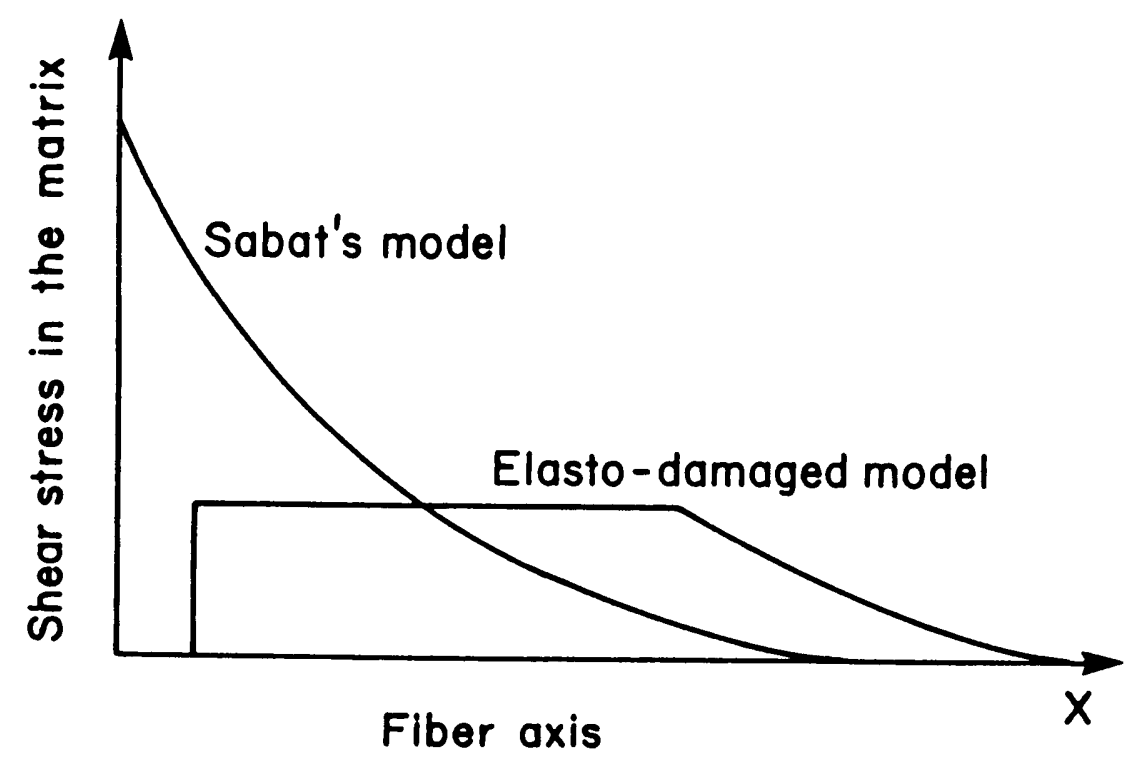

Figure 11. Schematic of the elasto-damaged model 


$$
\frac{-\sigma R_{f} E_{f} \eta}{2 \beta E_{a}} \exp [-\eta X r]=S_{m}
$$

or

$$
X r=-1 / \eta \ln \left[-2 \beta E_{a} S_{m} / \bar{\sigma} R_{f} E_{f} \eta\right]
$$

In both cases, it is assumed that no load is transferred between the matrix and the fiber from the end of the fiber to the point of abscissa $\mathrm{Xr}$.

The length $\mathrm{Xd}$ of the zone where damage occurs must now be defined. The solution can be found through the formula

$$
\int_{0}^{X l} \tau_{m}(x) d x=\tau_{y}(X d-X r)
$$

which equates the surfaces under the two curves in Figure 11, and where $\tau_{y}$ is the yielding shear stress of the matrix.

In order to solve Eq. 22 we need to define $\mathrm{Xl}$ the point for which the shear stress takes the value of the yielding point of the matrix. The equation for the shear stress in terms of $\mathrm{Xl}$ is given by:

$$
\tau_{m}(X l)=\tau_{y}
$$

The shear stress is represented by either Eq. 7 or Eq. 8 whether the value of the shear stress at the end of the overstressed zone is smaller or bigger than $\tau_{y}$ the shear yielding point of the matrix. Consequently, as it has been done before to solve Eq. 18, Eq. 23 is solved in two steps. Eq. 22 is first solved for the case when $\tau_{m}\left(8 R_{f}\right)>\tau_{y}$, and Eq. 7 is inserted into Eq. 23:

$$
\frac{\bar{\sigma} E_{f} R_{f} \eta}{2 \beta E_{a}} \exp \left[-\eta X I\left(c_{l}+\frac{X l}{8 R_{f}}\left(1-c_{i}\right)\right)=\tau_{y}\right.
$$




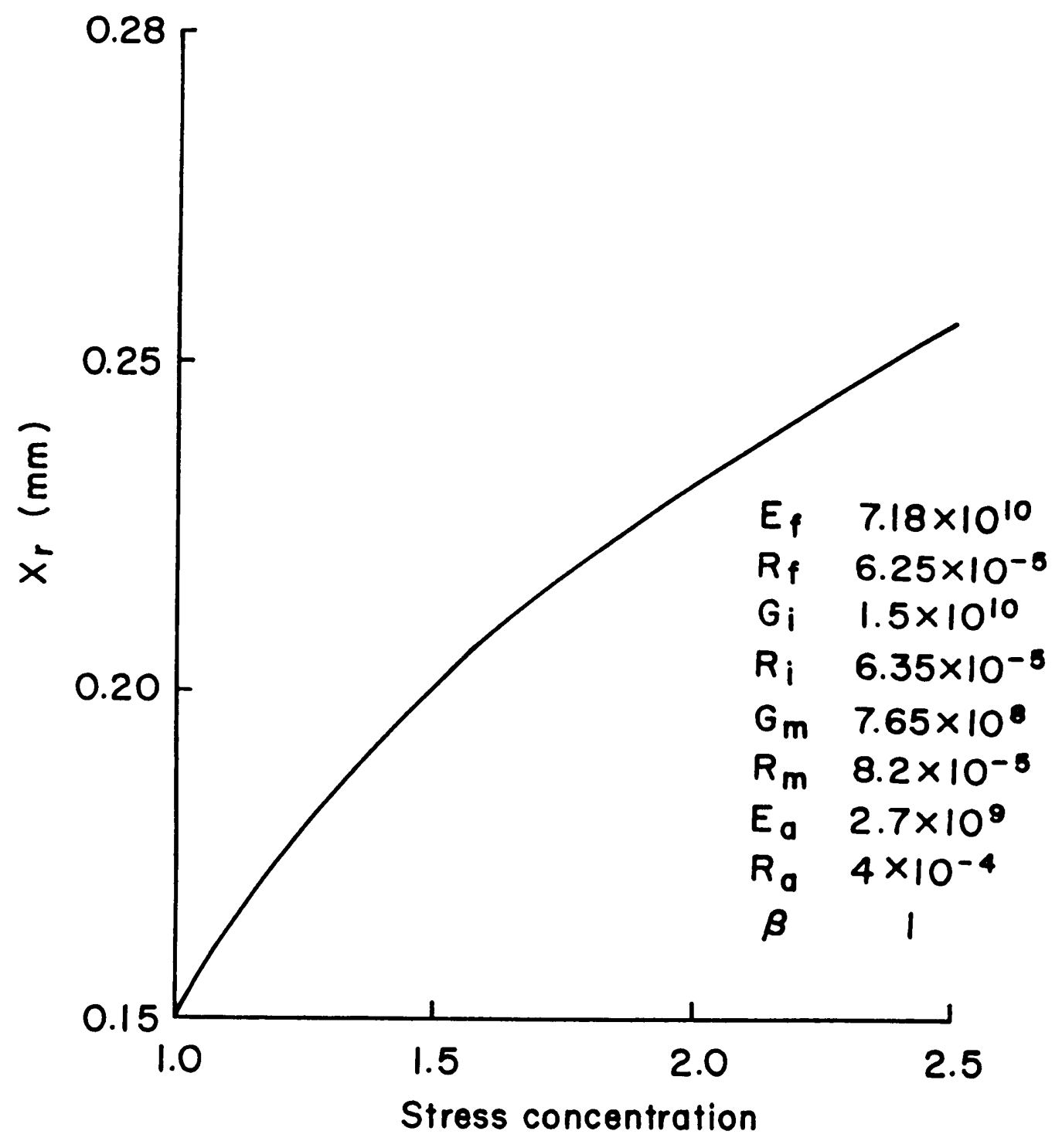

Figure 12. Length of the rupture zone 
This equation, as Eq. 19, is to be solved numerically, and Figure 13 gives the solution as a function of the stress concentration factor $c_{i}$. In this case, when $\tau_{m}(x)$ for $\mathrm{x}$ between zero and $\mathrm{Xl}$ is entirely described by Eq. 7, Eq. 22 becomes

$$
\int_{0}^{X l}\left[\frac{-\bar{\sigma} E_{f} R_{f} \eta}{2 \beta E_{a}} \exp [-\eta x]\left(c_{l}+\frac{x}{8 R_{f}}\left(1-c_{l}\right)\right)\right] d x=\tau_{y}(X d-X r)
$$

or

$$
\frac{-\bar{\sigma} E_{f} R_{f} \eta}{2 \beta E_{a}}\left[c_{l} \int_{0}^{X l} \exp [-\eta x] d x+\frac{1-c_{l}}{8 R_{f}} \int_{0}^{X l} x \exp [-\eta x] d x\right]=\tau_{y}(X d-X r)
$$

or

$$
X d=\frac{\bar{\sigma} E_{f} R_{f}}{2 \beta E_{a} \tau_{y}}\left[c _ { i } \left(\exp [-\eta X \eta-1)+\frac{1-c_{l}}{8 R_{f}}((\eta X l+1) \exp [-\eta X \eta-1)]+X r\right.\right.
$$

where $\mathrm{Xl}$ and $\mathrm{Xr}$ are respectively given in Eq. 24 and Eq. 19. The influence of the stress concentration on the length of the damaged zone is represented in Figure 14.

For $\tau_{m}\left(8 R_{f}\right)<\tau_{y}$ Eq. 8 is inserted into Eq. 23 :

$$
X l=-1 / \eta \times \ln \left[-2 \beta E_{a} \tau_{y} / \bar{\sigma} E_{f} R_{f} \eta\right]
$$

In this case, $\tau_{m}(x)$ for $\mathrm{x}$ between zero and $\mathrm{Xl}$ is described partly by Eq. 7, and partly by Eq. 8. As a result, Eq. 22 becomes 


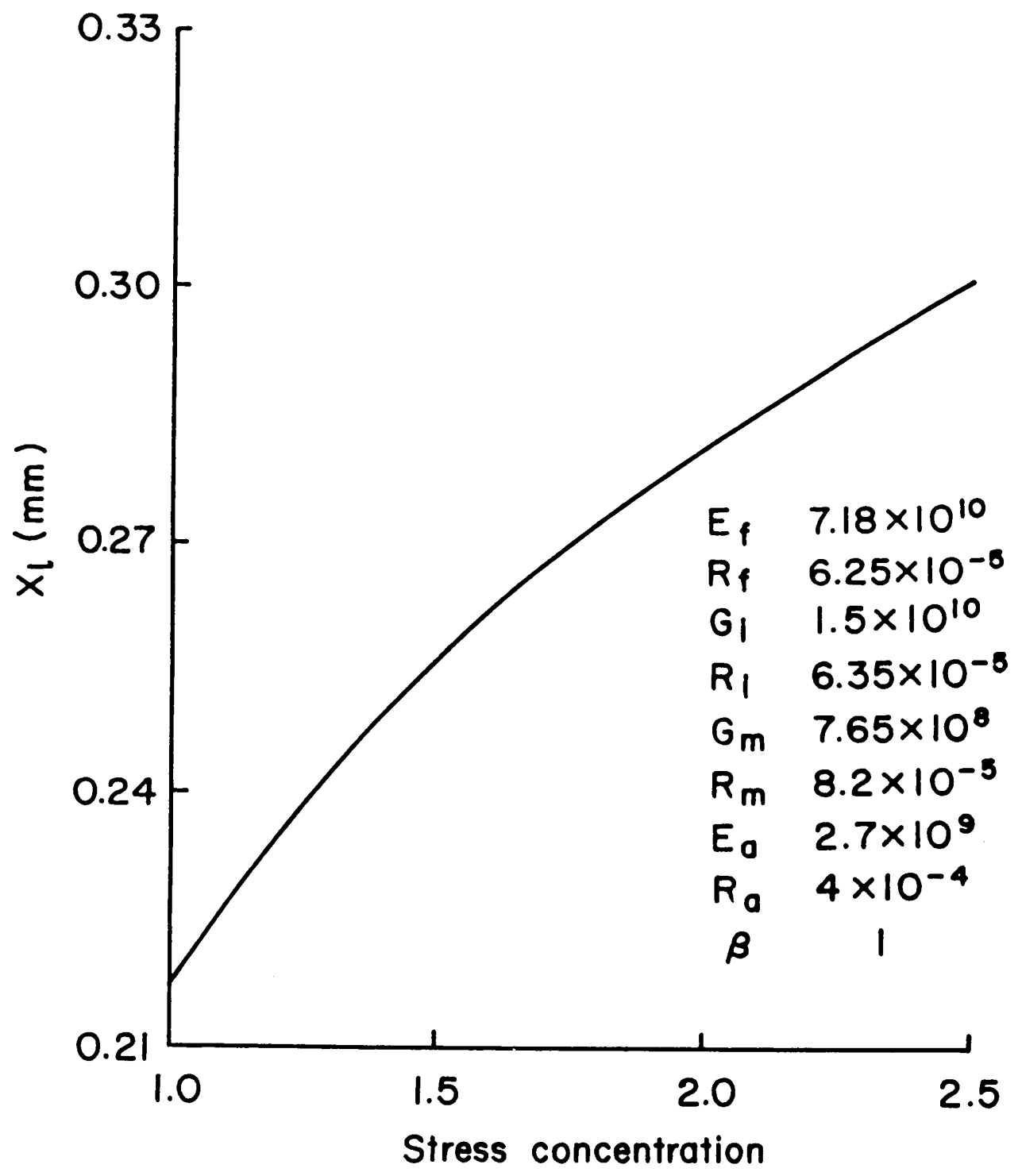

Figure 13. Length XI 


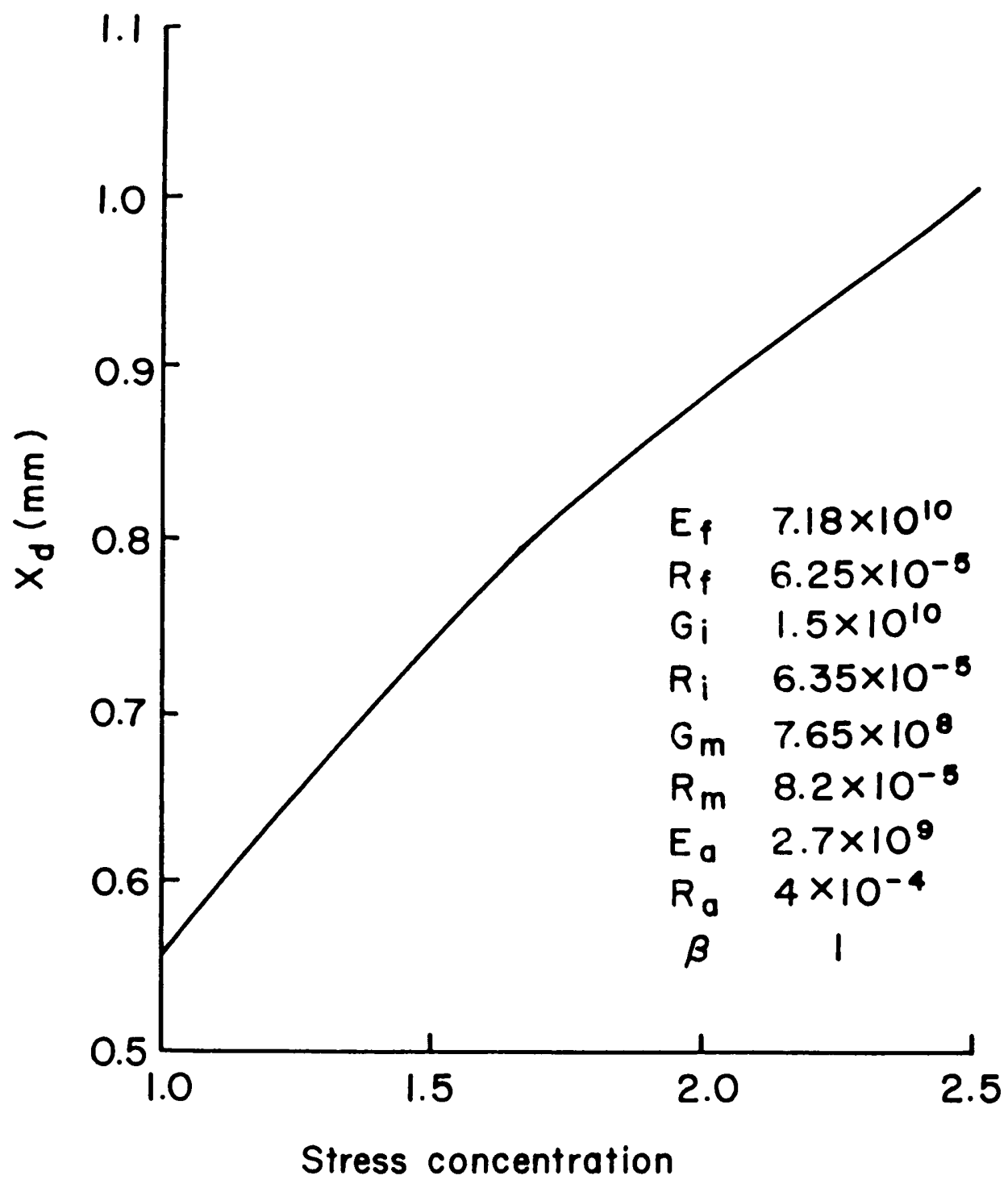

Figure 14. Length of the damaged zone 


$$
\begin{aligned}
\int_{0}^{8 R_{f}} \frac{-\bar{\sigma} E_{f} R_{f} \eta}{2 \beta E_{a}} & \exp [-\eta x]\left(c_{l}+\frac{x}{8 R_{f}}\left(1-c_{l}\right)\right) d x \\
& +\int_{8 R_{f}}^{X l} \frac{-\bar{\sigma} E_{f} R_{f} \eta}{2 \beta E_{a}} \exp [-\eta x] d x=\tau_{y}(X d-X r)
\end{aligned}
$$

and by integrating Eq. 29 we get:

$$
\begin{aligned}
X d= & \frac{\bar{\sigma} E_{f} R_{f}}{2 \beta E_{a} \tau_{y}}\left[c_{l}\left(\exp \left[-8 R_{f} \eta\right]-1\right)+\frac{1-c_{l}}{8 R_{f} \eta}\left(\left(8 R_{f} \eta+1\right) \exp \left[-8 R_{f} \eta\right]-1\right)\right. \\
& \left.+\exp [-\eta X \eta]-\exp \left[-8 R_{f} \eta\right]\right]+X r
\end{aligned}
$$

After the point of abscissa Xd, the matrix stays in its elastic domain and the shear stress function $\tau_{m}^{d}(x)$ needs to be defined in order to calculate the tensile stress $\sigma_{f}^{d}(x)$ in the fiber. In order to accomplish this, we note that, for $0<\mathrm{X}<\mathrm{Xr}$

$$
\tau_{m}^{d}(x)=0
$$

and

$$
\sigma_{f}^{d}(x)=0
$$

For $\mathrm{Xr}<\mathrm{x}<\mathrm{Xd}$

$$
\tau_{m}^{d}(x)=\tau_{y}
$$

Inserting Eq. 33 into Eq. 9 and integrating we get:

$$
\sigma_{f}^{d}(x)=\frac{-2 \beta}{R_{f}} \tau_{y}(x-X r)
$$


For $\mathrm{Xd}<\mathrm{X}$, the shear stress $\tau_{m}^{d}(x)$ in the matrix can be obtained by a simple translation of the function represented either by Eq. 7 or by Eq. 8. The choice between Eq. 7 or Eq. 8 depends on whether the length of the damaged zone in the matrix is smaller or larger than eight times the radius of the fiber, the length of the overstressed zone. The amplitude of the translation is equal to the difference of the length of the damaged zone to the legnth X1.

For $\mathrm{Xd}<\mathrm{x}<8 R_{f}+\mathrm{Xd}-\mathrm{Xl}$, and recalling Eq. 7:

$$
\tau_{m}^{d}(x)=\frac{-\bar{\sigma} E_{f} R_{f} \eta}{2 \beta E_{a}} \exp [-\eta(x-X d+X l)] \times\left[c_{l}+\frac{x-X d+X l}{8 R_{f}}\left(1-c_{l}\right)\right]
$$

Integrating Eq. 9:

$$
\sigma_{f}^{d}(x)=-2 \beta / R_{f}\left[\int_{X r}^{X d} \tau_{y} d x+\int_{X d}^{x} \tau_{m}^{d}(x) d x\right]
$$

and inserting Eq. 35 into Eq. 36 we obtain:

$$
\begin{aligned}
\sigma_{f}^{d}(x)= & \frac{-2 \beta \tau_{y}}{R_{f}}(X d-X r)+\frac{\bar{\sigma} E_{f} \eta}{E_{z}}\left[\frac{-c_{l}}{\eta} \exp [-\eta(x-X d+X I)]\right. \\
& \left.-\frac{1-c_{l}}{8 R_{f}} \frac{\eta(x-X d+X I)}{\eta^{2}} \exp [-\eta(x-X d+X I)]\right]_{X d}^{x}
\end{aligned}
$$

and developing gives:

$$
\begin{aligned}
\sigma_{f}^{d}(x)= & \frac{-2 \beta \tau_{y}}{R_{f}}(X d-X r)-\frac{\bar{\sigma} E_{f}}{E_{a}}\left[\left(c_{l}+\frac{1-c_{l}}{8 R_{f}} \frac{\eta(x-X d+X)+1}{2}\right)\right. \\
& \left.\times \exp [-\eta(x-X d+X)]-\left(c_{l}+\frac{1-c_{l}}{8 R_{f}} \frac{\eta X l+1}{\eta}\right) \exp [-\eta X I]\right]
\end{aligned}
$$

For $\mathrm{Xd}<8 R_{f}+\mathrm{Xd}-\mathrm{Xl}<\mathrm{X}$, the shear stress $\tau_{m}^{d}(x)$ can be represented by the translation of Eq. 8 


$$
\tau_{m}^{d}(x)=\frac{-\bar{\sigma} R_{f} E_{f} \eta}{\beta E_{a}} \exp [-\eta(x-X d+X I)]
$$

Then, the integration of Eq. 9 gives:

$$
\sigma_{f}^{d}(x)=\frac{-2 \beta}{R_{f}}\left[\int_{X r}^{X d} \tau_{y} d x+\int_{X d}^{8 R_{f}+X d-X l} \tau_{m}^{d}(x) d x+\int_{8 R_{f}+X d-X l}^{x} \tau_{m}^{d}(x) d x\right]
$$

Inserting both Eq. 35 and Eq. 38 respectively in the second and third integrals of Eq. 39 we get:

$$
\begin{aligned}
\sigma_{f}^{d}(x)= & \frac{-2 \beta}{R_{f}} \tau_{y}(X d-X r)-\frac{\bar{\sigma} E_{f}}{E_{a}}\left[\left(c_{l}+\frac{1-c_{l}}{8 R_{f}} \frac{8 R_{f} \eta+1}{\eta}\right) \times \exp \left[-8 R_{f} \eta\right]\right. \\
& \left.-\left(c_{l}+\frac{1-c_{l}}{8 R_{f}} \frac{\eta X l+1}{\eta}\right) \exp [-\eta X l]+\exp [-\eta(x-X d+X I)]-\exp \left[-8 R_{f} \eta\right]\right]
\end{aligned}
$$

For $8 R_{f}+X d-X l<X d<X, \tau_{m}^{d}(x)$ is represented by the translation of Eq. 8 as in Eq. 38 , and integrating Eq. 9, we obtain:

$$
\sigma_{f}^{d}(x)=\frac{-2 \beta}{R_{f}}\left[\int_{X r}^{X d} \tau_{y} d x+\int_{X l}^{x-X d+X l} \tau_{m}(x) d x\right]
$$

and inserting Eq. 38 into Eq. 41 we get:

$$
\sigma_{f}^{d}(x)=\frac{-2 \beta}{R_{f}} \tau_{y}(x d-x r)-\frac{\bar{\sigma} E_{f}}{E_{a}}[\exp [-\eta(x-X d+X l]-\exp [-\eta X \eta]
$$

All the logical cases have been reviewed and are summarized in a flow chart represented in Figure 15. The overstressed line follows the path used to generate the curves in Figures 13 and 14 after the data reported in Table 2. Figures 16 and 17 show the influence of the stress concentration on the shear stress in the matrix and the tensile stress in the fiber, respectively. 


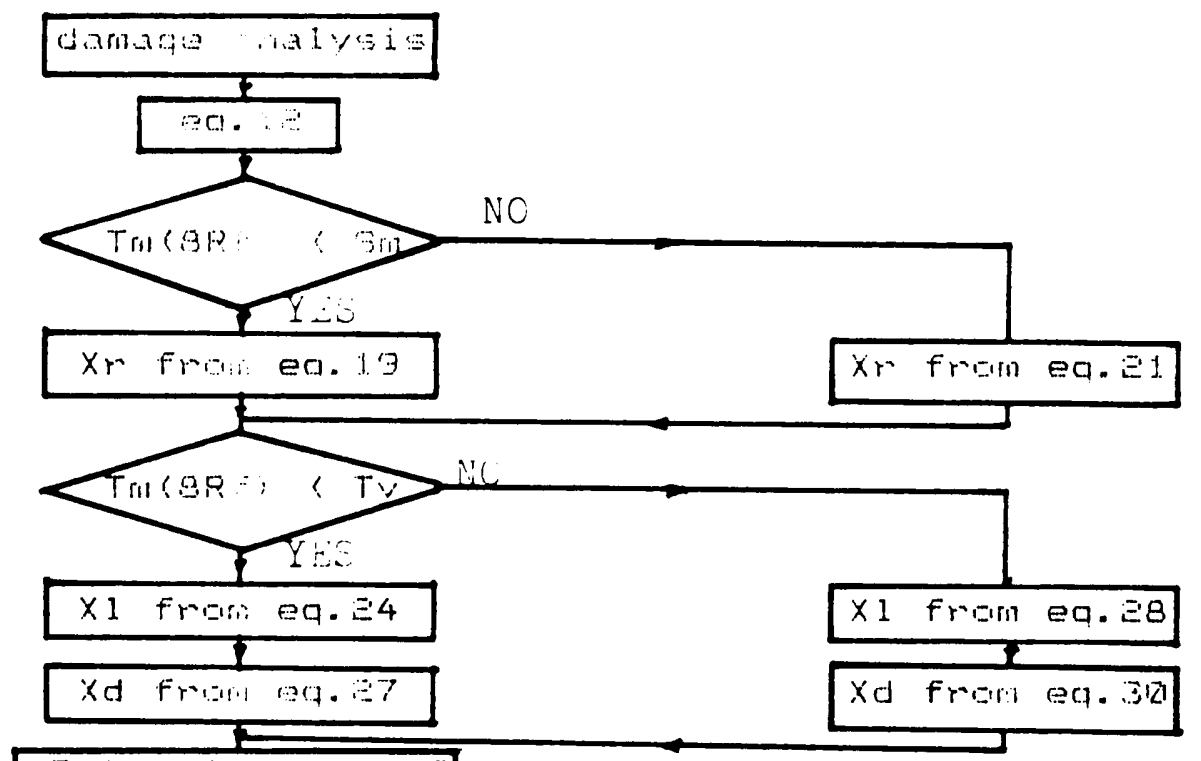

Determinting

$F r a(x)$ arial $F(x)$

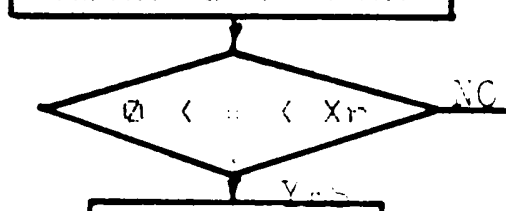

$\operatorname{Tri}\left(x^{\circ}=\pi\right.$

$f(x)=\ddot{n}$

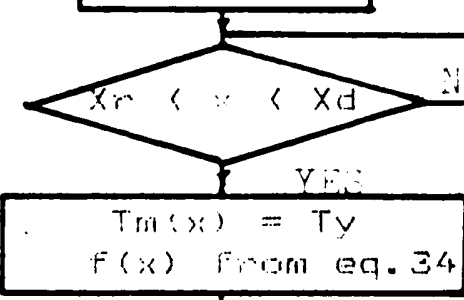

Figure 15. Flow chart of the computer program to compute the ineffective length 


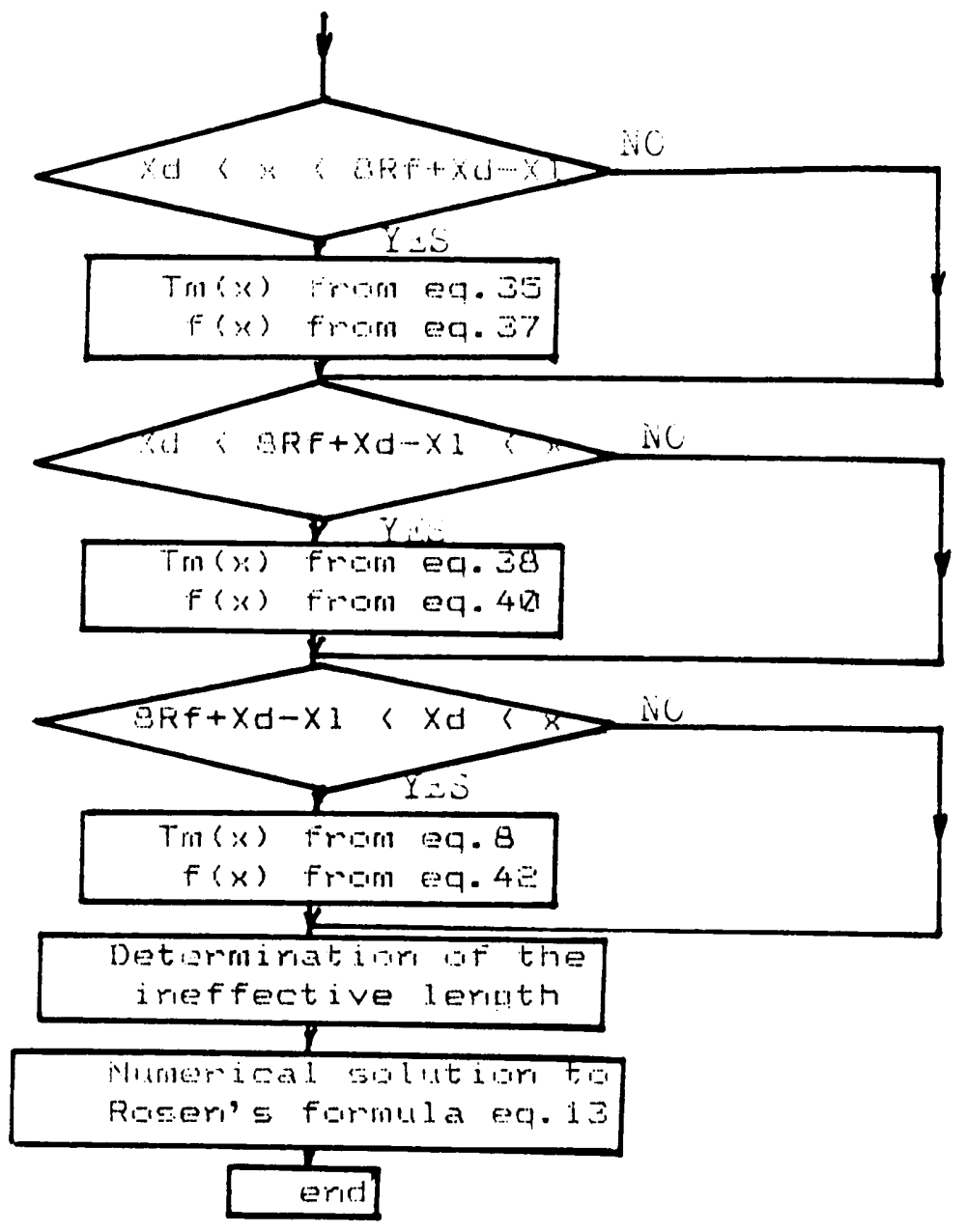

Figure 15. Flow chart, continued 


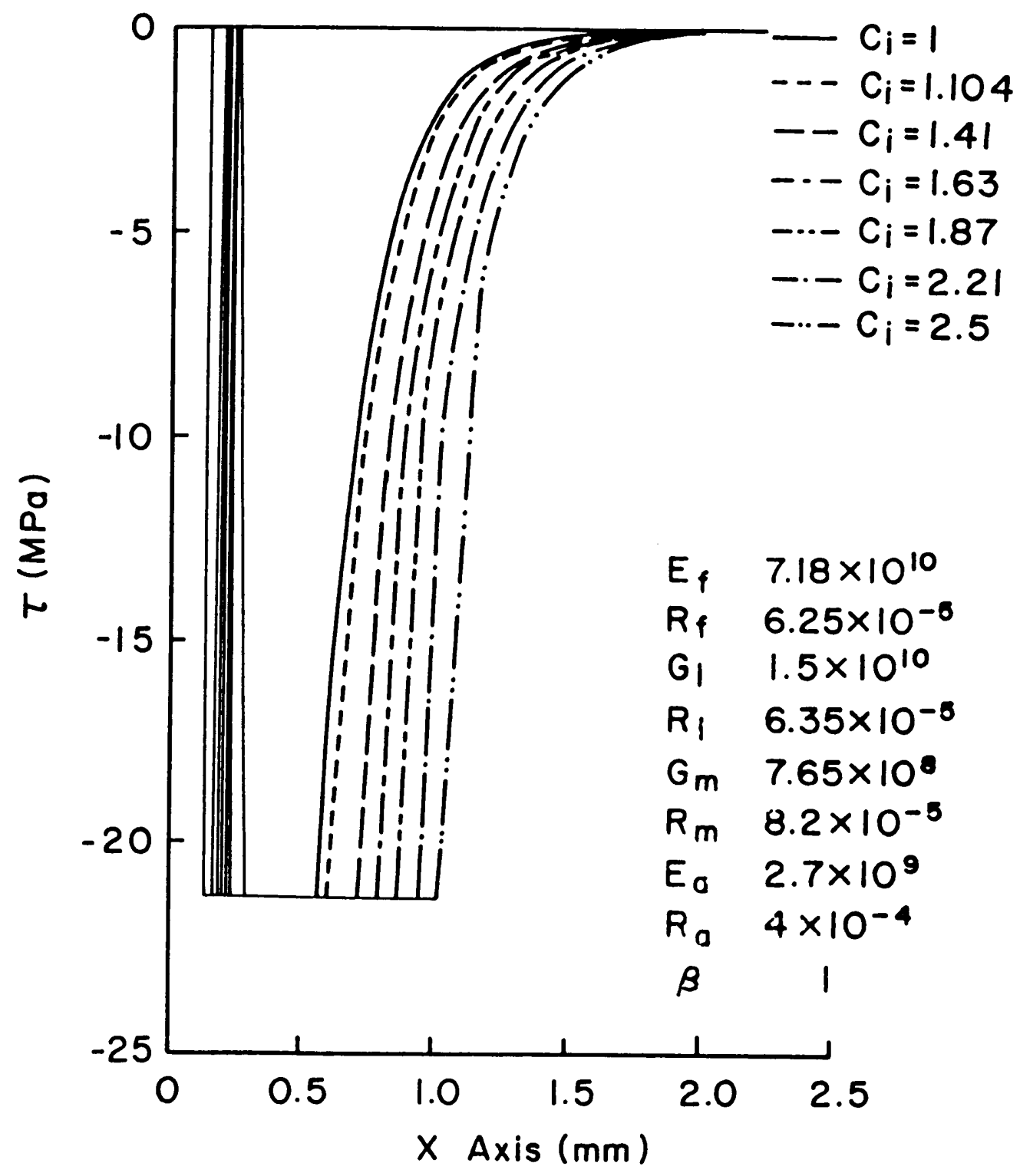

Figure 16. Elasto-damaged model: shear stress in the matrix (for one to six broken neighboring fibers) 


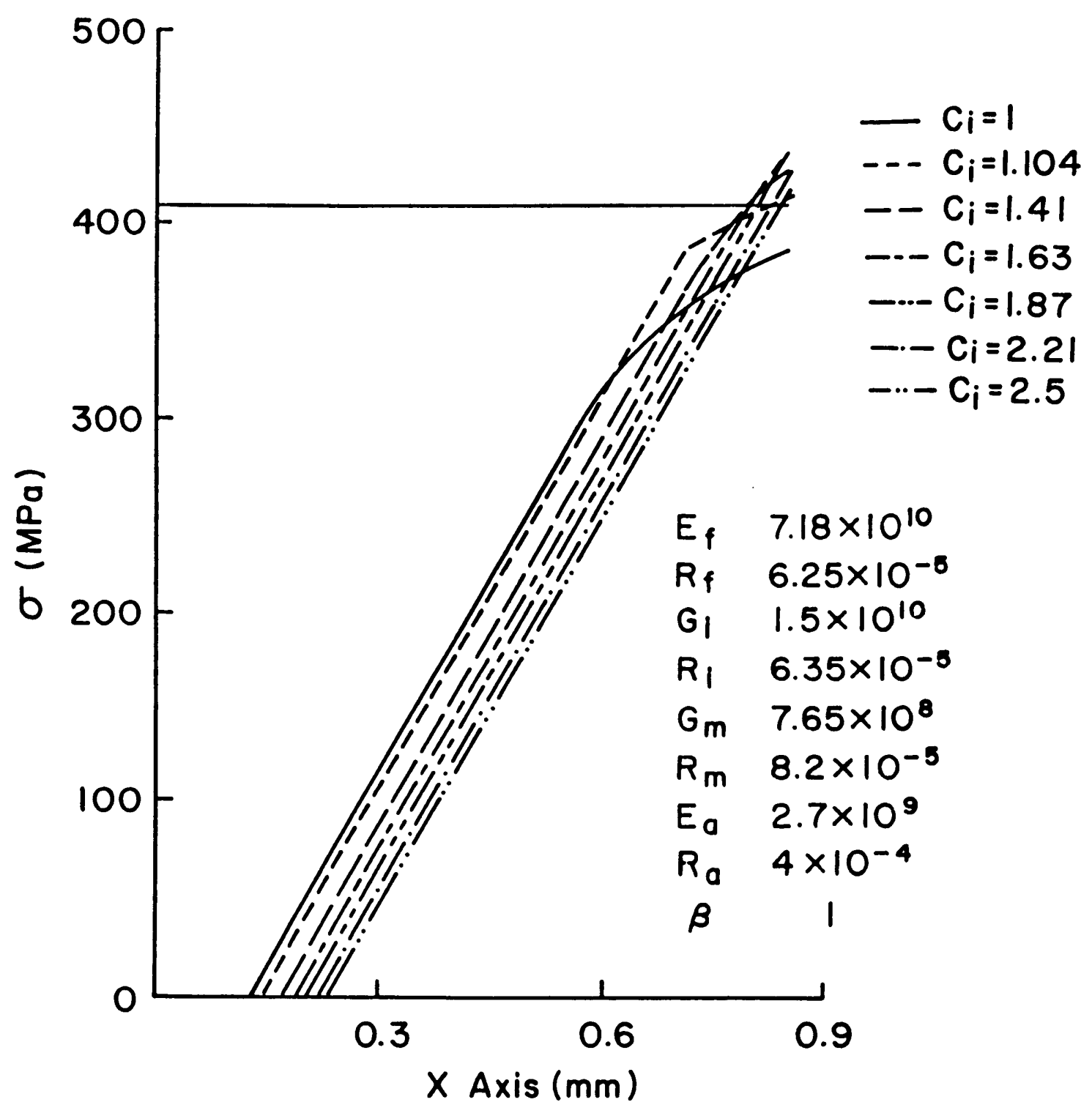

Figure 17. Elasto-damaged model: tensile stress in the fiber (for one to six broken neighboring fibers) 
The tensile stress in the fiber is now totally defined, and Rosen's formula for the fiber efficiency can be used again to find the ineffective length $\delta$. In Figure 18, the applied stress is chosen in order to obtain in the center part of the fiber a stress intensity equal to the fiber strength. This maximum value is a material characteristic, and thus, the ineffective length still appears as a function of the stress concentration only.

\section{Results and Discusssion}

The present analytical model improves the accuracy of the mathematical representation of the matrix-fiber stress transfer by considering the possibility of damage in the matrix or in the interphase and the stress concentration near fiber breaks. As a result, the equations which describe the stress fields in the matrix and in the fiber take complex forms, thus the particular influence of the different parameters is difficult to evaluate.

The influence of the stress concentration around fiber breaks is illustrated in Figure 18. This curve exhibits a minimum value which is characteristic of the fiber-matrix system. The location of this minimum on the stress concentration axis is related to the ratio of the fiber strength to the yielding point of the matrix. One must also notice in Figure 18 that when the stress concentration increases, the ineffective length does not drop but remains in the same order of magnitude. This is not the case when the calculations are performed only in the elastic domain. If this tendency were verified experimentally, single fiber samples could be used, at least for a first approximation, to evaluate the efficiency of the matrix-fiber stress transfer in composites.

Experimental measurements of the ineffective length are available in the literature $[4,6,40]$, and, as described later in this report, we have conducted several series of experiments of our own and taken many measurements. For the comparison to be possible between experimental measurements and analytical values obtained through the elasto-damaged model, a short parametric study must be conducted to examine the influence of the main material properties. Figures 19 and 20 show the influence of the radius of the fiber and of the shear modulus of the matrix respectively 


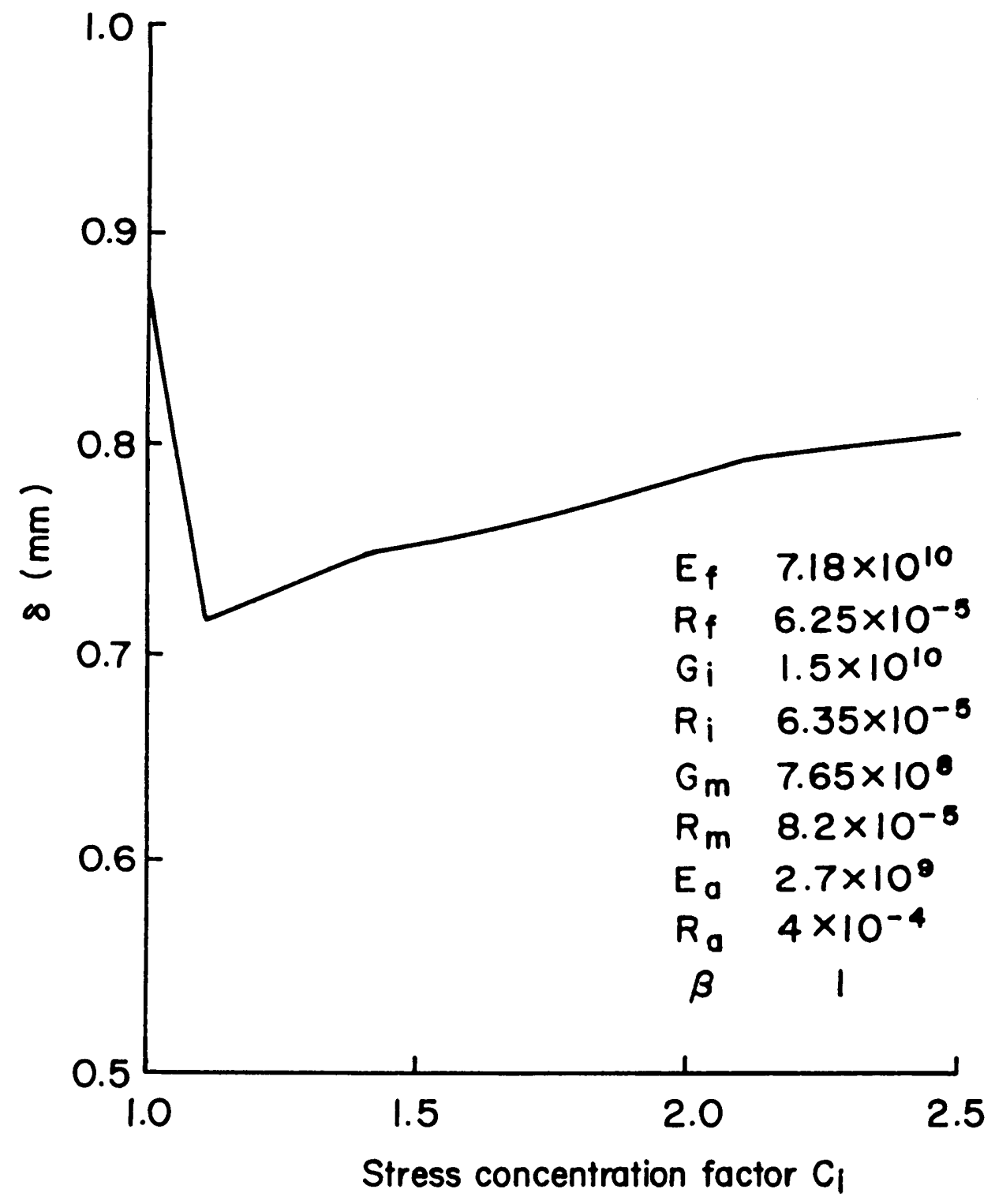

Figure 18. Elasto-damaged model: Ineffective length as a function of the stress concentration 
on the ineffective length. In order to refer in Figure 20 to the different types of resins used in the previous studies, we also varied the values of the shear yielding point and of the shear strength of the matrix. The mechanical responses under shear loading of the different matrices used in Figure 20 are reported in Table 3.

\section{E. LIMITED FRICTION}

\section{Stress Field in the Fiber}

For many fiber-matrix systems, the model previously developed, assuming the perfect bonding of the fibers to the matrix, gives much lower results than the experimental measurements of the ineffective length with polarized light. For thermoplastic matrix composite materials by example, the polymer does not undergo further polymerization during the fabrication of the composite. Consequently, it is less likely to react with the fibers than a thermosetting resin. The same abscence of chemical bonding can also occur in glass/epoxy systems when the fibers undergo certain surface treaments. Also in the case where there is chemical bonding between the matrix and the fibers, the interface may constitute a weak boundary layer which breaks before the matrix reaches its damaged state.

In these two cases, the possibility of fiber slippage in the matrix reported in reference 4 must be considered. Consequently, in this section, a mathematical model using the basic theory of elasticity is developed for the shear stress at the interface and for the tensile stress in the fiber.

For fibrous composite materials in which the fibers are not bonded to the matrix, and which are loaded in tension, the shear stress in the matrix is generated by frictional forces due to the lateral contraction of the matrix. This can be represented by: 


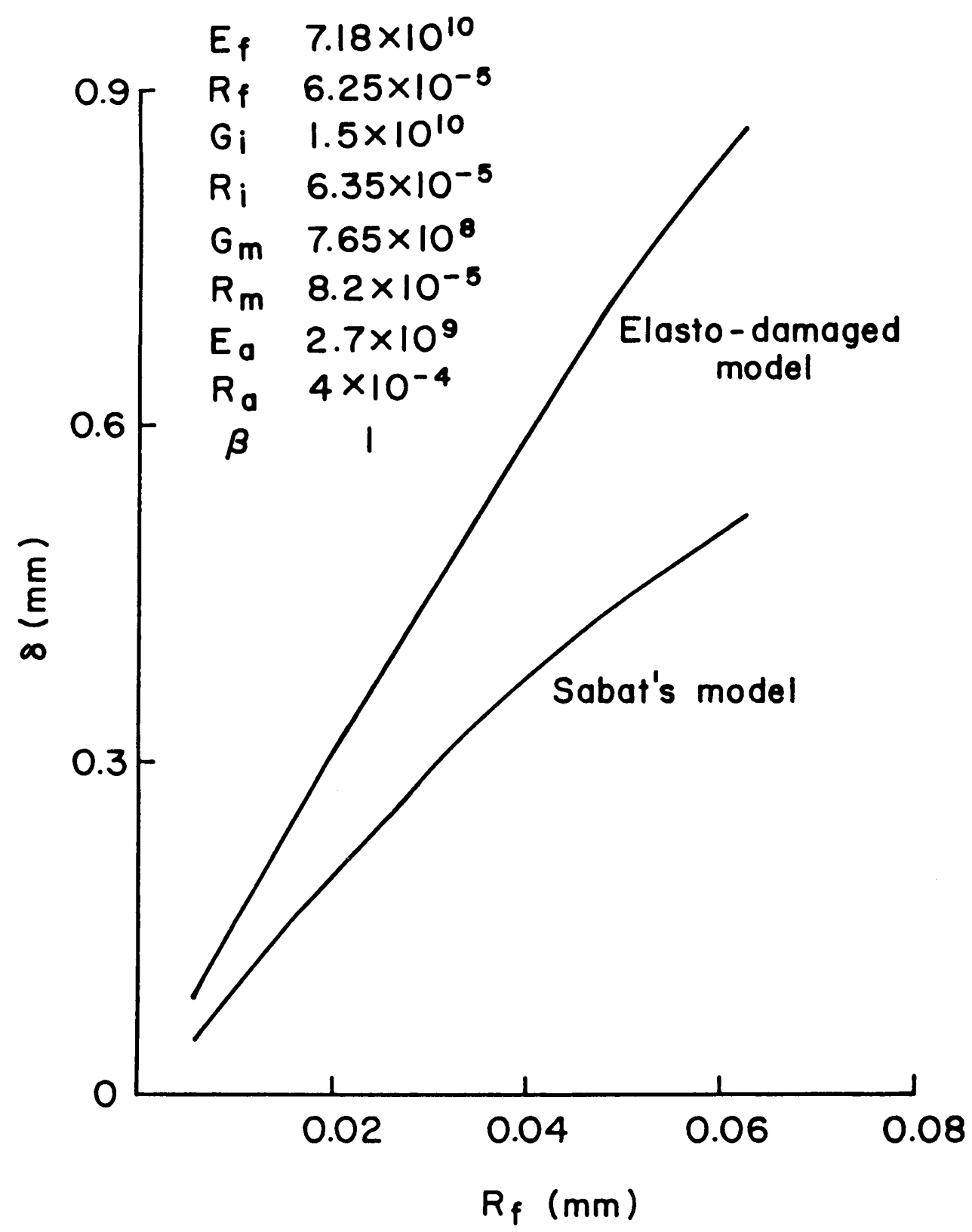

Figure 19. Influence of the radius of the fiber on $\delta$ (elasto-damaged model) 


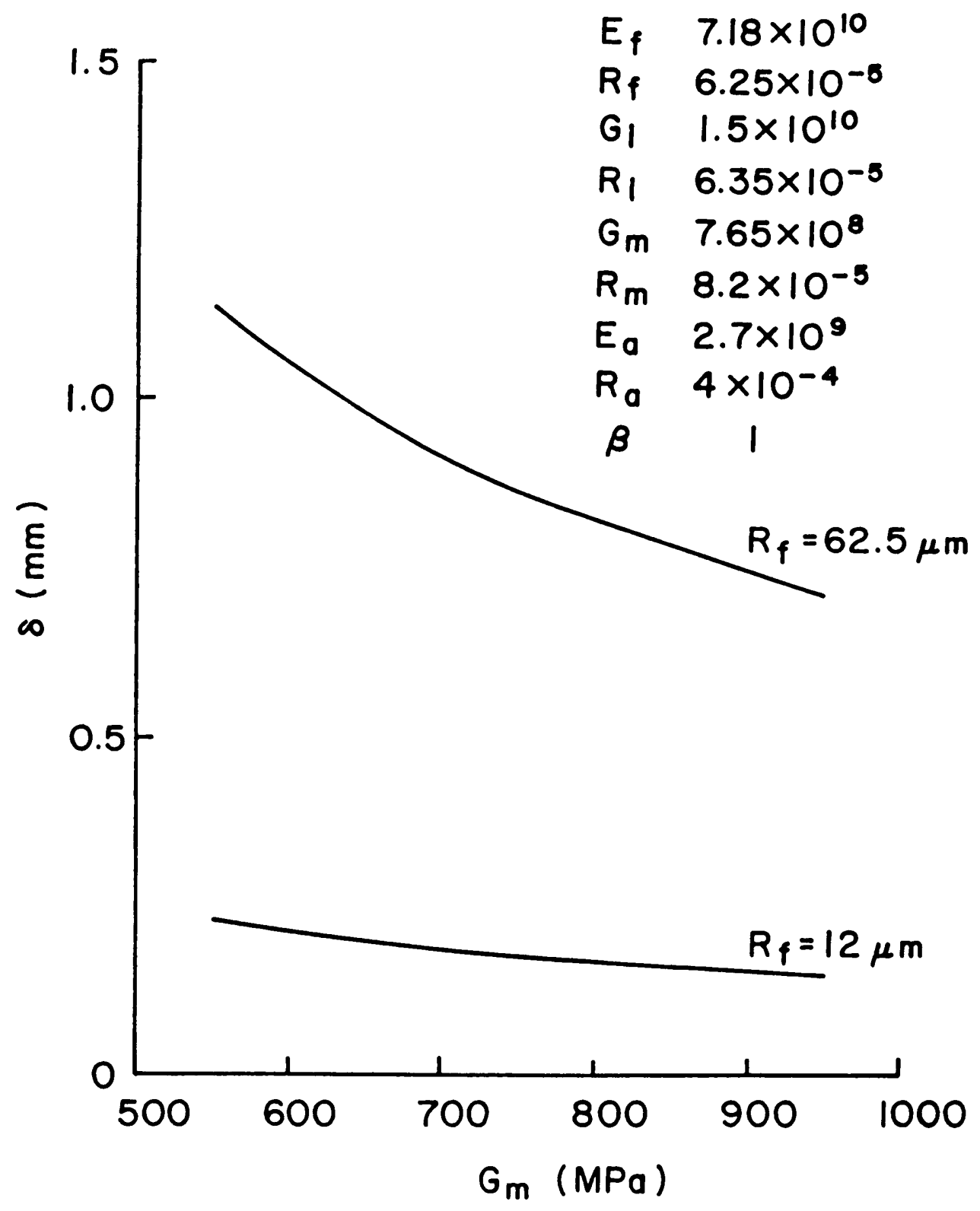

Figure 20. Influence of $\mathrm{Gm}$ on the ineffective length (elasto-damaged model) 
Table 3. Mechanical response of the matrices used to generate Figure 20

\begin{tabular}{lll}
\hline $\begin{array}{l}\text { Gm } \\
(\mathrm{MPa})\end{array}$ & $\begin{array}{c}\tau \text { yielding } \\
(\mathrm{MPa})\end{array}$ & $\begin{array}{c}\mathrm{Sm} \\
(\mathrm{MPa})\end{array}$ \\
\hline 550 & 15.36 & 25.3 \\
650 & 18.15 & 29.9 \\
750 & 21.37 & 34.5 \\
850 & 23.74 & 39.1 \\
950 & 26.53 & 43.7 \\
\hline
\end{tabular}




$$
\tau_{l}=\mu P_{l}
$$

where $\tau_{l}$ is the shear stress in the matrix at the interface, $\mu$ is the coefficient of friction between the fiber and the matrix, and $P_{1}$ is the lateral pressure at the interface.

The solution for equation 1 is found through the equilibrium of the unit cell represented in Figure 21. The matrix and the fiber are both considered isotropic linear elastic materials. Consequently, the principle of superposition can be applied as follows:

Equilibrium of the unit cell in Figure 21:

$$
\pi R_{f}^{2} \sigma_{f}+\pi\left(R_{m}^{2}-R_{f}^{2}\right) \sigma_{m}=F
$$

Equilibrium of the fiber (Figure 21):

$$
2 \pi R_{f} \tau_{l} d x+\pi R_{f}^{2} \frac{d \sigma_{f}}{d x} d x=0
$$

After simplification of Eq. 3:

$$
\tau_{l}=\frac{R_{f}}{2} \frac{d \sigma_{f}}{d x}
$$

The pressure $P_{1}$ can be obtained by considering the compatibility of the radial deformation at the interface:

$$
U_{f F}+U_{f P_{i}}=U_{m F}+U_{m P_{i}}
$$

where $U_{f F}$ is the radial deformation of the fiber due to the applied load, $U_{f P_{i}}$ is the radial deformation of the fiber due to the applied load, $U_{f P_{i}}$ is the radial deformation of the fiber due to interfacial pressure, $U_{m F}$ is the radial deformation of the matrix due to the applied load, and $U_{m P_{i}}$ is the radial deformation of the matrix due to interfacial pressure. 


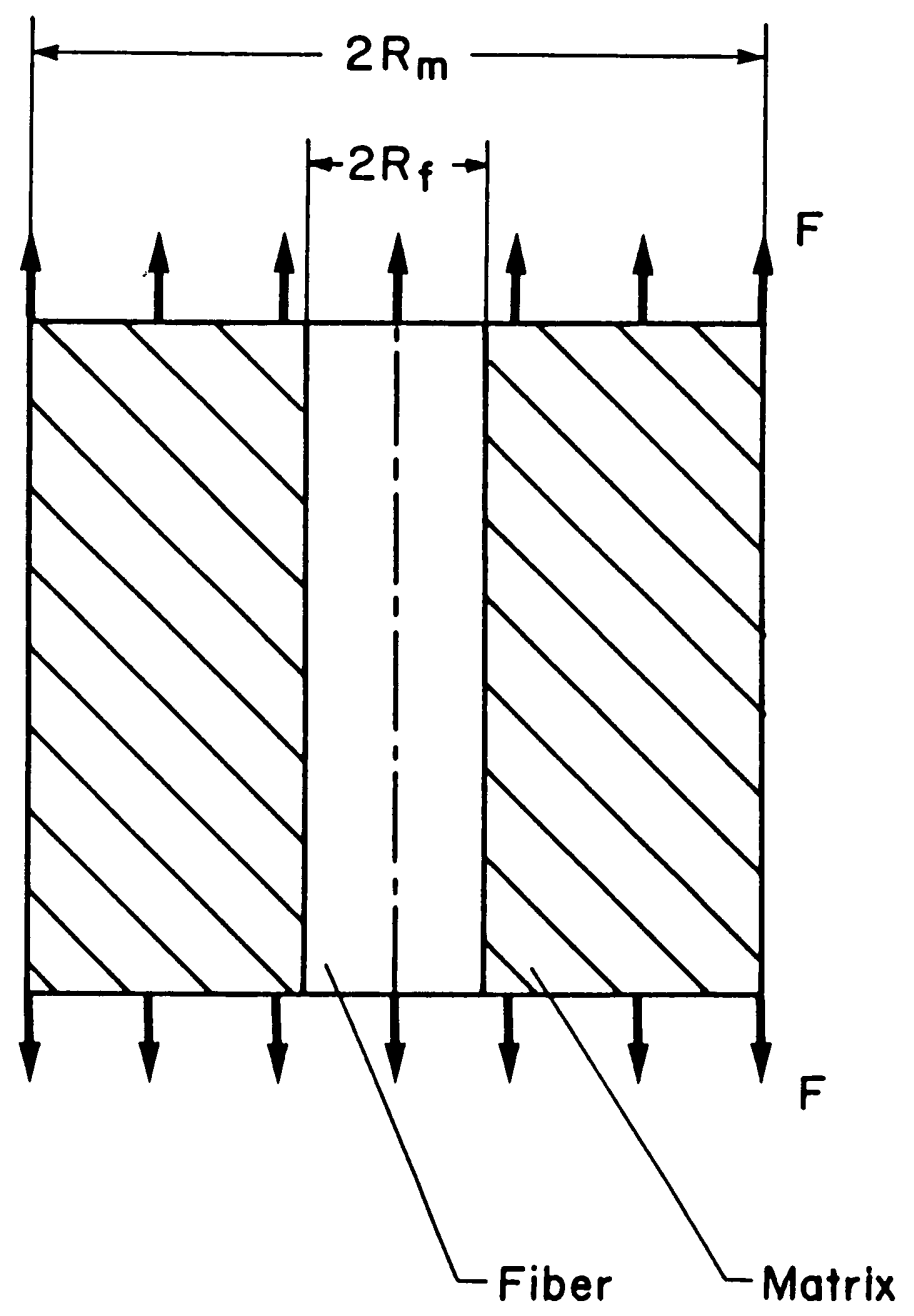

Figure 21. Unit cell for the limited friction model 

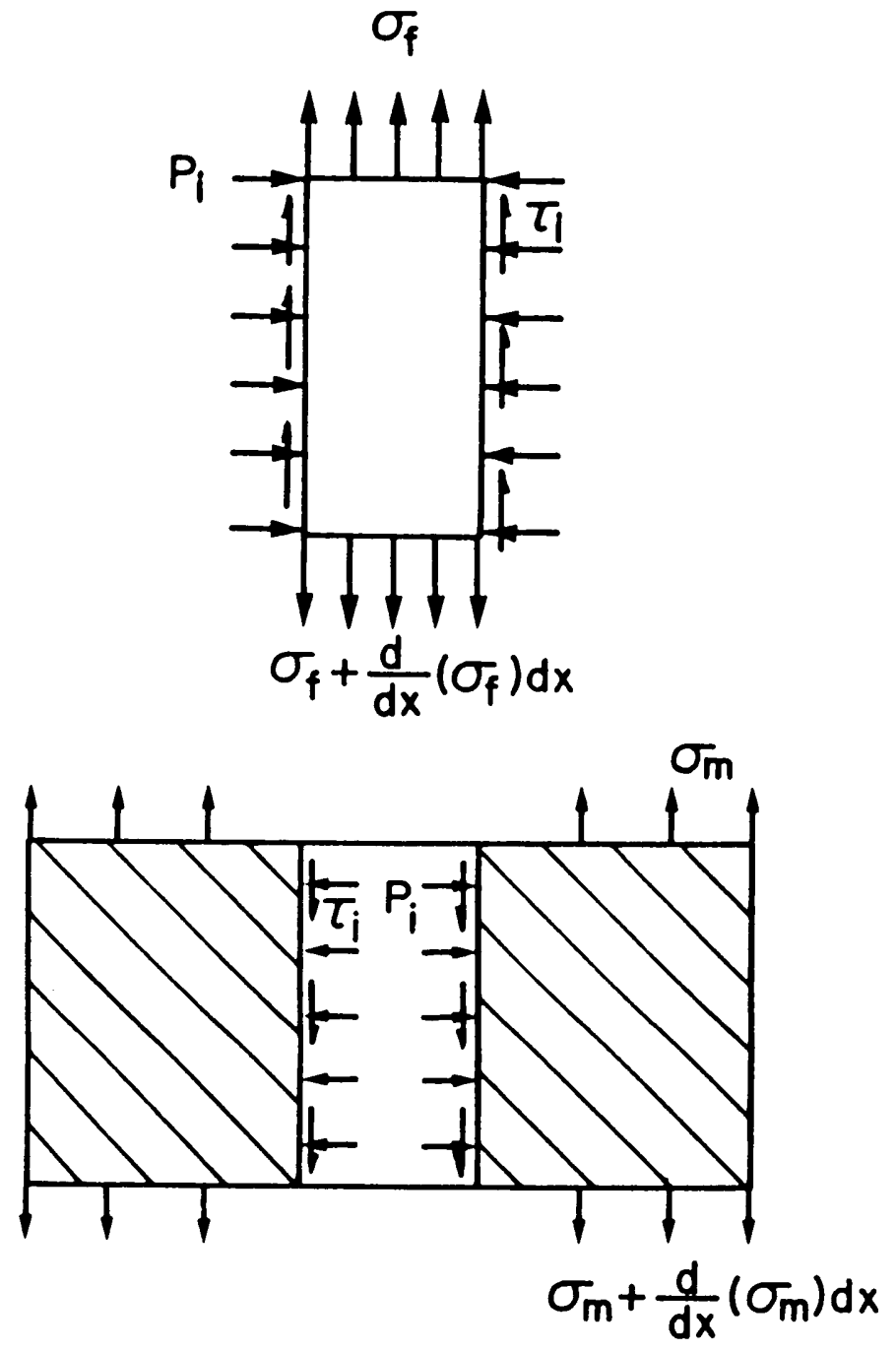

Figure 22. Free body diagrams for the element $(x, x+d x)$ of the unit cell 


\section{Determination of $U_{f F}$}

The fiber is assumed to undergo only tensile load as represented in Figure 23a. We write Hooke's law for the fiber:

$$
\sigma_{f}=E_{f} \varepsilon_{x}
$$

and by definition of Poisson's ratio

$$
\varepsilon_{x}=\frac{\varepsilon_{r}}{v_{f}}
$$

Eq. 7 is introduced into Eq. 6:

$$
\sigma_{f}=E_{f} \frac{\varepsilon_{r}}{v_{f}}
$$

The integration of Eq. 8 gives:

$$
U_{f F}=\frac{-v_{f} \sigma_{f}}{E_{f}} R_{f}
$$

Determination of $U_{f P_{i}}$

The fiber is now loaded in lateral compression only as represented in Figure 23b. Equilibrium of the fiber can be written as follows:

$$
\sigma_{r}=-P_{l} \quad \text { and } \quad \sigma_{\theta}=-P_{l}
$$

We now write Hooke's law for the fiber:

$$
\varepsilon_{\theta}=\frac{1}{E_{f}}\left(\sigma_{\theta}-v_{f} \sigma_{r}\right)=\varepsilon_{r}
$$

And the strain displacement relationship reads: 


$$
\Delta r=r \varepsilon_{\theta}
$$

Introducing Eq. 10 and 11 into Eq. 12 we obtain:

$$
u_{f P_{i}}=\frac{-P_{l} R_{f}}{E_{f}}\left(1-v_{f}\right)
$$

Determination of $U_{m} f$

Eq. 2 is used to define $\sigma_{m}$ the tensile stress in the matrix represented in Figure 23c

$$
\sigma_{m}=\frac{F-\pi R_{f}^{2} \sigma_{f}}{\pi\left(R_{m}^{2}-R_{f}^{2}\right)}
$$

From Lame theory [39]

$$
\varepsilon_{r}=\varepsilon_{\theta}=\varepsilon_{H}
$$

Consequently the strain displacement can read:

$$
\Delta_{r}=\frac{r}{E_{r}}\left(\sigma_{\theta}-v_{m} \sigma_{r}-v_{m} \sigma_{H}\right)
$$

Boundary conditions:

$$
\sigma_{H}=\sigma_{m} \quad ; \quad \sigma_{\theta}\left(R_{f}\right)=0 ; \quad \sigma_{r}\left(R_{f}\right)=0
$$

Including these three boundary conditions into Eq. 16 gives:

$U_{m f}=\frac{-R_{f}}{E_{m}} v_{m} \frac{F-\pi R_{f}^{2} \sigma_{f}}{\pi\left(R_{m}^{2}-R_{f}^{2}\right)}$

Determination of $U_{m} P_{i}$

As before, Lame theory is used to solve the problem shown in Figure $23 \mathrm{~d}$ of the matrix undergoing the interfacial pressure only. 

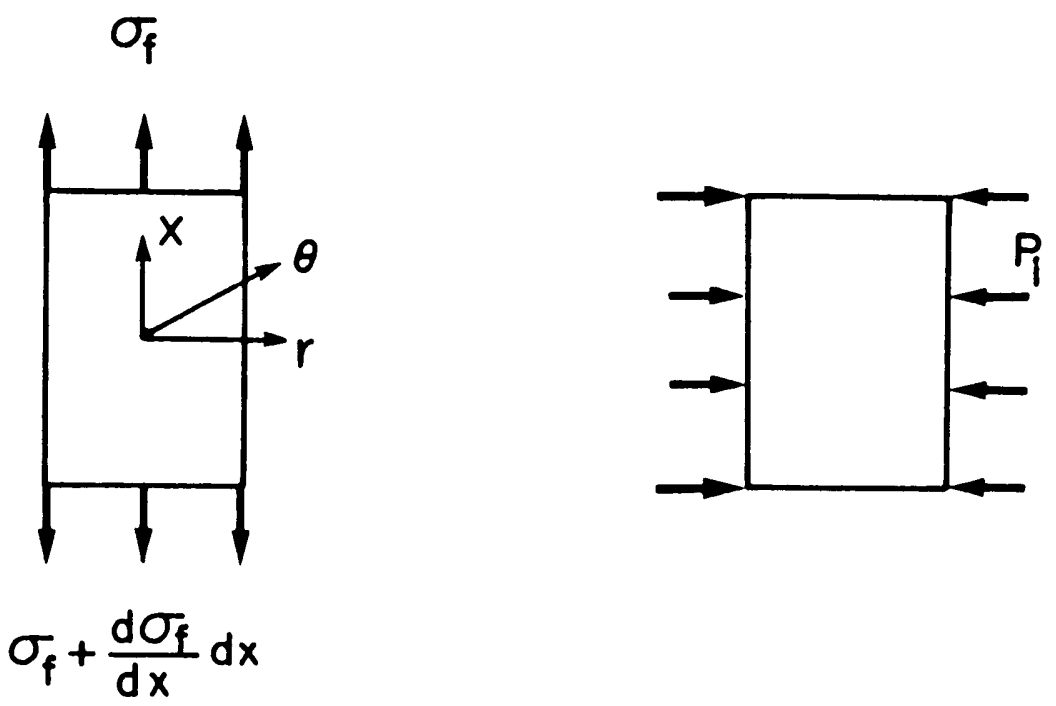

$\sigma_{m}$
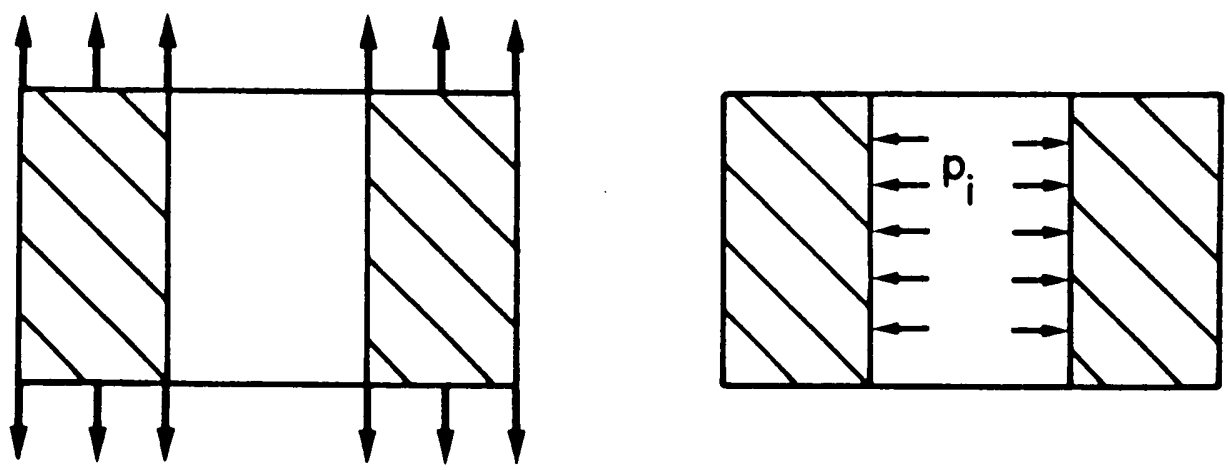

$$
\sigma_{m}+\frac{d \sigma_{m}}{d x} d x
$$

Figure 23. Principle of superposition 
We write Hooke's law for the matrix:

$$
\Delta r=\frac{r}{E_{m}}\left(\sigma_{H}-v_{m} \sigma_{r}\right)
$$

The equilibrium of the matrix gives:

$$
\sigma_{H}=P_{i}\left[\frac{\left(R_{m} / r\right)^{2}+1}{\left(R_{m} / R_{f}\right)^{2}-1}\right]
$$

and

$$
\sigma_{r}=-P_{i}\left[\frac{\left(R_{m} / r\right)^{2}-1}{\left(R_{m} / R_{f}\right)^{2}-1}\right]
$$

For $\mathrm{r}=R_{f}$, Eq. 20 becomes:

$$
\sigma_{r}=-P_{l}
$$

and Eq. 19 becomes:

$$
\sigma_{H}=P_{l}\left[\frac{\left(R_{m} / R_{f}\right)+1}{\left(R_{m} / R_{f}\right)-1}\right]
$$

Eq. 21 and 22 into Eq. 18 give:

$$
U_{m P_{i}}=\frac{P_{l} R_{f}}{E_{m}}\left[\frac{\left(R_{m} / R_{f}\right)^{2}+1}{\left(R_{m} / R_{f}\right)^{2}-1}-v_{m}\right]
$$

All the displacements having been defined by Eq. 9, 13, 17, and 23, are now included into the compatibility equation, Eq. 5 .

$$
P_{i}\left[\frac{1-v_{f}}{E_{f}}+\frac{1}{E_{m}}\left(\frac{\left(R_{m} / R_{f}\right)^{2}+1}{\left(R_{m} / R_{f}\right)^{2}-1}+v_{m}\right)\right]=\frac{v_{m}}{\pi E_{m}\left(R_{m}^{2}-R_{f}^{2}\right)} F-\sigma_{f}\left[\frac{v_{f}}{E_{f}}+\frac{v_{m} R_{f}}{E_{m} R_{m}}\right]
$$


or, introducing the constants $S_{1}, S_{2}$, a, b, and c, Eq. 24 becomes:

$$
P_{l}=S_{1} F-S_{2} \sigma_{f}
$$

where

$$
S_{1}=1 / \pi\left(R_{m}^{2}-R_{f}^{2}\right)\left[\frac{a^{2}+1}{v_{m}\left(a^{2}-1\right)}+1+\frac{1-v_{f}}{v_{m}} b\right]
$$

and

$$
S_{2}=\left(1-\frac{a b}{c}\right) / a\left[\frac{a^{2}+1}{v_{m}\left(a^{2}-1\right)}+1+\frac{1-v_{f}}{v_{m}} b\right]
$$

and

$$
a=\frac{R_{m}}{R_{f}} ; b=\frac{E_{m}}{E_{f}} ; c=\frac{v_{m}}{v_{f}}
$$

Introducing Eq. 25 into Eq. 1

$$
\tau_{l}=\mu\left[S_{1} F-S_{2} \sigma_{f}\right]
$$

Eq. 28 into Eq. 4:

$$
\frac{R_{f}}{2} \frac{d \sigma_{f}}{d x}=\mu\left[S_{1} F-S_{2} \sigma_{f}\right]
$$

and developing Eq. 29, we obtain

$$
\frac{d \sigma_{f}}{d x}+\frac{2 \mu}{R_{f}} S_{2} \sigma_{f}=\frac{2 \mu}{R_{f}} S_{1} F
$$

Because the end of the fiber is free of stress, the solution for Eq. 30 is: 


$$
\sigma_{f}(x)=\frac{S_{1}}{S_{2}} F\left(1-\exp \left[-2 \mu S_{2} x / R_{f}\right]\right)
$$

Figure 24 shows the repartition of the tensile stress along the fiber for a unit force $F$ and for different values of the friction coefficient.

\section{Ineffective Length}

The ineffective length can still be defined as before in this report by Rosen's formula:

$$
\phi=\sigma_{f}(\delta) / \sigma_{f}(\infty)
$$

where:

$$
\sigma(\infty)=\frac{F}{\pi R_{m}^{2}} \frac{E_{f}}{E_{a}}
$$

Eq. 31 and 33 into Eq. 32

$$
\phi=\frac{\pi S_{1} R_{m}^{2} E_{a}}{S_{2} E_{f}}\left(1-\exp \left[-2 \mu S_{2} \delta / R_{f}\right]\right)
$$

Therefore, the ineffective length is equal to:

$$
\delta=\frac{-R_{f}}{2 \mu S_{2}} \ln \left(1-\phi \frac{S_{2} E_{f}}{\pi S_{1} R_{m}^{2} E_{a}}\right)
$$




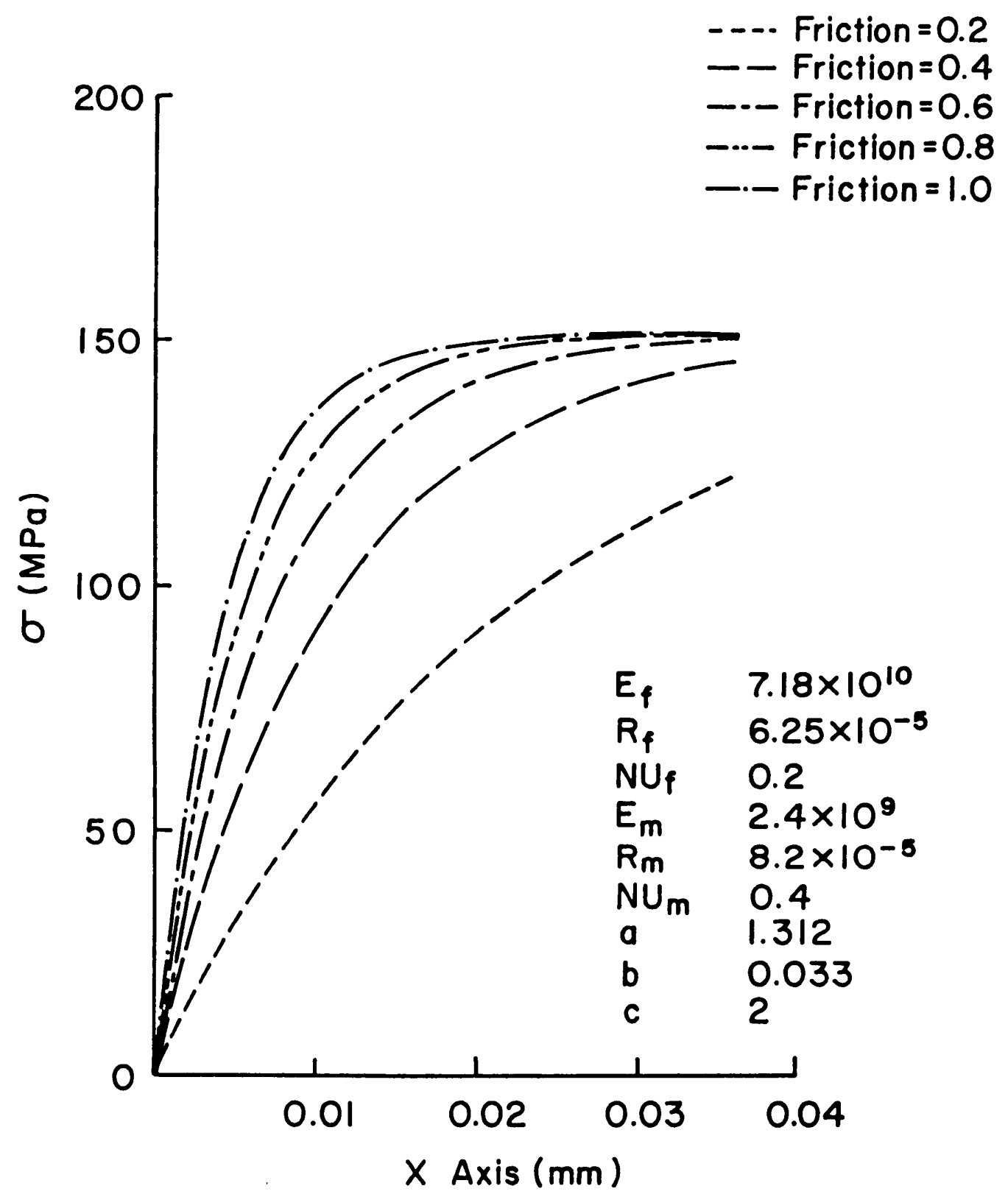

Figure 24. Limited friction model: tensile stress in the fiber 


\section{Results and Discussion}

It must be noted that the formulation of this model is very basic, and is presented in this report only in order to complement the elasto-damaged model. A more elaborate model of limited friction or a model such as Adams' [41] could be applied to the length where the rupture of either the matrix or the interface occurs.

Figure 25 shows the influence of the coefficient of friction $\mu$ on the ineffective length. Eq. 34 illustrates that the value of $\delta$ depends only on the material properties. When slippage occurs, the ineffective length, as just defined, has the same significance as in the case of perfect bond, as far as he stress transfer between the matrix and the fibers is concerned. However, we have not found a good solution to verify experimentally the results given by Eq. 34. The measurement, under polarized light, of the deformation zone in the matrix becomes difficult because of fiber slippage.

This model of limited friction does not take into account any interfacial layer because the interphase has bcen defined as a weak boundary layer, and thus does not constitute a structural bond as in the "perfect bond" model. The contribution of the interphase to the stiffness of the composite is also neglected because of the very small volume of this layer compared to the other constituents.

This model is also affected by the mathematical limitation which is due to the logarithmic form of the solution in Eq. 35. The term in the logarithm cannot be negative, and as a result the mechanical and geometrical properties of the materials cannot be varied freely. For example, the modulus of the average material in the fiber-matrix system used to draw Figure 25 cannot be less than $2.3 \mathrm{E} 10 \mathrm{~Pa}$. Consequently, the single fiber test where the average material is the resin itself, cannot be investigated with this model. Another problem attributed to the mathematics of the solution is the impossibility of applying this model to a case without slippage. The friction coeffcient is in the denominator of the fraction, consequently the infinite value corresponding to a "perfect bond" yields a value for the ineffective length equal to zero. This has been proved false through both experimental and analytical studies of the matrix-fiber stress transfer. 


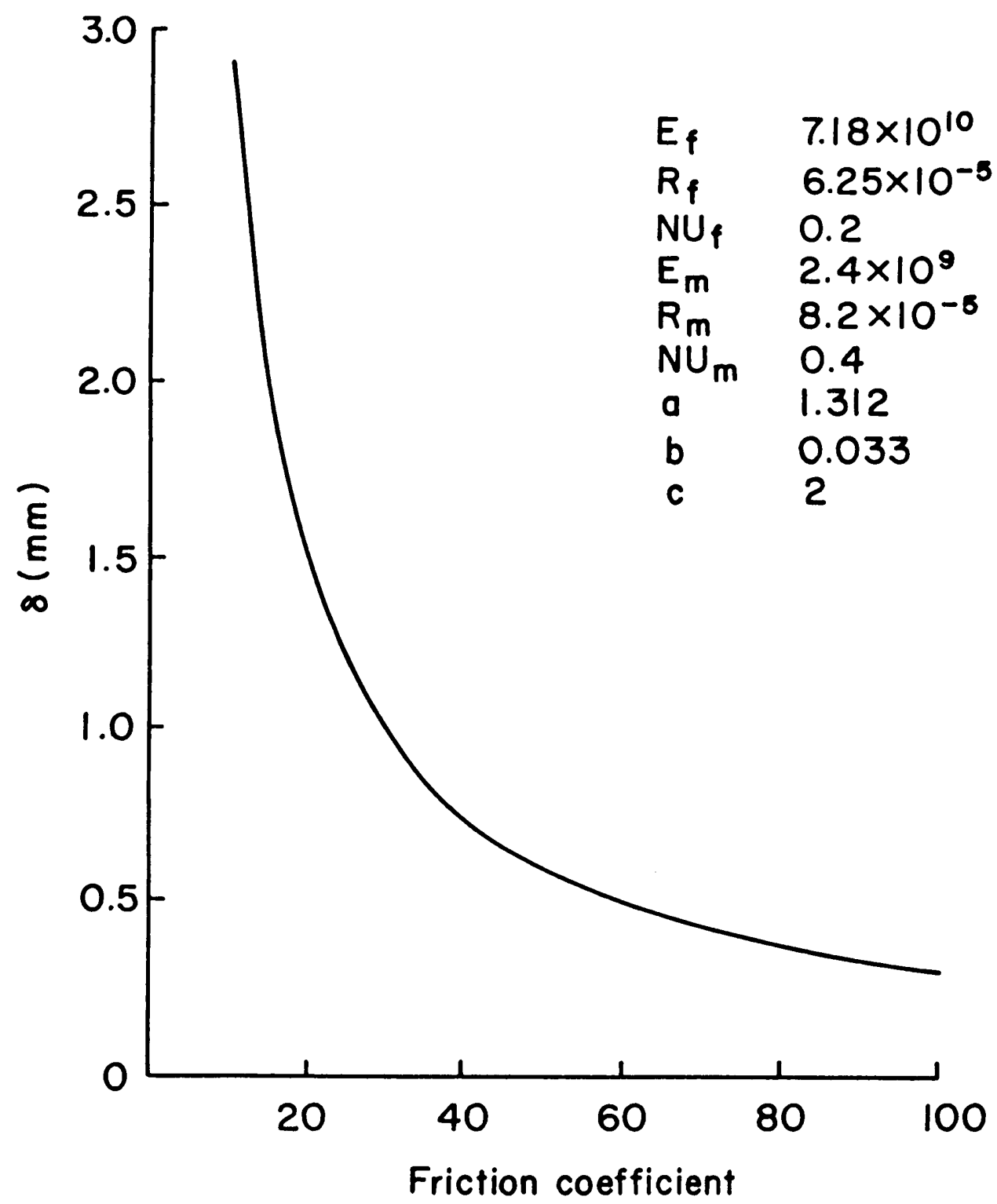

Figure 25. Limited friction model: ineffective length as a function of the friction coefficient 


\section{EXPERIMENTAL PROCEDURES AND}

\section{OBSERVATIONS}

\section{A. DESCRIPTION OF THE MATERIALS}

Fibers Three types of glass fiber have been used in this study:

- Corning optical fibers (outer diamter $125 \mu \mathrm{m}$; core diameter $85 \mu \mathrm{m}$ )

- Corning optical fibers: The original outer diameter of the fibers is $125 \mu \mathrm{m}$. The filaments are etched in a bath of hydrofluoric acid to obtain a diameter of $80 \mu \mathrm{m}$. The diameter of the fibers decreases at the rate of $3 \mu \mathrm{m} / \mathrm{min}$. Thus the fibers stay in the bath of acid during 15 minutes, and then are rinsed with distilled water.

- Vetrotex Saint-Gobain E-glass fibers (diameter $24 \mu \mathrm{m}$ )

Matrix We used an epoxy system composed of Epon 828 resin produced by Shell and cured with either 35,45 , or 50 weight parts of jeffamine D230 produced by Texaco Chemicals. The curing cycle of the specimens is described in Figure 26. 


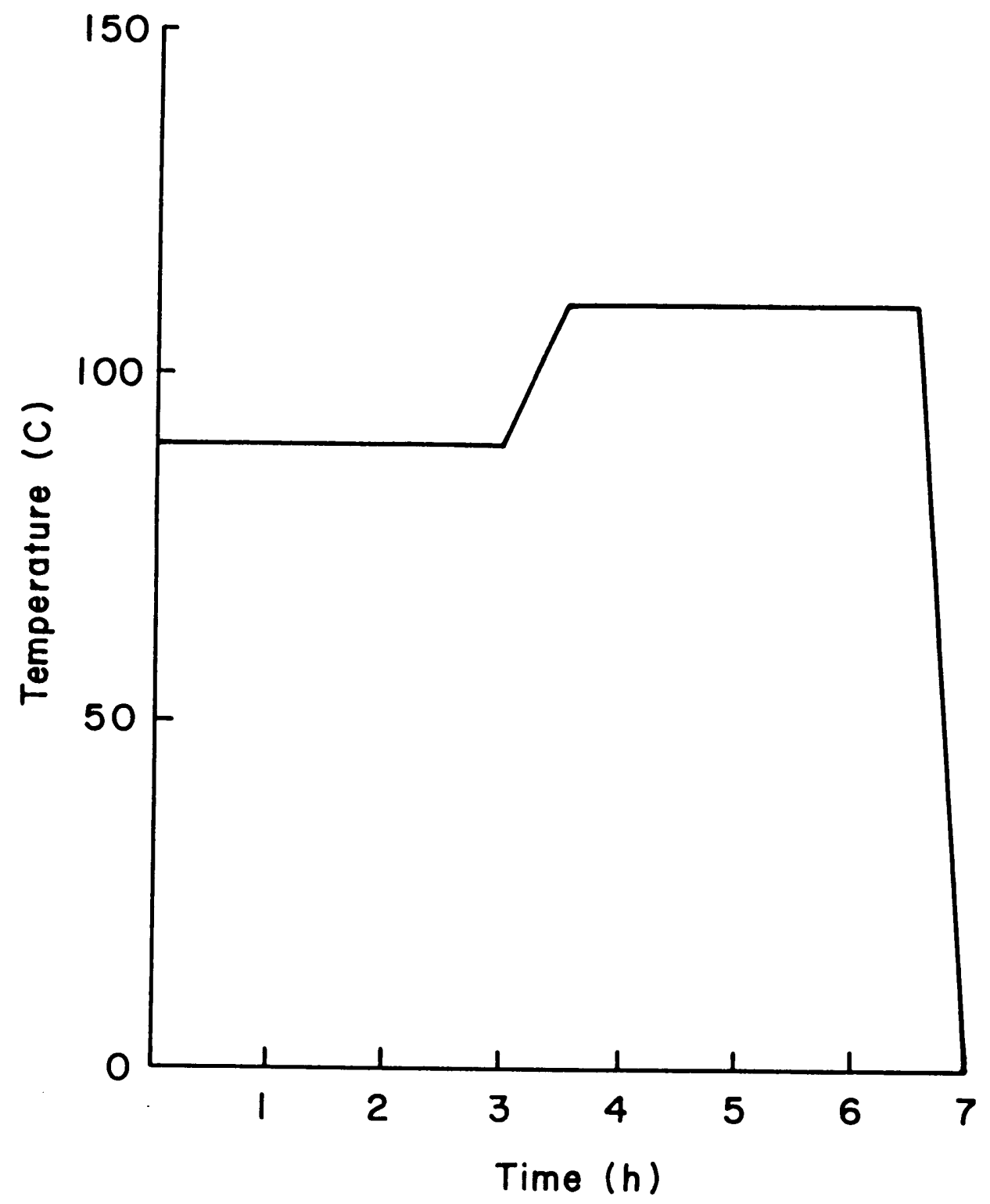

Figure 26. Cure cycle (EPON $828+$ D230) 
Interphase The acrylate coating is removed from the optical fibers with a razor blade. All the fibers are first cleaned with acetone then thoroughly rinsed with distilled water. Some of the fibers are etched in hydrofluoric acid.

\section{B. PROPOSAL FOR A FIBER-MATRIX ADHESION ADVANCED TEST METHOD}

\section{Background}

The fiber matrix appears to be a determining factor of the fibrous composite materials' strength. As long as the stress transfer between the matrix and the fibers is not quantified, the micromechanical approach of the mechanical properties of composites will remain an inapplicable theory.

A method largely used in the past to quantify the stress transfer between the matrix and the fibers consists of embedding a single fiber in a thermoplastic or thermoset matrix and then submitting the matrix to a tensile load in the direction of the fiber [24-29]. If the fiber matrix bond is strong enough to transfer a load able to break the filament, a minimum legnth of the fiber pieces will be reached, Figure 27. In the particular cases of a single fiber embedded in a transparent matrix, the critical fiber length can be measured with an optical microscope. If the matrix is opaque, it can be dissolved and filtered to separate the small pieces of fiber.

The critical fiber length, lc, is characteristic of the maximum load that can be transfered from the matrix to the fiber by shear. Kelley derived a simple expression for the shear stress at the interface: 


$$
\tau_{c}=\frac{\sigma_{c} d}{2 l_{c}}
$$

where $\sigma_{c}$ is the tensile stress in the fiber, and $\mathrm{d}$ is the diameter of the fiber. As explained by Frazer $[25,26]$ this value corresponds to the shear strength of the weakest link which can be either the matrix near the fiber or the interfacial layer between the fiber and the matrix. Consequently, it is more accurate to refer to $\tau_{c}$ as the "stress transfer coefficient".

This test can be modified to study the effects of the fiber-fiber interaction on the fiber matrix stress transfer. To do so, several fibers have to be embedded parallel and close together in the same specimen. Bascom and Jensen [27] have been the pioneers in this domain, using specimens that contain two to five fiber aligned in the same plane. In keeping with the study of fibrous composites, a sample containing a three-dimensional array of fibers is developed in this study.

\section{Description of the Sample}

As shown in Figure 4, the dogbone shape of the single fiber specimen is kept, but seven fibers are now embedded in the matrix in a hexagonal configuration.

In order to take measurements of the critical fiber length on the central fiber, it has to be possible to differentiate it from the others. Consequently, we have used optical fibers without plastic coating, embedded in a transparent epoxy resin. Thus, besides carrying mechanical load, the glass fibers provide an optical path. A laser light is conducted only through the central fiber, and the specimen is loaded in tension. As described before the fiber breaks in several parts, and at each of the breaks a part of the light intensity is transmitted through the break to the other piece of the fiber, and the rest of the light is dispersed in the surrounding matrix signaling the location of the break. If the proportion of light transmitted to the other part of the fiber is large, it is possible to see several breaks. We have been able during our experiments to observe a maximum of twenty three breaks. The light transmission through the breaks has been considerably improved by the 


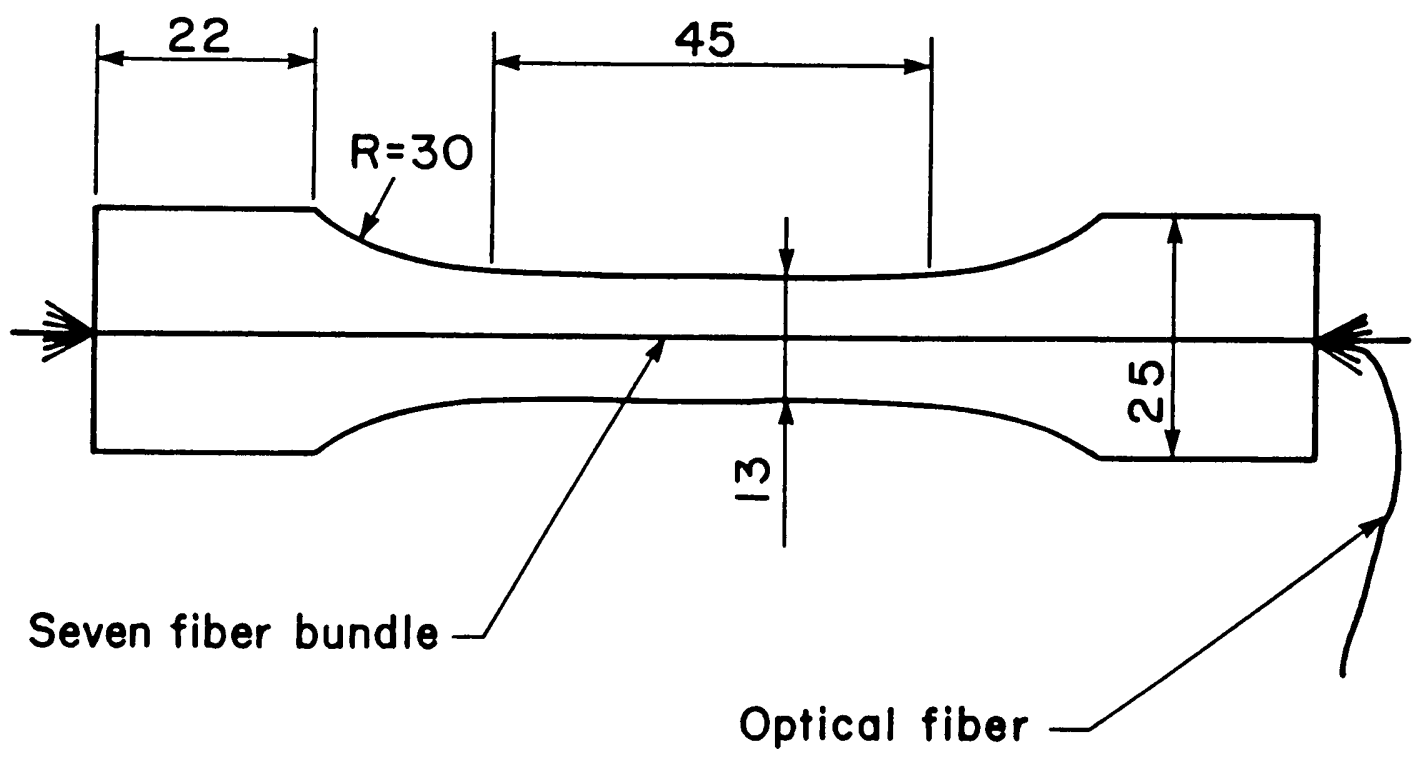

(a)

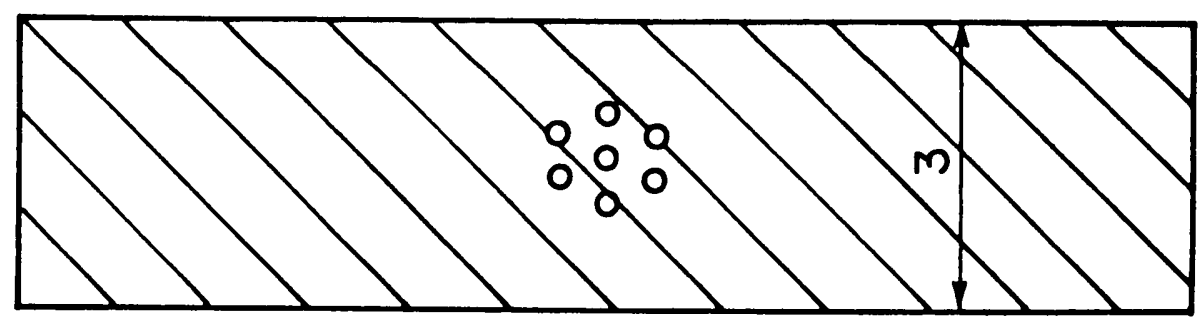

(b)

Figure 27. a) Seven fiber critical length test (scale 1); b) Cross section of the central part of the specimen (scale 10) 
usage of multi-mode fibers. These fibers have a bigger diameter core and consequently a larger acceptance cone. The other problem encountered in the study of epoxy specimens is the very low strain to failure of the matrix itself. This inconvenience has been avoided with the help of the Virginia Tech Polymers Laboratories which developed a system which undergoes seven percent elongation before failure.

The production of these specimens is tedious, and performed manualy. This procedure does not allow the use of small diameter fibers, and as a result, does not allow the study of the types of fibers normally used in composite materials. Consequently, a device to organize automatically the fibers in the mold has to be developed to remove this limitation before this test method can be of any utility.

\section{SPECIMENS PREPARATION}

This study requires four different types of specimens:

- NEAT RESIN DOGBONE SPECIMENS: They are machined from a plate obtained by casting bulk resin in the following manner: degassed matrix is poured into an open air mold that is kept perfectly horizontal in order to obtain a thickness as constant as possible with the lowest residual stress due to the casting. After machining, the specimens are grinded and dry polished. The geometry of the specimen is shown in Figure 28.

- IOSPIESCU SPECIMENS: These are machined from the same plate as the dogbone specimens. The geometry of the specimens is shown in Figure 29.

- SINGLE FIBER SPECIMENS: Single fiber specimens are obtained by following the process related by P. J. Sabat in reference 6 . The fibers are first mounted in the mold as indicated in Figure 

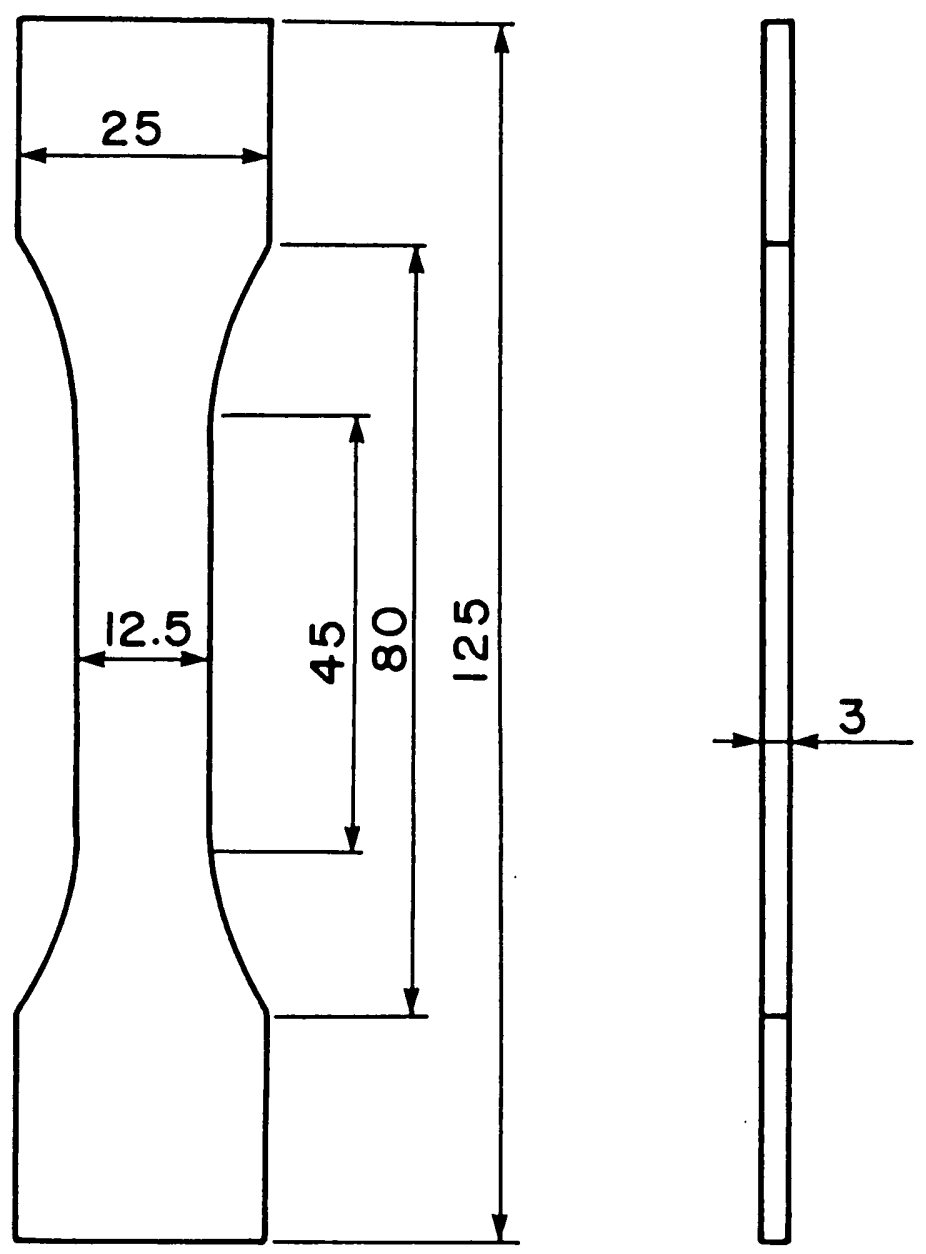

Figure 28. Neat resin dogbone specimen (geometry) 

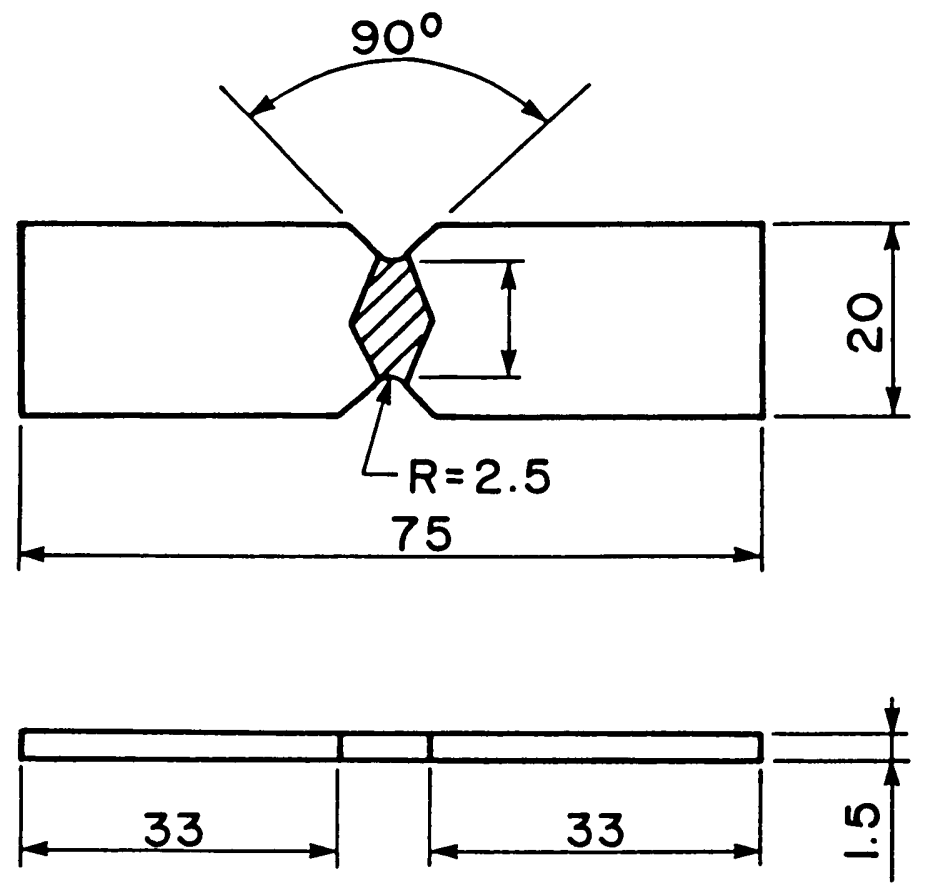

Figure 29. Neat resin losipescu specimen (geometry) 
30, and then degassed matrix is poured into the mold at room temperature. The TRV 3032 silicone rubber produced by Dow Coming has been chosen to make the mold because of the particular properties of this material: accurate reproduction of standard dogbone specimens, nonadhesion to epoxy resin, high temperature resistance, and easy usage. The final geometry of the samples is shown in Figure 30.

- SEVEN FIBER SPECIMENS: A bundle of seven fibers is first prepared out of the mold.

Step 1: Seven fibers are placed into a plastic tube, its inner diameter equal to three times the external diameter of the fibers. The fibers arrange themselves in an hexagonal array according to the dimension of the tube. A six inch strand of each fiber is left out of the tube. The bundle is kept in position in the tube by a droplet of glue.

Step 2: The part of the ribers outside the tube is stripped of its coating with a razor blade, dipped into acetone to remove the remaining particles of coating, rinsed with distilled water, and in certain cases, etched with $\mathrm{NaOH}$.

Step 3: The fibers are placed on a silicone rubber plate and maintained in position with two pieces of tape as shown in Figure 31. The free ends of the fibers are then bonded together with a droplet of glue.

Step 4: The center parts of the fibers are brought closer to each other by tightening two pieces of very thin thread around them as shown in Figure 31.

Step 5: The bundle is mounted in the same mold used to prepare the single fiber specimens, and the degassed matrix is poured into the mold. 

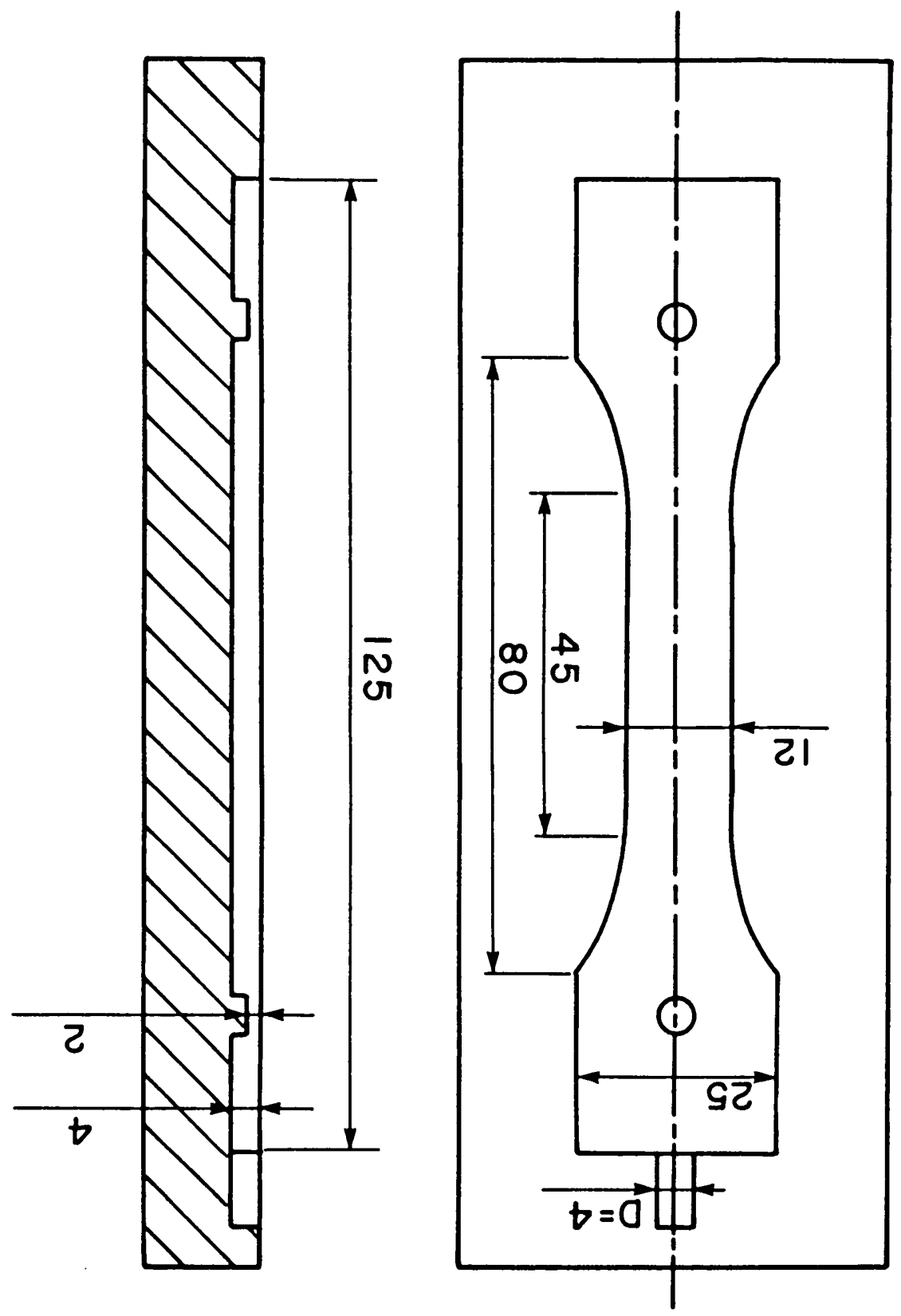

Figure 30. Silicone rubber mold for both single and 7 fiber specimens 


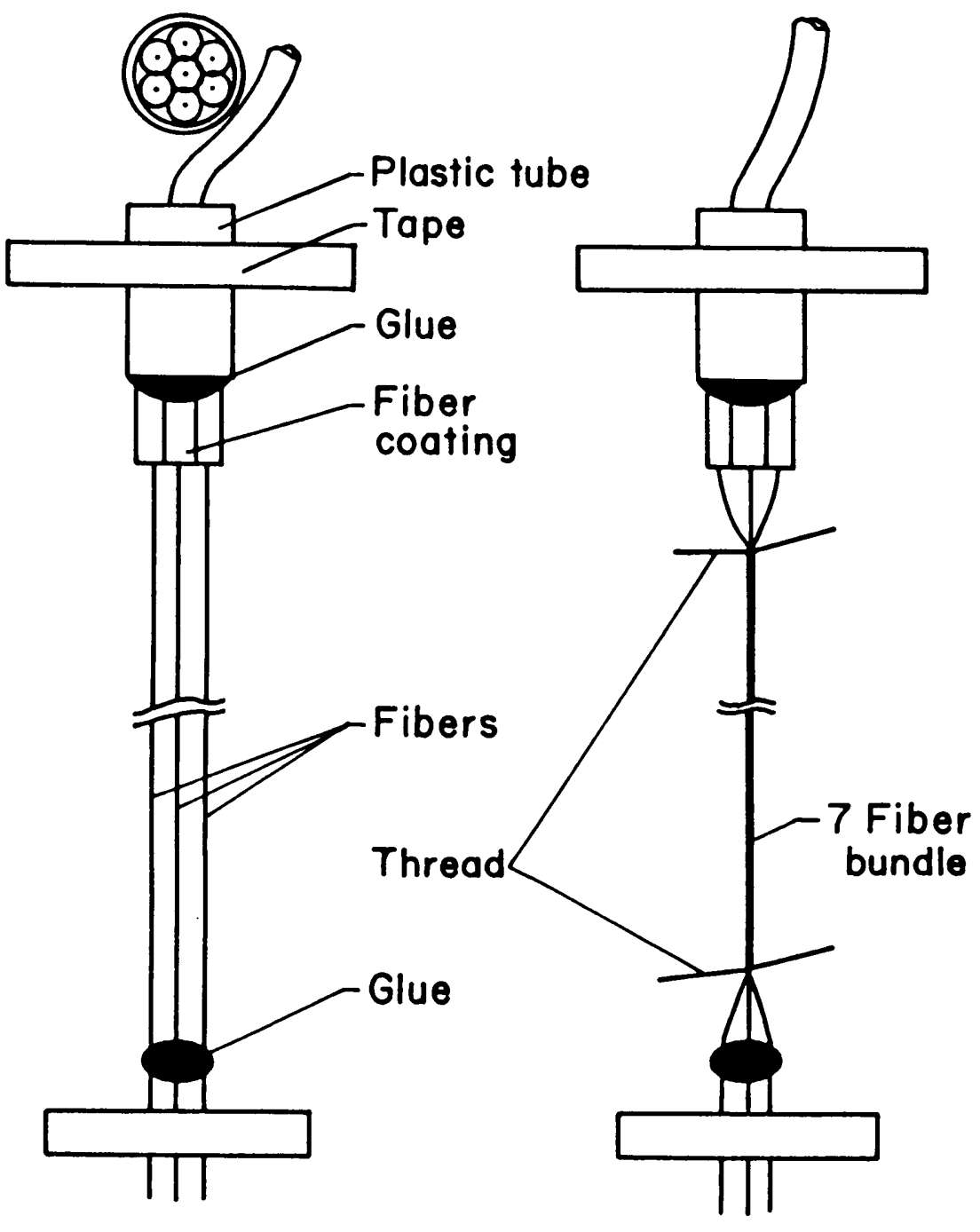

Figure 31. Steps 3 and 4 of the 7 fiber specimen preparation 


\section{MECHANICAL TESTING}

\section{Tensile Testing of the Fibers}

In order to obtain the tensile strength of the fibers as a function of its length, a tensile test is performed according to ASTM 3379-75 on an Instron macine, model $1122 \mathrm{~s} / \mathrm{n} 4470$. The test is run for three different gage lengths with a constant cross head speed of $0.2 \mathrm{in} / \mathrm{mn}$. The results are presented in Table 4.

\section{Shear Testing of the Matrix}

We demonstrate in the analytical part of this report that the shear modulus, the shear yielding point, and the shear strength of the matrix have a crucial influence on the approximation of the ineffective length, and consequently on the evaluation of the strength of the composite itself.

As a result, the shear test methods commonly used have been reviewed to select the most accurate with regard to the measurement of the three mechanical properties we are interested in. From a theoretical point of view, the most uniform shear stress is obtained by applying a torsional load to a thin wall tube, but this test cannot determine the shear strength because failure occurs due to the buckling of the specimen. Previous studies [42] have demonstrated that the torsion of a solid rod is not the solution either, because of the nonlinear distribution of the shear stress along the radius of the rod in the case of plastic deformation. The plate twist method and the split ring test were also abandoned because they measure only the shear modulus. Similarly, the short beam shear test is not suitable because it measures only the shear strength. Other test methods such as the rail shear test and the cross sandwich beam test are not considered because stress concentrations in the tested part of the specimens make their results questionable. 
Table 4. Tensile properties of the fibers

\begin{tabular}{lccc}
\hline Radius in $\mu \mathrm{m}$ & 12 & 40 & 62.5 \\
\hline Gage length in mm & 200 & 120 & 50 \\
\hline Ef in MPa & 65000 & 72100 & 71800 \\
\hline Strength in $\mathrm{MPa}$ & 802 & 701 & 650 \\
\hline Weibull parameters & 3.59 & & 3.09 \\
& 2628.7 & & 1127.3 \\
\hline
\end{tabular}


Finally, the simplest test satisfying all the requirements is known as the Iosipescu shear test from the name of Nicolae Iosipescu, who first proposed this test in the beginning of the 1960's at the University of Bucharest. The test was primarily designed to study metals, but it has been largely used to test materials such as adhesives and adhesive bonds in Lockheed Laboratories, and composite mateirals at NASA Langley and VPI\&SU $[42,43,44]$. The different methods used to investigate this test are listed in Reference 3 and the conclusions can be summarized as follows:

- The Iosipescu specimen produces a zone of uniform shear stres large enough to perform measurements (shaded area in Figure 29).

- The notches have to be rounded to avoid stress concentrations that would cause the failure of the specimen before the actual shear strength of the material is reached.

The mechanical analysis of the test is given in the original paper [45] by Nicolae Iosipescu and is confirmed in reference 42 .

Test description:

The tests are run in the NASA Program Laboratories at VPI\&SU using the fixture designed by D. F. Adams and shown in Figure 32 with a specimen mounted. The tests are performed with a cross head speed of 0.02 inches per minute.

Because of the error introduced by the compressive deformation at the laoding points, measuring the relative displacement of the two halves of the fixture is not an accurate way to obtain the shear strain at a point located on the line between the notches' tips. Consequently, we use rectangular rosettes that we bonded between the notches to measure the shear strain. The Micro Measurcments rosettes are positioned with the 45 degree gage at the center of the specimen as shown in Figure 33, following Walrath's and Adams' procedure. The smallest strain gages have been chosen in order to fit into the zone of uniform deformation. According to Iosipescu himself and also to later photoelastic studies [42] this zone has a width of $2.5 \mathrm{~mm}$. The data acquisition is performed through the MATPAC software developed by J. Hidde at VPI\&SU, and the results are 


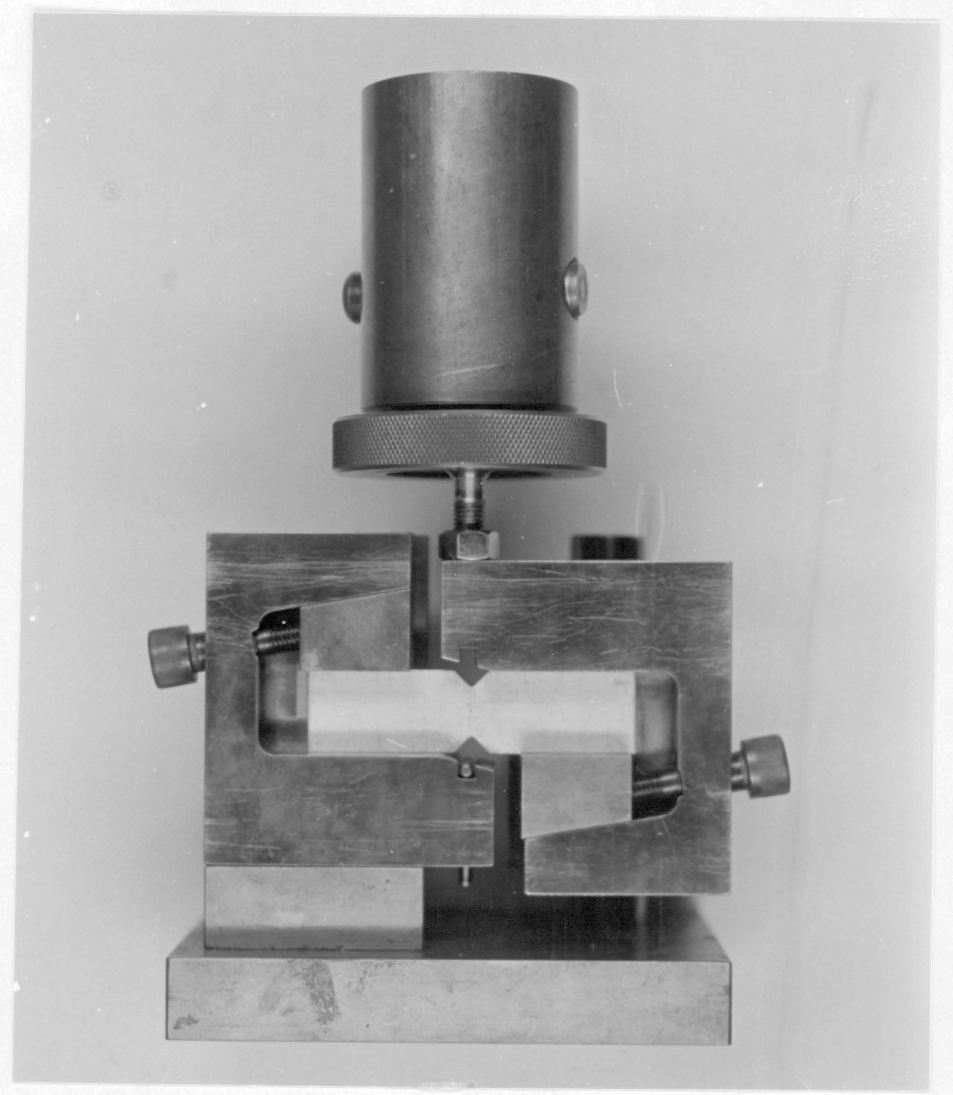

Figure 32. Iosipescu test fixture (specimen mounted) 
post processed with Supercalc 4 to correct the errors due to transverse sensitivity and gage misalignment. The gage misalignment is measured under optical microscope before testing the sample.

Six tests have been run and the results are reported in Table 5. The curve in Figure 34 has been recorded during the loading of the specimen number one. This test has been conducted until specimen failure occurs without being interrupted by the buckling of the sample. This has not been the case for tests numbers two, four, and six.

\section{Observation with Polarized Light of the Single Fiber Sample}

The epoxy system used in this study is a birefringent material. Consquently, it is possible, using polarized light, to study the state of stress of the matrix near a fiber break. The accuracy of this experimental technique that has been sued with success in the past $[6,46]$, has been improved in this research by the usage of high quality optics and tensile devices.

The specimen is first loaded in tension with a micro tensile rig, the MINIMAT, built by Polymer Laboratories and represented in Figure 35. This apparatus, small enoguht to mount on the stage of a microscope and controlled by computer, provides the stress-strain curve of the tests. Once loaded to its maximum stress, the specimen is either kept loaded or unloaded. The stressed zone in the matrix is observed through a polar microscope built by Spectra-Tech, Figure 36. For each of the fiber-matrix systems, fifty breaks are investigated. The quality of the optics allows us to observe different zones along the fiber, as shown in Plate 37:

- Zone 1: This black region near the tip of the fiber is probably due to the breakage of either the matrix or the interface. The size of this zone remains the same when the specimen is unloaded.

- Zone 2: This bright write area is the stressed region. Its length diminishes when the specimens are unloaded. Consequently, we tend to think that when the load is applied, both plastically and 


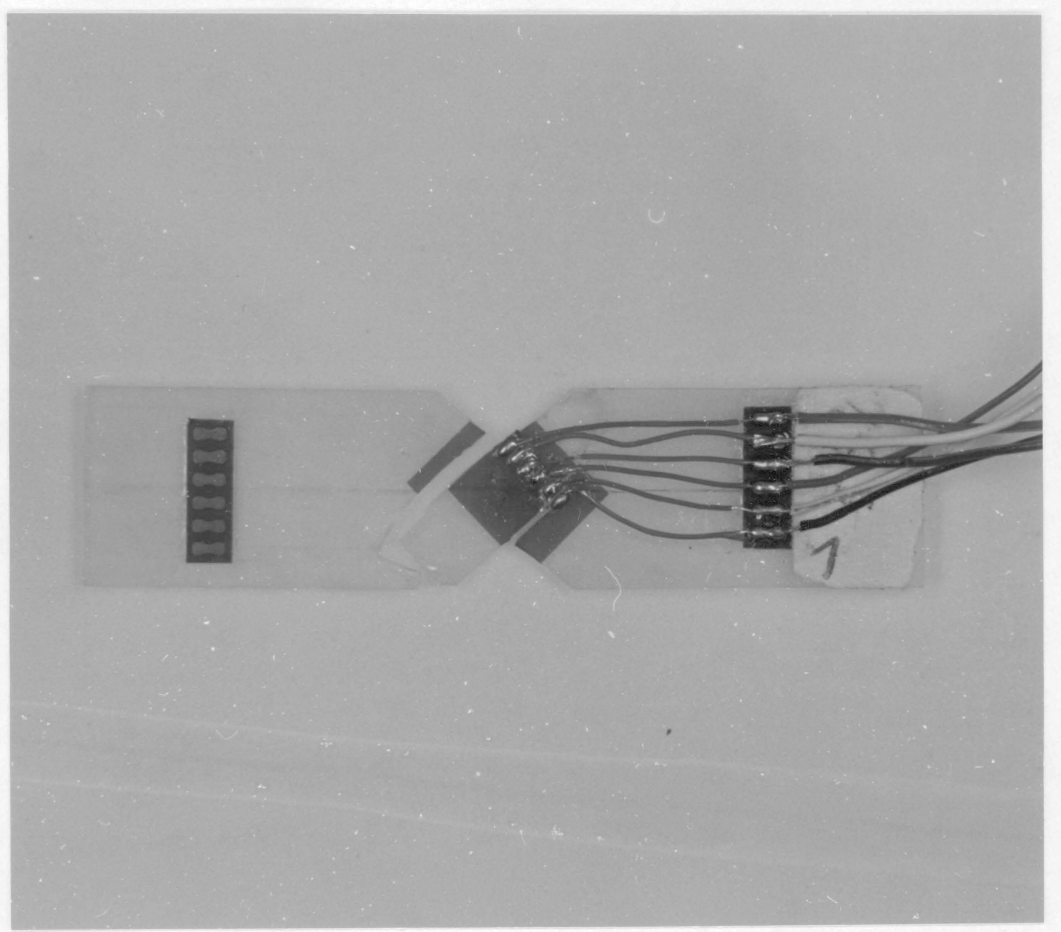

Irigure 33. Iosipescu specimen (rosette mounted). Fiailure in shear. 
Table 5. Iosipescu shear test results

\begin{tabular}{lllllll}
\hline Specimen number & 1 & 2 & 3 & 4 & 5 & 6 \\
\hline $\begin{array}{l}\text { Number of part } \\
\text { of D230 }\end{array}$ & 35 & 35 & 45 & 45 & 50 & 50 \\
\hline $\begin{array}{l}\text { Gm (MPa) } \\
\begin{array}{l}\tau \text { Yielding (MPa) } \\
.02 \% \text { offset }\end{array}\end{array}$ & 950 & 900 & 765 & 748 & 720 & 732 \\
\hline $\begin{array}{l}\text { Shear strength } \\
\text { (Mpa) }\end{array}$ & 26.53 & 21.37 & & 18.20 \\
\hline
\end{tabular}




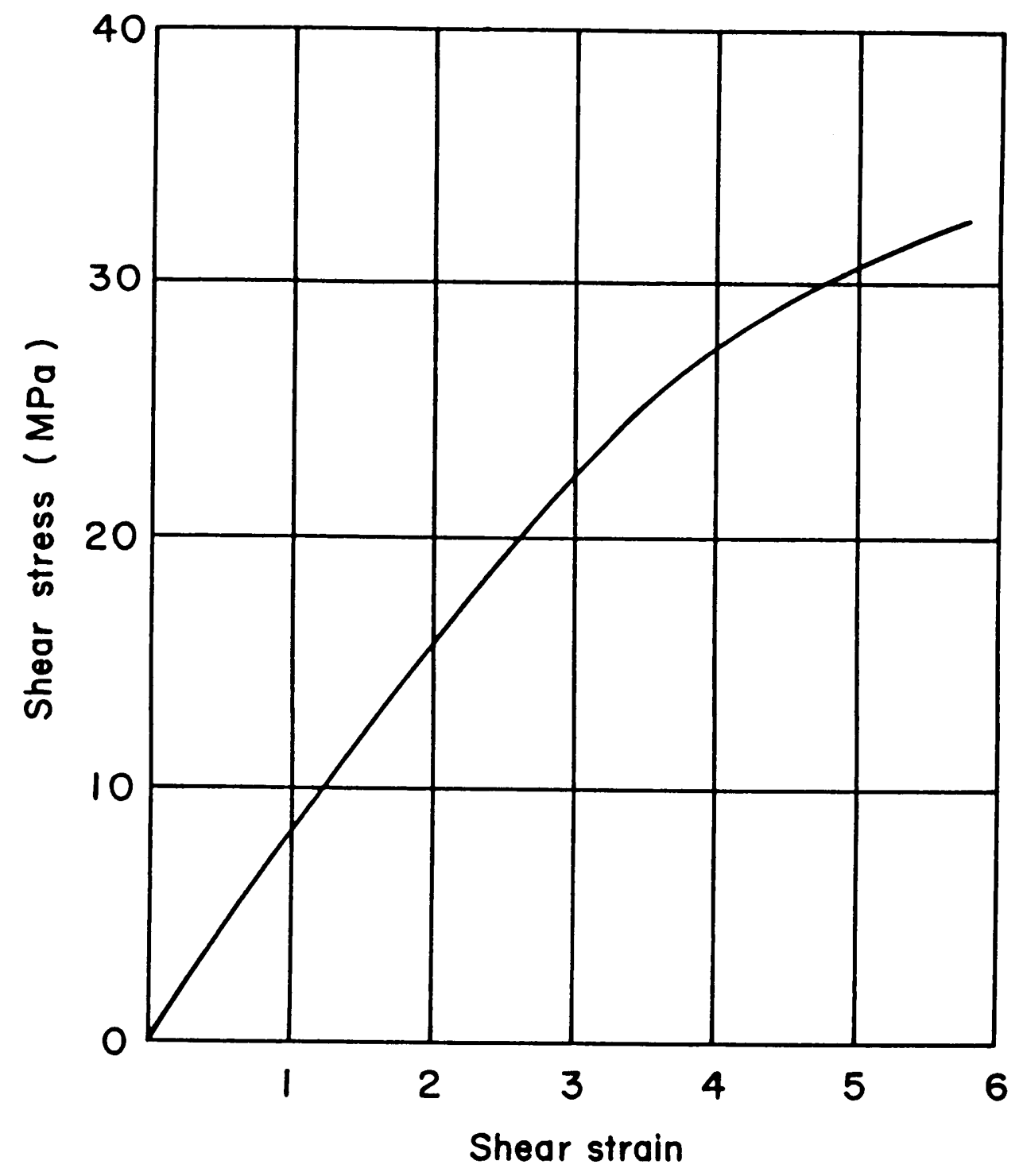

Figure 34. Neat resin shear stress-shear strain curve (Iosipescu test) 


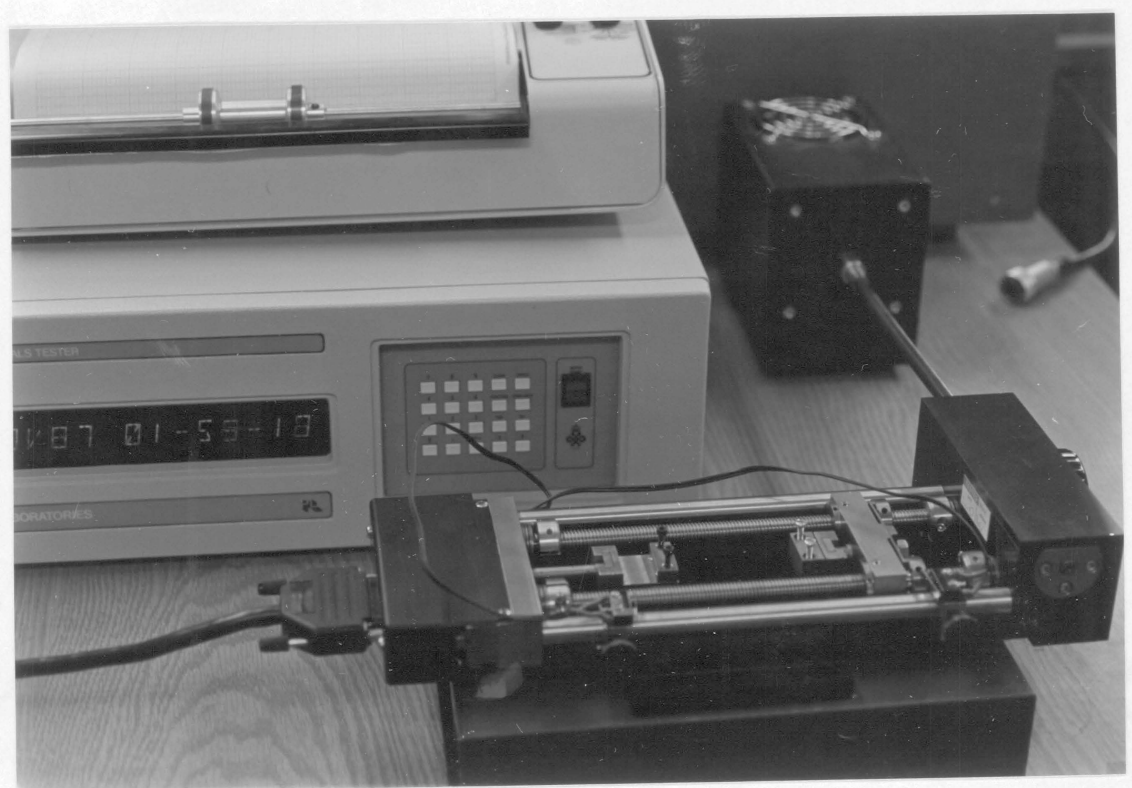

lïgure 35. MININIAT 


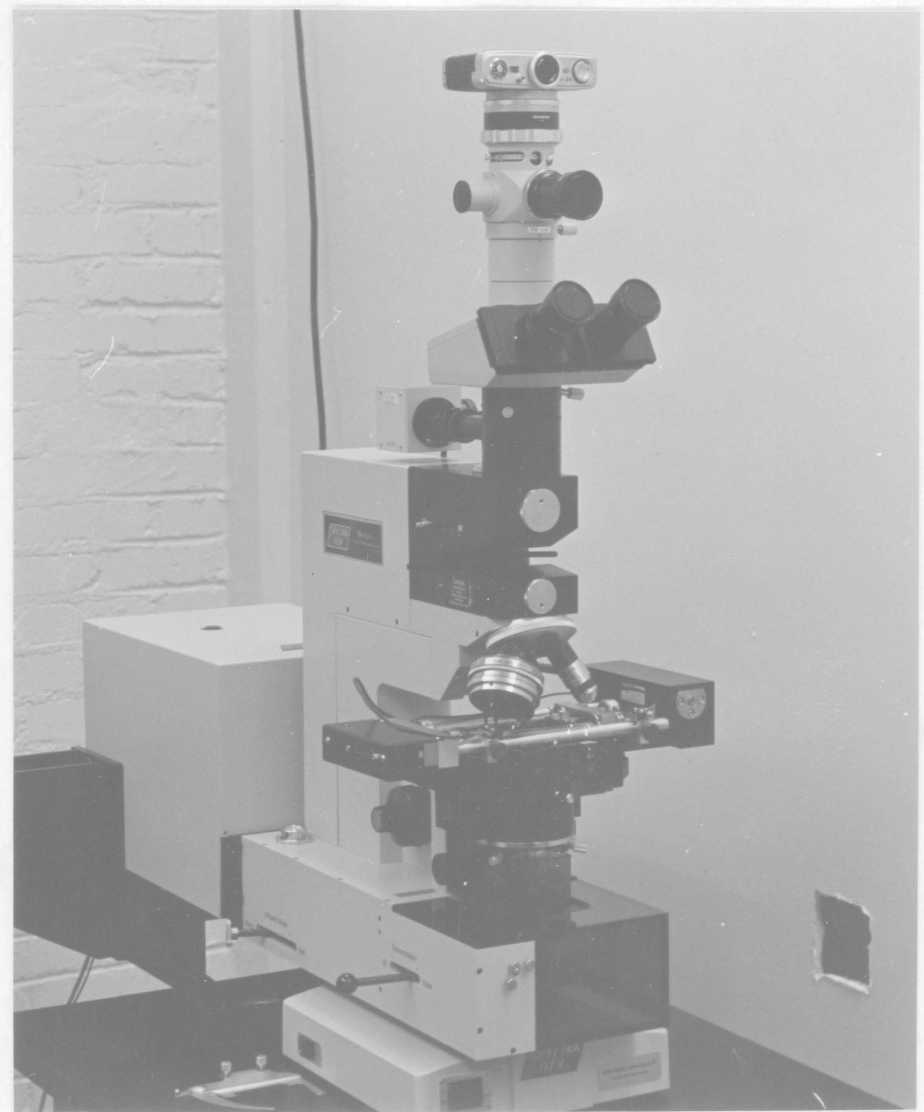

Figure 36. Spectra-tech microscope (minimat mounted) 

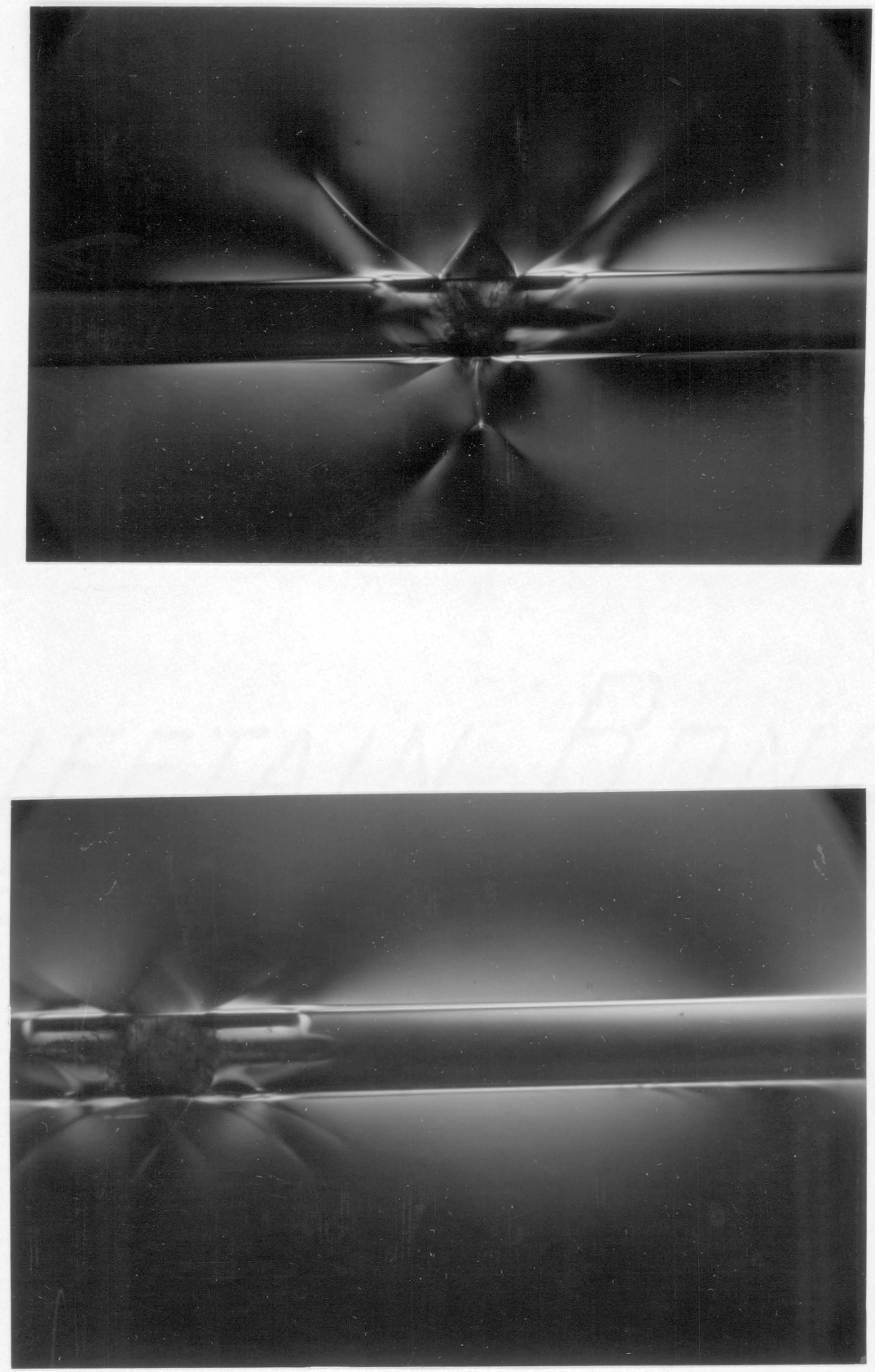

Figure 37. Single fiber break a)specimen unloaded b)specimen loaded 
elastically deformed zones are evidenced, and that in this case, the length of this zone is the ineffective length. When the load is released, only the plastically deformed zone appears.

- Zone 3: This zone along the center part of the fiber has a uniform grey color, and represents the unstressed area of the matrix.

\section{Critical Fiber Length Test}

Encouraged by the correlation between our theoretical results and P. J. Sabat's experimental measurements, we use this test again, even if it has not been entirely satisfctory in the past $[6,27]$. The critical fiber length test allows an easy qualitative comparison between different fiber-matrix systems, but the quantitative results of this method are still impossible to relate to any of the matrix-fiber stress transfer theories.

However, in the present study, we use this test to investigate qualitatively the difference between the single and the seven fiber specimens. The single fiber samples are loaded in tension with the Minimat, but because of the maximum loading force of two hundred newtons of this device, the seven fiber samples are loaded on an Instron machine (model $1122 \mathrm{~S} / \mathrm{N} 4470$ ). A force of $270 \mathrm{~N}$ has to be applied to the seven fiber specimens to reach the maximum number of breaks of the central fiber.

A laser beam generated with a $10 \mathrm{~mW}$ laser gun is shined into the central fiber of the seven fiber samples to take measurements of the broken segments. To ensure that the maximum power enters the optical fiber, the laser beam is first focalized through a convergent lens, and then, the end of the fiber is brought to the focus of this lens with a stage equipped with micrometric displacement screws. The setup is represented in Figure 38.

The measurements are taken on a Zeiss microscope at different magnifications according to the diameter of the fibers. For the $24 \mu \mathrm{m}$ diameter fibers we use a $160 \mathrm{X}$ magnification with a 5 


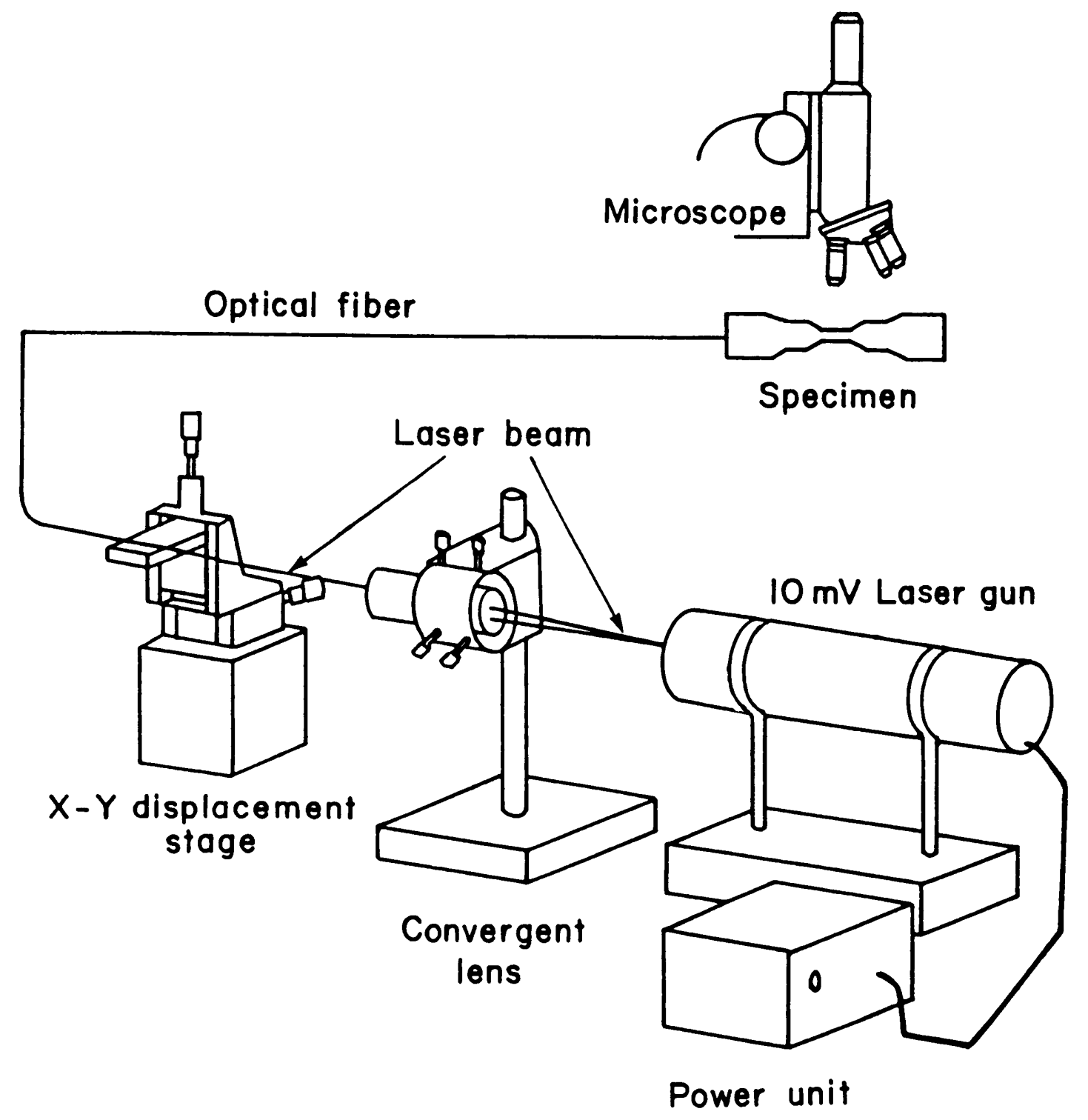

Figure 38. Critical fiber length test setup 
$\mu \mathrm{m}$ precision. For the 80 and the $125 \mu \mathrm{m}$ diameter fibers we use a $40 \mathrm{X}$ magnification with a 20 $\mu \mathrm{m}$ precision.

\section{Results and Discussion}

\section{a. Critical Fiber Length Test}

\section{Single Fiber Samples}

The results of the series of tests are presented in Table 6. The epoxy matrix cured with 35 weight parts of jeffamine D230 appears to be too brittle at room temperature, so the first break of the fiber results in the immediate failure of the specimen. Consequently, these specimens are tested under a $100 \mathrm{~W}$ lamp to elevate their temperature to about $60^{\circ} \mathrm{C}$.

As expected, the diameter of the fibers influences severely the critical length. On the other hand the influence of the shear modulus of the matrix is totally masked by the broad variability of the results. The dependency of the critical length on the stmegth and geometry of the fiber results in a standard deviation of the measurements equal to about one third of the average value. This is large enough to hide the expected variation of twenty percent due to the modulus of the matrix.

The influence, if any, of etching on the critical fiber length appears to be smaller than the standard deviation of the results. Because we do not observe any major change whether the fiber is etched or not, we would tend to think tha for this fiber matrix system the interface is stronger than the matrix, even when the fiber is not surface treated.

\section{Seven Fiber Samples}

The results of this series of tests are reported in Table 7. We tried to perform these experiments under the same conditions as the single fiber test, but less tests have been run because of the 
Table 6. Critical fiber length (single fiber sample)

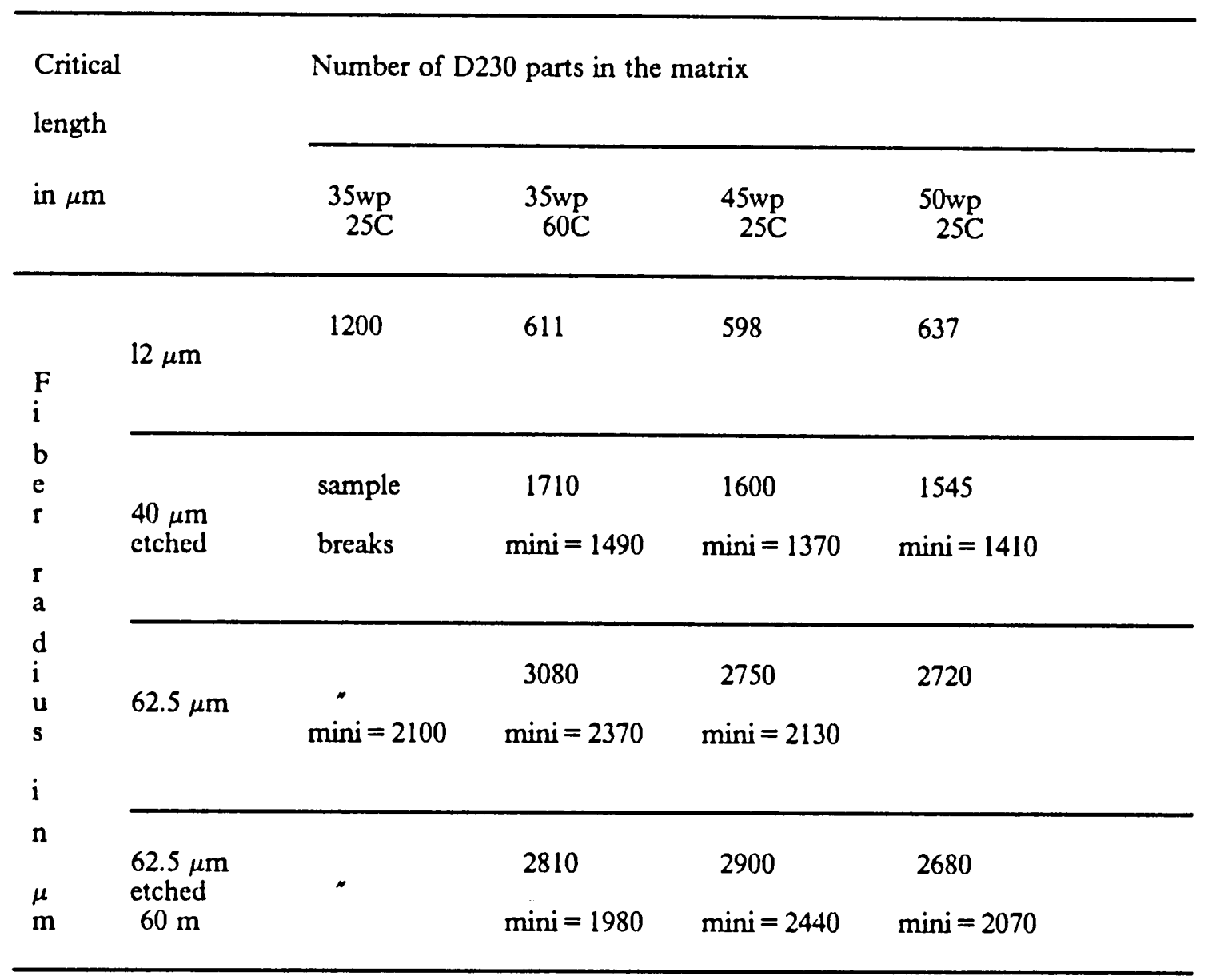


complexity involved in making the specimens. However, the influence of the fiber diameter is still sensitive.

Some post testing observations of the specimens lead us to think that the failure process is different in the seven fiber samples than in the single fiber one. After testing the seven fiber samples, we ground and polished the four sides of the broken dogbones so we could observe the fiber breaks from different angles under a microscope. We obtained through this observation two significant results. First, a break in the central fiber, located by a spot of light, is always in the same plane as at least one other fiber break. This would tend to prove that the matrix-fiber stress transfer is "good," and that the stress concentration near a fiber break is sensitive for the neighboring fibers. The second observation is also related to the number of coplanar breaks. In the six specimens we observed, we have not found more than three coplanar breaks. This is probably because we used fibers of a large diameter that can carry a fraction of the laod which is not negligible with respect to the strength of the samples. Consequently, the rupture of more than three fibers in the same plane leads to the immediate failure of the sample, and this is probably the explanation for the high value of the average critical length recorded in this series of tests.

\section{b. Measurement of the Deformed Zone in the Matrix Under Polarized Light}

Table 8 presents the measurements of the rupture zone recorded on the single fiber samples. This value can be obtained fairly accurately with a standard deviation of about one fifth of the fiber diameter, because of the well defined border of the rupture zone. Each of the figures in Table 8 is the average of one hundred measurements (fifty breaks). This observation has a high degree of reproductibility, and the standard deviation is smaller than the precision of the measure itself. Consequently, the small effect of the variation of the matrix' mechanical properties can be recorded. As expected, the length of the rupture zone decreases when the strength of the matrix increases.

For the specimen still being loaded at constant deformation in the Minimat, the value recorded for the length of the deformed zone depends greatly on the time between the loading and 
Table 7. Critical fiber length (7 fiber sample)

\begin{tabular}{lll}
\hline $\begin{array}{l}\text { Critical } \\
\text { length } \\
\text { in } \mu \mathrm{m}\end{array}$ & EPON $828+\begin{array}{c}50 \mathrm{wp} \text { of D230 } \\
25 \mathrm{C}\end{array}$ \\
\hline $\begin{array}{l}\text { Fiber } \\
\text { radius }\end{array}$ & 40 & $\begin{array}{l}\text { Lc average }=9300 \\
\text { Lc mini }=2150\end{array}$ \\
\cline { 2 - 3 } & 62.5 & $\begin{array}{l}\text { Lc average }=12100 \\
\text { in } \mu \mathrm{m}\end{array}$ \\
\hline
\end{tabular}


Table 8. Observation under polarized light.

\begin{tabular}{|c|c|c|c|c|c|}
\hline \multirow{2}{*}{$\begin{array}{l}\text { Rupture } \\
\text { length } \\
\text { in } \mu \mathrm{m}\end{array}$} & & \multicolumn{4}{|c|}{ Number of D230 parts in the matrix } \\
\hline & & $\begin{array}{r}35 w p \\
25 \mathrm{C}\end{array}$ & $\begin{array}{r}35 w p \\
60 \mathrm{C}\end{array}$ & $\begin{array}{r}45 w p \\
25 \mathrm{C}\end{array}$ & $\begin{array}{r}50 w p \\
25 \mathrm{C}\end{array}$ \\
\hline $\begin{array}{l}\mathrm{F} \\
\mathrm{i} \\
\mathrm{b} \\
\mathrm{e}\end{array}$ & $12 \mu \mathrm{m}$ & $32 \mu \mathrm{m}$ & $35 \mu \mathrm{m}$ & $40 \mu \mathrm{m}$ & $40 \mu \mathrm{m}$ \\
\hline $\begin{array}{l}\mathbf{r} \\
\mathbf{a} \\
\mathrm{d}\end{array}$ & $40 \mu \mathrm{m}$ & sample & & $90 \mu \mathrm{m}$ & \\
\hline $\begin{array}{l}\mathrm{i} \\
\mathrm{u} \\
\mathrm{s}\end{array}$ & $62.5 \mu \mathrm{m}$ & $"$ & $128 \mu \mathrm{m}$ & $142 \mu \mathrm{m}$ & $153 \mu \mathrm{m}$ \\
\hline
\end{tabular}


the measurement. A measure taken 24 hour after the test, while the sample is still loaded, is the same when the sample is unloaded. This is not surprising, because of the viscoelastic behavior of the matrix. Consequently, we try to take the measurements immediately after the breaks occur in order to record the value that corresponds to both the elastic and the plastic deformation of the matrix, and as a result, corresponds to the ineffective length as defined in the analytical part of this report. The results of this series of tests are reported in Table 9. Because of the shallow contour of the zone, the error on this measurement is about one time the diameter of the fiber. This repressents a precision of about ten percent which is small enough not to mask the variation of the ineffective length with the mechanical properties of the matrix.

The measurements of the deformed zone 24 hour after the sample has been unloaded are reported in Table 10. These values are characteristic of the permanent damage that occurs in the matrix when a fiber breaks. The length of this damaged zone does not change after 24 hours; we spot checked the specimens two weeks after the tests, and the same values were recorded. 
Table 9. Observation under polarized light. Ineffective length.

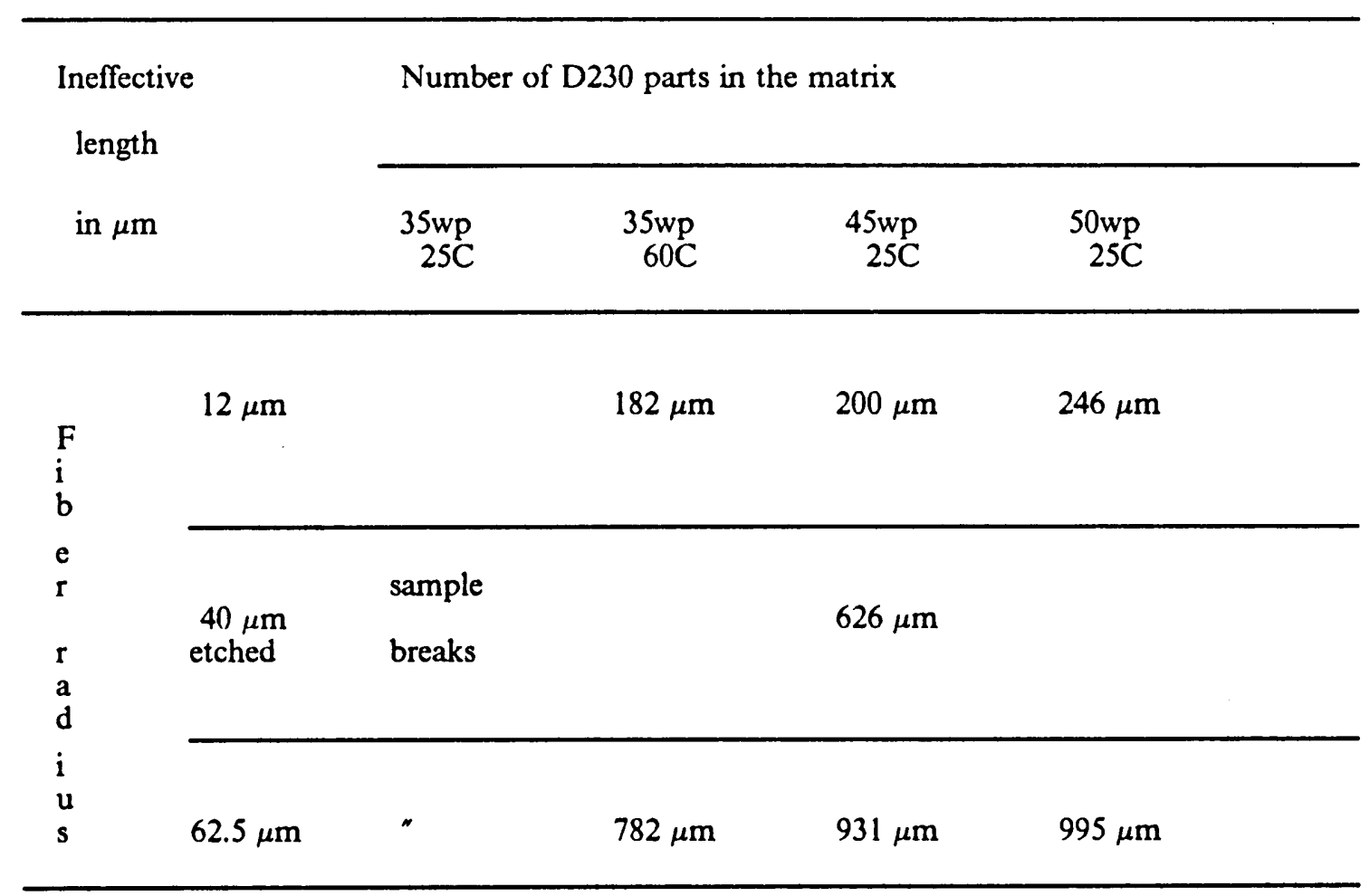


Table 10. Observation under polarized light. Damage length.

\begin{tabular}{|c|c|c|c|c|c|}
\hline \multirow{2}{*}{\multicolumn{2}{|c|}{$\begin{array}{l}\text { Damage } \\
\text { length } \\
\text { in } \mu \mathrm{m}\end{array}$}} & \multicolumn{4}{|c|}{ Number of D230 parts in the matrix } \\
\hline & & $\begin{array}{r}35 w p \\
25 \mathrm{C}\end{array}$ & $\begin{array}{r}35 w p \\
60 \mathrm{C}\end{array}$ & $\begin{array}{r}45 w p \\
25 \mathrm{C}\end{array}$ & $\begin{array}{r}50 w p \\
25 C\end{array}$ \\
\hline $\begin{array}{l}\mathrm{F} \\
\mathrm{i} \\
\mathrm{b}\end{array}$ & $12 \mu \mathrm{m}$ & & $95 \mu \mathrm{m}$ & $100 \mu \mathrm{m}$ & $120 \mu \mathrm{m}$ \\
\hline $\begin{array}{l}\text { e } \\
\text { r } \\
\text { r } \\
\text { a } \\
d\end{array}$ & $\begin{array}{l}40 \mu \mathrm{m} \\
\text { etched }\end{array}$ & $\begin{array}{l}\text { sample } \\
\text { breaks }\end{array}$ & $350 \mu \mathrm{m}$ & & \\
\hline $\begin{array}{l}\mathrm{i} \\
\mathrm{u} \\
\mathrm{s}\end{array}$ & $62.5 \mu \mathrm{m}$ & " & $520 \mu \mathrm{m}$ & $560 \mu \mathrm{m}$ & $610 \mu \mathrm{m}$ \\
\hline
\end{tabular}




\title{
V. COMPARISON BETWEEN THE
}

\author{
PREDICTIONS OF THE
}

\section{"ELASTO-DAMAGED" MODEL AND THE OBSERVATIONS UNDER POLARIZED}

\section{LIGHT}

The approximate agreement between the analytical predictions of the elasto-damaged model and the measurements taken under polarized light is demonstrated in Figures 39,40 , and 41 . The theoretical and experimental results are represented by solid lines and point markers, respectively. However, we remain critical in regard to our model. Because a mathematical model is based on assumptions, we discuss in this section the discrepancies as well as the resemblances between theory and experiments.

Figure 39 which represents the length $\mathrm{Xr}$ of the rupture zone along the fiber, is probably the easiest of the three graphs to interpret. Theoretically, only the shear strength of the matrix, or of the bond, influences the value of $\mathrm{Xr}$. The assumption that the matrix and the interphase are per- 
fectly elasti-plastic does not introduce any error in this result. Consequently, the experimental measurement of the length $\mathrm{Xr}$ is a reliable input data for calculating the bond strength. However, Figure 39 shows a sensitive difference between our measurements and the analytical curve. The fracture of the bond always appears to be longer than the calculated value. A possible explanation of this phenomenon is that the plane of maximum stress concentration passes through the crack tip, and consequently, moves along the fiber when the crack propagates. Furthermore, the stress concentration at the instant of the break can possibly be larger than the value calculated according to reference 7. This instantaneous phenomenon can be attributed to the sudden relaxation of an important quantity of energy. The influence of this "dynamic overshoot" has been addressed by Hedgepeth [34], and the results are on the order of 1.2. Such an increase in the stress concentration would significantly influence the length $\mathrm{Xr}$. But we have not included this factor in our mathematical model because the lack of results and literature on the subject prevents us from comparing values obtained through different methods. This instantaneous phenomenon is also very vaguely defined in the literature, and to model it mathematically would require a study of its own.

Figures 40 and 41 represent the length $\mathrm{Xd}$ of the plastically deformed zone in the matrix and the ineffective length, respectively. These two graphs show a very encouraging agreement between our theory and the measurements. The slightly higher values of the experimental results can be attributed to the length $\mathrm{Xr}$ which appears, as explained previously, larger than the value expected. However, such a close agreement (less than 9.5 percent) is unexpected, considering all the assumptions we have made concerning the behavior and the mechanical properties of the matrix and of the interphase in particular. As a result, a more thorough experimental study is necessary to validate our mathematical model. This experimental study should define more precisely the chemical nature of the adhesion, and examine a wider variety of materials. 


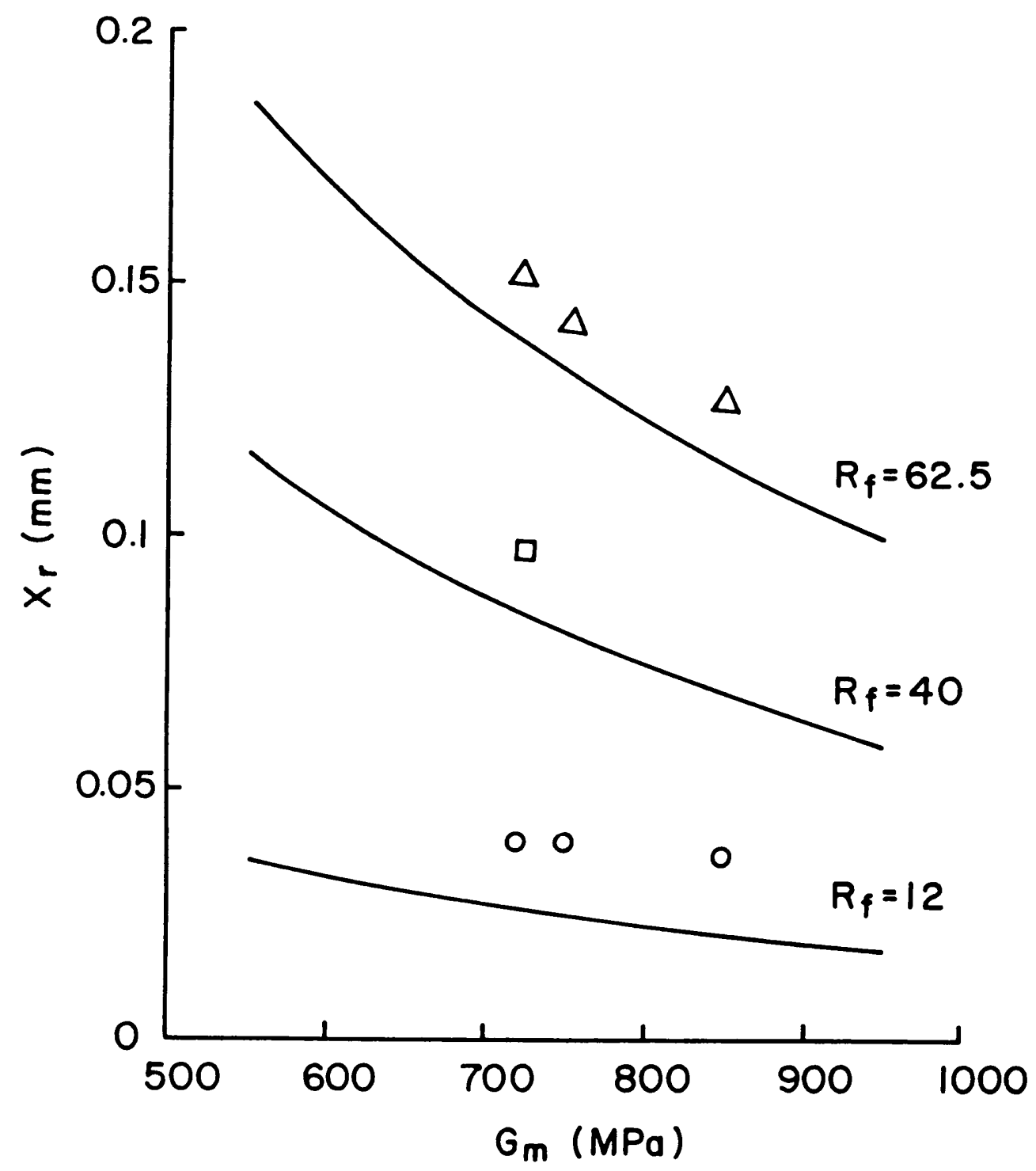

Figure 39. Rupture length $\mathrm{Xr}$ as a function of $G_{m}$ 


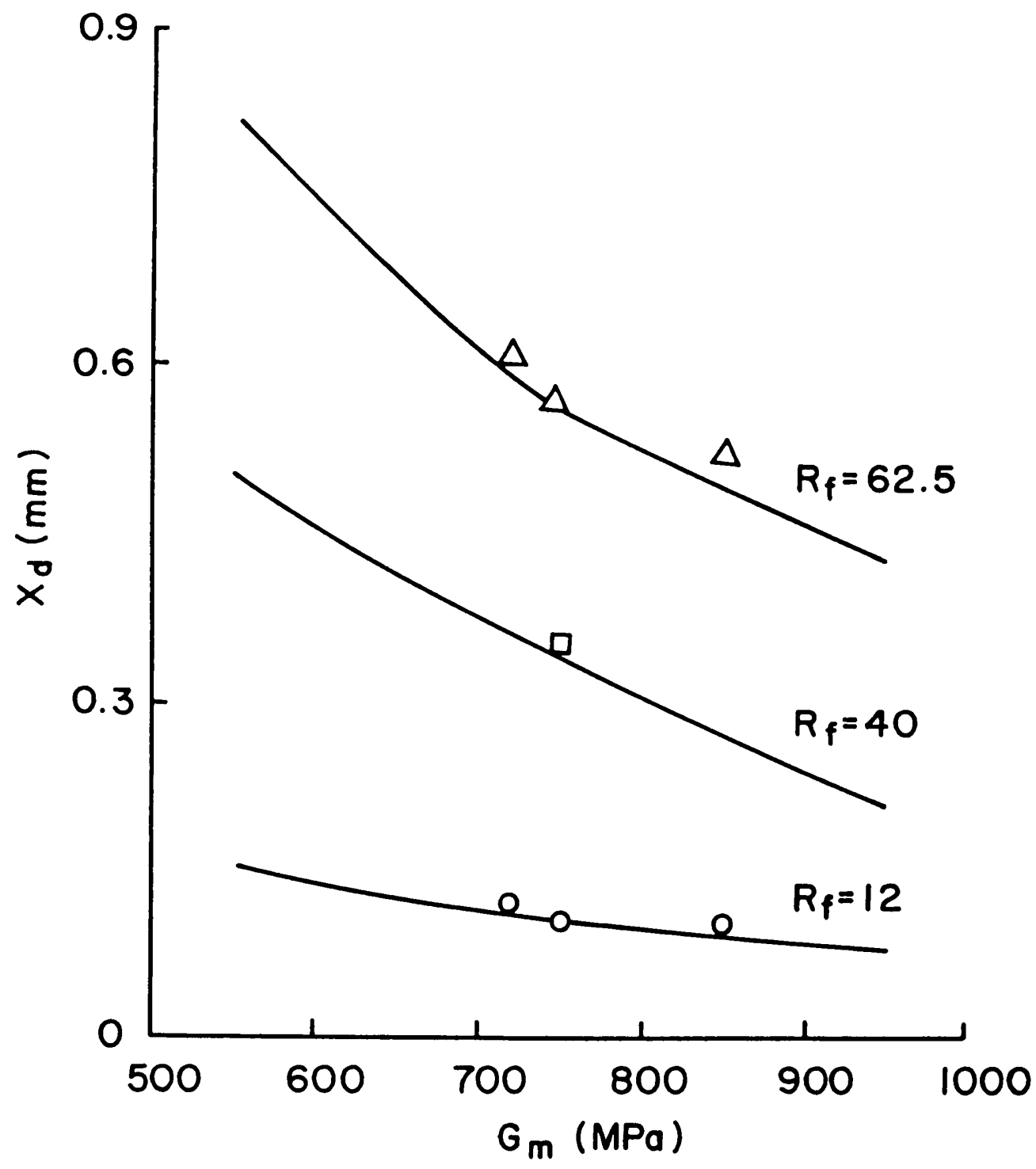

Figure 40. Damage length $\mathrm{Xd}$ as a function of $G_{m}$ 


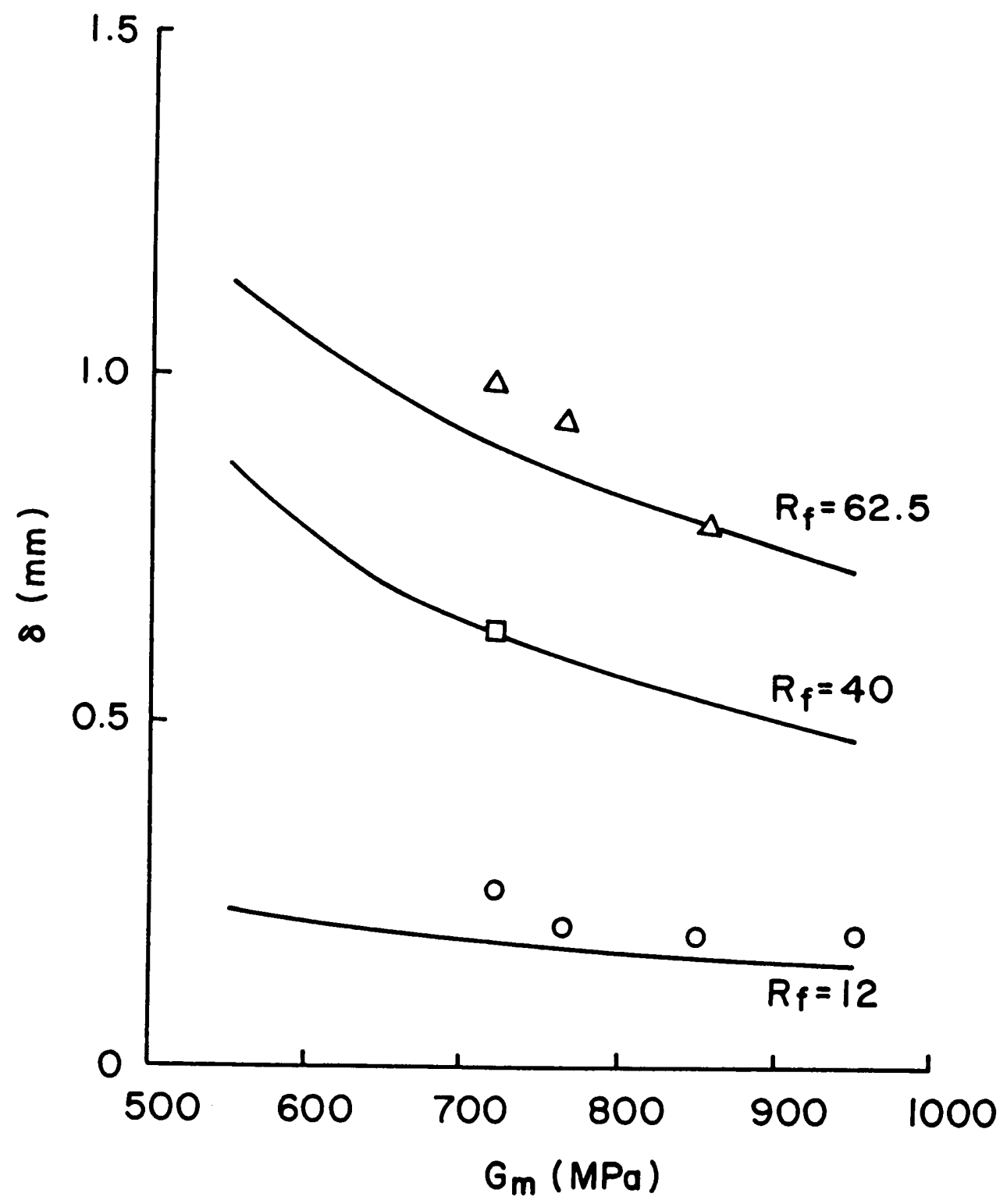

Figure 41. Ineffective length $\delta$ as a function of $G_{m}$ 


\section{SUMMARY AND CONCLUSION}

The purpose of this reseach was to improve the understanding of the fiber-matrix adhesion in fibrous composite materials, and to develop a micromechanical model of the matrix-fiber stress transfer. Attention was focused on the stress concentration near fiber breaks and on the damage in the matrix and in the interphase.

In order to achieve these goals, the research program was designed by combining: (1) two models of matrix-fiber stress transfer, applicable to two different types of fibrous composites, (2) mechanical tests on single fiber samples, (3) in situ optical microscopy under polarized light, and (4) elaboration and mechanical testing of a new type of sample containing seven fibers.

In the analytical part of this research, a mathematical model was developed that includes the mechanical properties of the interphase, the stress concentration near fiber breaks, and the elasticplastic behavior of both the matrix and the interphase. The concept of ineffective length mentioned in this section led to the series of measurements taken under polarized light. These measurements appeared to correlate better with the model than did the critical fiber length. A second model was then studied to take into account the slippage of the end of the fibers in the matrix. This scheme, based on elasticity theory, is only valid for a fiber volume fraction small enough so that the matrix shrinks around the fibers. This is the case for a single fiber specimen, but it is not true for most of the fibrous composite materials in which the fibers often touch each other. Such a model must 
be elaborated in order to be combined with our "elasto-damaged" model. A combination of these two theories would constitute a fairly complete treatment of the matrix-fiber stress transfer.

The results of the critical fiber length tests that were performed on single fiber samples demonstrate that there is no relationship between this test and the matrix-fiber adhesion. The results gave only quantitative information on the matrix-fiber stress transfer. The same tests run on the seven fiber specimens were even less significant because of teh premature fracture of the sample due to multiple coplanar fiber breaks. This type of multiple fiber specimen, however, probably has a promising future because of the potential information it contains about fiber-fiber interaction and matrix cracking.

The observation under polarized light, of the matrix near the fiber breaks, gave precise and reproducible results that correlate with the predicted value given by the "elasto-damaged" model. This observation, performed with a high quality optical microscope, is the most accurate means of investigating the matrix-fiber stress transfer. This is not, however, a universal test method because it requires that the matrix be a birefringent material, which is not the case in most composites. Consequently, along with a thorough chemical investigation of the fiber-matrix adhesion, a mechanical test method needs to be developed. This new test should involve the observation of a precisely defined phenomenon, and should also be applicable to the variety of materials commonly found in commercial composites. 


\section{REFERENCES}

1. Evans, T., "Mechanic response of interface," Naval Research Laboratories Workshop, Washington, D.C., March 1987.

2. Theocaris, P. S., and Papanicolaou, G. C., "The effect of the boundary interphase on the thermomechanical behaviour of composite reinforced with short fibres," Fib. Sci. Tech., 1979.

3. Broutman, L. J., and Agarwal, B. D., "A theoretical study of the effect of an interfacial layer on the properties of composites," Poly. Eng. Sci., August 1974, No. 8.

4. Berger, E. J., and Eckstein, Y., "Epoxy resin wetting of E-glass single filaments as it relates to shear strength," Adhesive Joints, 1984, edited by K. L.Mittal.

5. Wesson, S. P., and Jen, J. S., "Surface energetics and surface composition of fiber glass reinforcements," I6th National SAMPE Technical conference, 9, 11, 1984.

6. Sabat, P. J., "Evaluation of the fiber-matrix interfacial shear strength in fiber reinforced plastics," Masters thesis at Virginia Polytechnic Institute and State University, 1986.

7. . Hedgepeth, J. M., and Van Dyke, P., "Local stress concentration in imperfect filamentary composite materials," J. Composite Materials, 1968.

8. Baun, W. L., "Applications of surface analysis techniques to studies of adhesion," Application of Surface Science, 4, 291-306, 1980.

9. Everhart, D. S., and Reilly, C. N., "Chemical derivatisation in electron spectroscopy for chemical analysis of surface functional groups introduced on low density polyethylene film," Anal. Chem., 53, 665, (1981).

10. Cox, H. L., "The elasticity and strength of paper and other fibrous materials," Brit. $J$. Appl. Phys., 3, 72 (1952).

11. Dow, N. F., "Study of stresses near a discontinuity in a filament reinforced composite metal," G. E. C. Missile and Space Division R63SD61 (1963). 
12. Outwater, J. O., Modern Plastics, March 1956, 56.

13. Rosen, B. W., Fibre Composite Materials, ASM Publication, 1965.

14. Kelly, A., and Tyson, W. R., J. Mech. Phys. Solids, No. 6, 329.

15. Zweben, C., "Tensile failure in fibrous composites," AIAA J., 6, (1968).

16. Batdorf, S. B., "Tensile strength of unidirectionally reinforced composites - 1,"J. Reinforced Plastics and Composites, vol. 1, April 1982.

17. Broutman, L. J., Interfaces in Composites, ASTM STP 327, Amer. Soc. for Testing Materials, 1963.

18. Atkinson, C., and Avila, J., "A comparison of exact and model solutions for the initiation of debond fracture," Int. J. Eng. Sci., Vol. 21, No. 9, 1983.

19. Atkinson, C., Avila, J., Betz, E., and Smelser, R. E., "The rod pull out problem, theory and experiment," J. Mech. Phys. Solids, Vol. 30, No. 3, 1982.

20. Miller, B., Mussi, P., and Rebenfeld, L., Composite Science and Technology, 1986.

21. Mandell, S. F., Grande, D. N., Tsiang, T. H., and McGarry, F. J., MIT research report R.84-3, 1984.

22. Mandell, S. F., Chen, J. H., and McGarry, F. J., "A microdebonding test for in situ assessment of fiber-matrix bond strength in composite materials," Int. J. Adhesion and Adhesives, 1980.

23. Broutman, L. J., "Measurement of the fiber-polymer matrix interfacial strength," Interfaces in Composites, ASTM STP 452, 1969.

24. Kelley, A., and Tyson, W. R., Mech. Phys. Solids, 13, 1965.

25. Frazer, W. A., Ancker, F. H., and DiBenedetto, A. T., Proc. Conf. of Reinforced Plastics, SPI Section $22 \AA$, p. 1, 1975.

26. Frazer, W. A., Ancker, F. H., Elbirli, B., and DiBenedetto, A. T., Polym. Comp. 4, 238 (1983).

27. Bascom, W. D., and Jensen, R. M., "Stress transfer in single fiber/resin tensile tests," J. Adhesion, 1986.

28. Holister, G. S., and Thomas, C., "Fiber reinforced materials," Elsevier (1966).

29. Amirbayat, J., and Hearle, J. W. S., "Properties of unit composites as determined by the properties of the interface. Part I: mechanism of matrix-fibre load transffer," Fibre Science and Technology, 2, 1969.

30. Barker, R. M., and MacLaughlin, 'T. F., "Stress concentration near a discontinuity in fibrous composites," J. Composite Materials, 5, 1971.

31. Carrara, A. S., and McGarry, F. J., "Matrix and interface stresses in a discontinuous fiber composite model," J. Composite Materials, 2, 222 (1968). 
32. Agarval, B. D., and Bansal, R. K., "Plastic analysis of fiber interactions in discontinuous fibre composites," Fibre Science and Technology, Vol. 10, 1977.

33. Chen, C. H., "Tension of a composite bar with fibre discontinuities and soft inter-fiber material," Fibre Science and Technology, Vol. 6, 1973.

34. Hedgepeth, J. M., "Stress concentration in filamentary structures," NASA TN D882, May 1961.

35. Williams, R. S., and Reifsnider, K. L., "Strain energy release rate method for predicting failure modes in composite materials," Fracture Mechanics, ASTM STP 677, 1979.

36. Batdorf, S. B., "Tensile strength in unidirectionally reinforced composites," J. of Reinforced Plastics and Composites, Vol. 1, 1982.

37. Weibull, W., "A statistical theory for the strength of materials," Ingeniorsretenskapakademiens, Handlinger Nr. 151, 1939.

38. Garg, S. K., Sralbonas, V., and Gurtman, G. A., Mancel dekker Inc., NY, 1973.

39. Goodier \& Timochenko., "Theory of elasticity", 3rd edition, McGraw-Hill.

40. Miwa, M., Ohsawa, T., and Tahara, K., "Effects of fiber length on the tensile strength of epoxy-glass fiber and polyester/glass fiber composites," J. Applied Polymer Science, Vol. 25, 1980, p. 798.

41. $\Lambda$ dams, D. F., "Laminate analysis, micromechanical creep response, and fatigue behavior of polymer matrix composite materials," Final Report, NASA N83-29316, Dec. 82.

42. Davis et al., "The testing and inspection of engineering materials," Civil Engineering Series, McGraw-Hill, New York, 1955.

43. Walrath, D. E., and Adams, D. F., "The Iosipescu shear test as applied to composite materials," Journal of Experimental Mechanics, 1982.

44. Herakovitch, C. T., Bergner, Jr., H. W., and Davis, Jr., J. G., "Analysis of shear test methods for composite laminates," Report VPI-E-77-14, VPI\&SU (April 1977).

45. Iosipescu, N., "New accurate procedure for single shear testing of metals," Journal of Materials, 2 (3), 1967.

46. Drzal, L. T., Rich, M. J., \& Lloyd, P. F., "Adhesion of graphite fibers to epoxy matrics: I. The role of fiber surface treatment," J. Adhesion, Vol. 16, 1982, pp. 1-30.

47. Reifsnider, K., class notes, 1987. 


\section{APPENDIX I.}

\section{CHANGE OF COORDINATE SYSTEM FOR THE}

\section{MODELS OF THE STRESS FIELD IN THE}

\section{MATRIX, THE INTERFACE, AND THE FIBER,}

\section{DEVELOPED BY P. J. S}

Figures A1 and A2, respectively, represent P. J. Sabat's coordinate system and the one used in this report. The following mathematical manipulation can be described as a change of origin and an inversion of the $X$ axis.

Consequently, the equations, p. 21 and 22 of reference 6 , because they describe the state of equilibrium, are not affected by this change of coordinate system. On the other hand, the differential equation

$$
\frac{d^{2} \tau m}{d x^{2}}-\eta^{2} \tau_{m}=0
$$


where

$\eta^{2}=\frac{2 R_{i} / E_{a}\left(R_{a}^{2}-R_{m}^{2}\right)+2 \beta / E_{f} R_{f}}{\left(R_{m}-R_{l}\right) / G_{m}+\beta\left(R_{l}-R_{f}\right) / G_{l}}$

has to be solved according to a precise coordinate system because of the boundary conditions. The solution of Eq. $1 \mathrm{~A}$ is of the form

$\tau_{m}(x)=A \exp (-\eta x)+B \exp (\eta x)$

and the boundary conditions are:

$\lim _{x \rightarrow \infty} \tau_{m}(x)=0 ; \sigma_{f}(0)=0 ; \lim _{x \rightarrow \infty} \sigma_{f}(x)=\bar{\sigma} \frac{E_{f}}{E_{a}}$

The first boundary condition and eq. $3 \mathrm{~A}$ imply:

$\tau_{m}(x)=A \exp (-\eta x)$

The equation representing the equilibrium of the fiber is now recalled:

$2 \pi R_{f} T_{l}+\pi R_{f}^{2} \frac{d \sigma(x)}{d x}=0$

P. J. Sabat also assumes that

$\tau_{i}(x)=\beta \tau_{m}(x)$

Including eq. $6 \mathrm{~A}$ into eq $5 \mathrm{~A}$ results in:

$\frac{d \sigma_{f}(x)}{d x}=\frac{-2 \beta}{R_{f}} \tau_{m}(x)$

Inserting eq. $4 \mathrm{~A}$ into eq. $7 \mathrm{~A}$ and integrating gives: 
$\sigma_{f}(x)=\frac{2 \beta}{R_{f} \eta} A(\exp [-\eta x]+K)$

The second boundary condition along with eq. $8 \mathrm{~A}$ leads to:

$\sigma_{f}(x)=\frac{2 \beta A}{R_{f} \eta}(\exp [-\eta x]-1)$

Inserting the third boundary condition in eq. $9 \mathrm{~A}$ gives:

$\bar{\sigma} \frac{E_{f}}{E_{a}}=\frac{-2 \beta A}{R_{f} \eta}$

or

$A=\frac{-\bar{\sigma} E_{f} R_{f} \eta}{2 \beta E_{a}}$

Finally the stress in the fiber and in the surrounding matrix can be described by

$\sigma_{f}(x)=\frac{\bar{\sigma} E_{f}}{E_{a}}(1-\exp [-\eta x])$

and

$\tau_{m}(x)=\frac{-\bar{\sigma} R_{f} E_{f} \eta}{2 \beta E_{a}} \exp [-\eta x]$

where $\eta$ takes the value expressed in eq. $2 \mathrm{~A}$. 


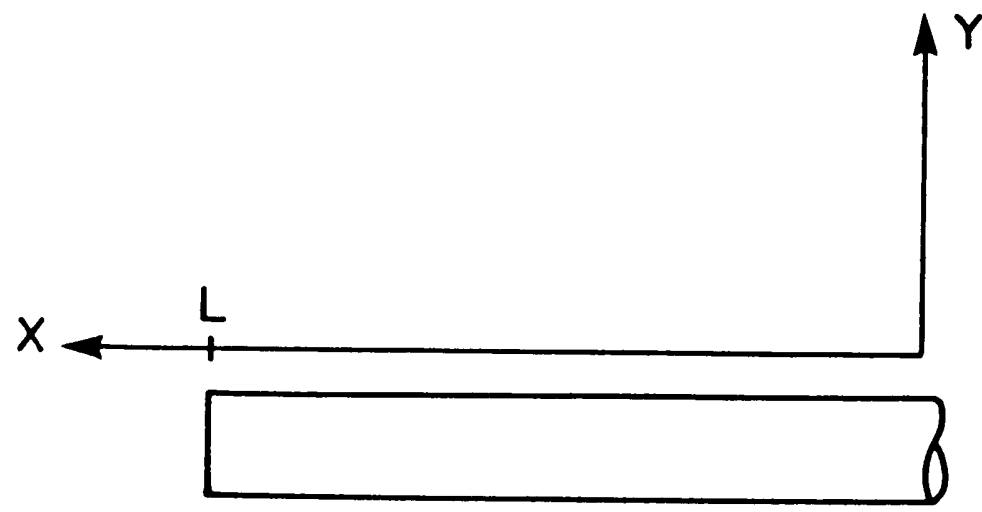

(a)

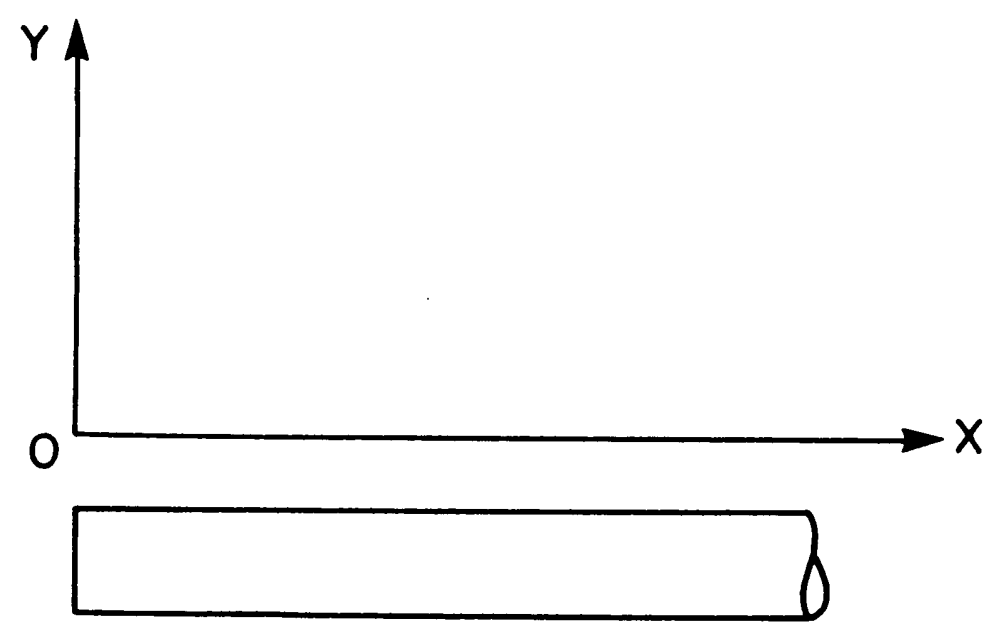

(b)

Figure 42. a) Sabat's coordinate system; b) Our coordinate system 


\section{The vita has been removed from the scanned document}

